\title{
Monday, October 6
}

8:00 am-10:00 am COMMITTEE MEETING

Continuing Education Committee

Chair: Curt Rom

8:00 am-10:00 am BOARD MEETING

Certified Professional Horticulturists Board

Chair: Janet Cole, CPH

8:00 am-10:00 am CENTENNIAL SPOTLIGHT

Centennial Spotlight: Video Interviews With Noted

Horticulturists

8:00 am-11:00 am COMMITTEE MEETING

Prunus Crop Germplasm Committee

Chair: To Be Announced

8:00 am-12:00 noon COMMITTEE MEETING

Cold Hardiness Committee

Chair : To Be Announced

8:00 am-9:00 am ORAL SESSION 41

\section{Consumer Horticulture and Master Gardeners}

Moderator: Ann Marie VanDerZanden

8:00 Phytochemistry and Horticultural Properties of $\mathbf{1 6}$ Edamame Varieties

William Sciarappa*1 ${ }^{* 1}$ Peter Nitzsche ${ }^{1}$, Qing-Li Wu², Ming-Fu Wang ${ }^{2}$, Jim Simon ${ }^{2}$, Tung-Ching Lee ${ }^{3}$

${ }^{1}$ Agriculture and Resource Management Agents, Rutgers University, Rutgers Cooperative Extension, 20 Court Street, Freehold, NJ, 07728, ${ }^{2}$ New Use Agriculture and Natural Plant Products Program, Department of Plant Biology and Pathology, Rutgers University, Cook College, Foran Hall, New Brunswick, NJ, 08901, ${ }^{3}$ Center for Advanced Food Technology, Rutgers University, Cook College Department of Food Science, New Brunswick, NJ, 08901

Higher value soybean varieties (Glycine max) bred for human food grade consumption have shown excellent commercial potential in three years of testing in New Jersey. Sixteen varieties of

\section{Monday, October 6, 2003}

Hours:

Registration:

Placement Service (Room 553)

Speaker "Ready Room" (Room 550A)

E-mail Stations (Ballroom A)

Poster Viewing (Ballroom A)

Exhibit Hall (Ballroom A)

Emeriti Lounge (Room 558B)

\section{Monday Highlights}

Colloquium 4 (Ballroom B/C)

Centennial Spotlight (Room 556 B)

Centennial Spotlight (Room 556 B)

Centennial Spotlight (Room 556 B)

Tour ${ }^{1}$-Mystic Seaport

7:00 am-2:00 pm

8:00 am $-12: 00$ noon

7:00 am-2:00 pm

7:00 am-2:00 pm

7:00 am-2:00 pm

7:00 am-2:00 pm

8:00 am-2:00 pm

8:00 am-12:30 pm

8:00 am-10:00 am

10:00 am-12:00 noon

2:00-4:00 pm

9;00 am -5:00 pm

${ }^{1}$ All tours will depart from the Sabin Street side of the Convention Center. edamame-vegetable soybean-grew vigorously utilizing trickle irrigated plasticulture. Ten varieties were harvestable within 90 days and the remaining six varieties were harvested within 120 days in growing zone 6. Considerable differences in bean size, shape, color and weight were measured. Average weights ranged from 1 to 3 grams per individual bean. Harvested beans were hydrolyzed and analyzed with high performance liquid chromatography coupled with ultra violet and electrospray ionization mass spectrometer. The key phytochemical compounds identified were 13 different isoflavones; including 3 aglycones, 3 glycosides and 7 glycoside malonates. The major isoflavones in fresh soy were daidzein, genistein glycozide and malonate conjugates. No acetyl conjugate was detected in these original fresh soy samples. All 16 cultivars appear to have the horticultural properties necessary for successful crop cultivation in the Mid-Atlantic region. Due to the structural similarity of these three identified isoflavones to estrogen 172-estrodial; fresh edamame harvested in New Jersey may exert potential health benefits in age-related and hormone independent diseases and other important bioactivities that have been found previously in dried, extracted or processed soy products.

8:15 Evolution of the Oregon Master Gardener Program During Budget Reductions

Ann Marie VanDerZanden*

Horticulture, Oregon State University, 4017 ALS Bldg., Corvallis, OR, 97331-7304

Nationally many public universities are experiencing significant budget reductions, and Oregon State University (OSU) is no exception. As a result of an over $80 \%$ reduction in the operating budget for the OSU Extension Service Master Gardener program for FY 02-03, Extension faculty members who manage the program throughout the state worked together to develop a position paper for the program followed by a program management strategy. The goal of the position paper was to critically evaluate the current program's strengths and weaknesses, and the internal and external "drivers of change" that influence how we do business. With this work in place we began to determine how the Master Gardener program in Oregon would look in the future. We identified three key areas to address: training issues (annual and advanced); the relationship between the Master Gardener program and the local and state non-profit association established to support the program; and specific ways to generate funds for the program. On a statewide level, the Master Gardener program is quite diverse and this lead to some unique challenges in creating uniformity within the program. Ultimately we developed a list of detailed action items with corresponding completion dates as well as formalized some overriding goals such as enhancing communication within our working group, emphasizing the importance of routine media exposure and maintaining political support of the program. The end result will be a new and improved model of the Oregon Master Gardener program.

\section{Post-Conference Activities}

Tuesday, October 7, 2003

\section{Special Event:}

HortLandmark Dedication Ceremony at the Arnold Arboretum

Afternoon

Tours ${ }^{1}$

Cranberry Harvest, Handling \& Product Manufacture Tour Vegetable \& Small Fruit Tour

Arnold Arboretum Tour 9:00 am-5:00 pm

${ }^{1}$ All tours will depart from the Sabin Street side of the Convention Center. 


\section{8:30 Horticultural Education With The Fall Flower \& Garden Fest}

Richard Snyder*, William Evans, Glenn Fain, Peter Hudson, Keri Paridon

Central Mississippi Research \& Extension Center, Mississippi State University, P.O. Box 231, Crystal Springs, MS, 39059

For the past 25 years, the Fall Flower \& Garden Fest has educated the public about vegetables, gardening, and horticulture, as well as serving as an open house for research and demonstrations at the Truck Crops Experiment Station in Crystal Springs, MS. Over the years, many enhancements have been implemented to make the event more attractive and increase the educational value of the two-day program. The 1.2 Ha garden, centerpiece of the Fest, is actually a composite of various specialty gardens, including vegetables, herbs, annual and perennial flowers, roses, ornamental grasses, turf plots, a shade garden, climbing garden, tunnel garden, All-America Selections garden, and various ethnic gardens, such as Asian, African, and Latino, with more than 400 cultivars on display. Garden Seminars (14 topics per day) give people a more structured way to learn from 30 or 60 minute talks on a wide variety of horticultural subjects. Other features of the event include wagon-ride tours of the station, a main tent with commercial and educational exhibits, and plant sales by area nurseries. Agriculture Agents, Home Economists, 4-H Agents, Specialists, and Master Gardeners all contribute by taking on portions of this increasingly popular event. In October 2002,4,600 visitors from throughout the southeast participated in the Friday and Saturday program. In addition, during Kid's Week the following Tuesday, Wednesday, and Thursday, 2,600 school children participated in planned "hay bale lessons", guided garden tours, wagon ride tours of the Station, and the corn maze. Coordinating and planning the Fall Flower \& Garden Fest is nearly a year round process, led by a Steering Committee which meets monthly. The Fest web site can be found at http://www.msstate.edu/dept/cmrec/fallgardenday.htm.

\section{8:45 Entry Gate Programs-An Extension Model for the Greenhouse Industry}

Svoboda (Bodie) Pennisi*1, Paul Thomas ${ }^{2}$

${ }^{1}$ Horticulture, The University of Georgia, 1109 Experiment Street, Griffin, GA, 30223, ${ }^{2}$ Horticulture, The University of Georgia, 215 Hoke Smith Building, Athens, GA, 30602-4356

The greenhouse industry is often regarded as an attractive, alternative business opportunity, especially by those looking from the outside in. Underemployed individuals looking for supplemental income, and people abandoning traditional farming often consider getting into the greenhouse business, with little or no background. As a result, many start their business with no or minimal training from the county delivery system. Most of these new businesses fail, leaving lower crop prices and poor industry images. Proper "turn-key" training, which allows a prospective business owner to size up the economic and technical challenges and the traditional industry risks is preferable. For the past 13 years, The University of Georgia Cooperative Extension Service in partnership with the Georgia Flower Grower Association has been offering an extensive training program titled "Getting Started in the Greenhouse Business School.” The goal has been to educate beginner growers, greenhouse employees and greenhouse managers in topics such as basic greenhouse management, irrigation and crop nutrition, cultural guidelines for major floricultural crops, integrated pest management, pesticide safety, and business and employee management. Between 1996 and 2003, the school has expanded into a 3-day program with separate greenhouse skills and greenhouse management tracks, and included half-day to full day hands-on workshops. Educators from the University of Georgia, experienced growers from the Georgia Flower Growers Association, and speakers from a variety of industry segments, present the program. As a result, over $70 \%$ of the attendees decide not to start a business once the depth of training, financial requirements and operation risks are presented in an unbiased manner. Those that do start have been successful as they have identified the diverse state business resources and been educated on industry norms.

8:00 am-9:15 am ORAL SESSION 42

Pest Management

Moderator: Gene Miyao

8:00 Winter-killed Cover Crops for Weed Management in Spring-planted Snap Pea

John Masiunas*, Orion Grimmer

Natural Resources and Environmental Sciences, University of Illinois, 260 ERML, 1201 W. Gregory Dr., Urbana, IL, 61801

Cover crops are commonly used in many sustainable or organic vegetable production systems to prevent erosion, build soil fertility and tilth, prevent diseases, and suppress weeds. The biggest problem with cover crop systems is the control of the cover crop so that it does not interfere with the vegetables. Using cover crops that winter-kill may be one method to overcome this problem for early planted vegetables such as pea. Our research determined the potential of oats, barley, white mustard, and canola as winter-killed cover crops for spring-planted snap peas and evaluated oat cultivars for their suitability for use as winter-killed cover crops. The field trials were conducted at Champaign (central) and Dixon Springs (southern), Illinois. At Champaign the cover crops were seeded on 31 August and at Dixon Springs were seeded on 30 September. The cover crops were evaluated for their residue production, residue presistence, and ability to suppress weeds. Pea growth and yield were determined in the spring. In the fall and at Champaign, white mustard produced the greatest dry weight of residue and barley and mustard allowed the fewest weeds to establish. Barley and oats maintained biomass over the winter while mustard lost significant biomass. For example, on 2 December both barley and mustard had approximately $100 \%$ cover while on 4 March, barley still had approximately $100 \%$ cover and mustard only had 50\% cover. Spring weed control was correlated with the surface coverage of the cover crops. Weed control was the major factor influencing snap pea yield. In the second study we evaluated nineteen commercial oat cultivars and five oat cultivars from the National Small Grain Germplasm Resporitory. Sequi and Blaze oats produced more biomass than did Ogle and Cayuse which are currently recommended for use as cover crops. In a greenhouse experiment, equal amounts of residue from the cultivars were compared for weed suppression. None of the cultivars differed in suppression of shepherd's purse or common lambsquarters, suggesting that the cultivars did not differ in allelochemical content. This study indicates that barley and oats have promise as winter-killed cover crops for snap pea and that oat cultivars producing the greatest biomass should be used in these systems.

8:15 Influence of Early Termination of Winter-grown Leguminous Cover Crop on Subsequent Processing Tomato Production

Gene Miyao*1, Mark Kochi², Lane Dickson ${ }^{3}$, Julie Reimers ${ }^{3}$ ${ }^{1}$ Cooperative Extension, Univ. of California, 70 Cottonwood Street, Woodland, CA, 95695, ${ }^{2} \mathrm{UCCE}$, Yolo County, 70 Cottonwood Street, Woodland, CA, 95695, ${ }^{3}$ Student Intern, UC Davis, 70 Cottonwood St., Woodland, CA, 95695

While winter-grown leguminous cover crops have increased tomato yield as well as reduced winter rainfall run off, processing tomato growers in California are reluctant to adopt the practice. Compared to the convention of maintaining vegetation-free fallow beds, seedbeds are difficult to prepare following a cover crop. In the Sacramento Valley, biomass production of a pea-vetch mix normally peaks at the end of March with a 2-foot tall mat of plants. The March growth spurt of the cover crop coincides with a prime window for planting early tomatoes. Our field evaluation used glyphosate to terminate the cover crop prior to full growth to aid in seedbed preparation. In a commercial field to be planted to tomatoes, 3 early termination dates were compared to an unsprayed, full growth treatment and to a non-planted control. Glyphosate was applied on either Feb 12, March 2, or March 
13 corresponding to $3,13,18$ tons per acre fresh weight of legume biomass, respectively. Full growth was 16 tons per acre. Plot design was a randomized complete block with 5 replications. Each plot was 500 square feet represented by a single bed centered on 5 feet. The field was disked twice on March $20^{\text {th }}$ and listed with a GPS-guided tractor to reestablish original location of plots. Tomato seedlings were transplanted into beds. At tomato crop harvest, vetch-free plots yielded 35.6 tons per acre while plots with vetch averaged 39.2 tons. The group comparison of vetch-free vs. vetch was statistically highly significant $(P=0.01)$. Termination date did not influence the yield outcome.

8:30 Transitioning Tomato and Cotton Production to Conservation Tillage in California's San Joaquin Valley

Jeffrey Mitchell*1, William Horwath ${ }^{2}$, Randy Southard², Karen Klonsky ${ }^{3}$, Rich DeMoura ${ }^{3}$, Dan Munk ${ }^{4}$,

Kurt Hembree ${ }^{4}$, Jon Wrobles ${ }^{4}$

${ }^{1}$ Vegetable Crops and Weed Science, University of California, Davis, 9240 S. Riverbend Avenue, Parlier, CA, 93631, ${ }^{2}$ Land, Air and Water Resources, University of California, Davis, One Shields Avenue, Davis, CA, 95616, ${ }^{3}$ Agricultural and Resource Economics, University of California, Davis, One Shields Avenue, Davis, CA, 95616, ${ }^{4}$ Fresno County, University of California Cooperative Extension, 1720 S. Maple Avenue, Fresno, CA, 93702

Since 1999, we have monitored the productivity and profitability of processing tomato and cotton rotations with and without winter rye (Secale cereale L.), triticale (Triticosecale) and vetch Vicia sativa L.) cover crops that are transitioning to conservation (CT), or reduced tillage practices. During the course of this transition, overall intercrop tillage operations have been decreased by about $50 \%$ in the $\mathrm{CT}$ systems relative to the standard tillage (ST) approaches. Processing tomato yields in the CT systems without cover crops matched yields in the standard till systems without cover crops in each of the first three years of the study. Yields in the CT system with winter cover crops were $12 \%$ lower than those of the standard till without cover crop systems in year 1,5\% higher in year 2 and $6 \%$ lower in year 3 . Accumulation of both crop and cover crop residues in the CT systems present challenges for tomato, cotton and cover crop establishment and weed management.

8:45 Cover Crops as Alternatives to Methyl Bromide in FreshMarket Tomato Production

Aref Abdul-Baki*1, Herbert Bryan², Waldemar Klassen², Qingren Wang ${ }^{2}$, Yuncong $\mathrm{Li}^{2}$, Merlyn Codallo

${ }^{1}$ Sustainable Agricultural Systems Laboratory, USDA-ARS, 10300 Baltimore Ave., Bldg. 001, Beltsville, MD, 20705, ${ }^{2}$ Tropical Research and Education Center, University of Florida, 18905 SW 280th St., Homestead, FL, 33031

A two-year experiment was conducted at Homestead, Florida to evaluate use of biological alternatives to methyl bromide $(\mathrm{MeBr})$ in growing fresh-market tomatoes (Lycopersicon esculentum Mill.). The biological alternative system consisted of a cropping rotation in which the nematode resistant cover crops [cowpea (Vigna unguiculata $\mathrm{cv}$. Iron Clay), velvetbean (Mucuna deeringiana) or sunn hemp (Crotalaria juncea cv. Tropic Sun)] were followed by 'Sanibel', a nematode resistant tomato cultivar in 2001 and 'Leila' a nematode susceptible cultivar for 2002. Harvested fruits were graded following Florida Tomato Committee Standards, and separated into extra large and total marketable. There were no significant differences in extra large fruits among the $\mathrm{MeBr}$ and the cover crop treatments in 2001. Yields of extra large fruits were higher in the cowpea and sunn hemp treatments than in $\mathrm{MeBr}$ treatment in 2002. Total marketable yield in 2001 was highest in $\mathrm{MeBr}$ and lowest in cowpea. Total marketable yield in 2002 was significantly highest in sunn hemp whereas, yields were similar in $\mathrm{MeBr}$ and velvetbean. In both years, the percentage of extra-large fruits was very high and total marketable yields of all treatments were higher than average yields for South Florida. Comparisons of production costs and net returns show that the alternative cropping systems have higher net returns than the
$\mathrm{MeBr}$ system and are safer to the environment.

9:00 Controlled Microbiotic Compost and Reactor Treated Swine Waste Compost Compared to Methyl Bromide in Plasticulture

Doug Sanders*1, Doug Monks ${ }^{1}$, Frank Louws ${ }^{2}$, Lisa Ferguson ${ }^{2}$, Greg Hoyt ${ }^{3}$

${ }^{1}$ Hort. Science, NC State University, Box 7609, NCSU, Raleigh, NC, 27965, ${ }^{2}$ Plant Pathology, NC State University, Box 7609, NCSU, Raleigh, NC, 27695, ${ }^{3}$ Soil Science, NC State University, Box 7609, NCSU, Raleigh, NC, 27965

Controlled Microbiotic Compost (CMC) applied at 330 and $660 \mathrm{~m}^{3}$ per ha and Reactor Treated Compost (RTC) applied at 6 and $12 \mathrm{~T}$ per ha was compared to the use of methyl bromide (MB) and nonamended plots in vegetable plasticulture production systems. Soil treatments were applied to the same plot each year and tomato, pepper, and cucumber cops were managed as sub-plots with rotation. In 1999, CMC and RTC increased marketable yield of cucumbers by $30 \%$ compared to nonamended and MB treated plots. Similarly CMC and RTC increased the marketable yield of tomatoes by $100 \%$ and $70 \%$ relative to the nonamended and MB treated plots. In 2000, marketable yields of cucumbers and tomatoes were greater with methyl bromide than either of the two composts or the nonamended. In $2001 \mathrm{MB}$ treated plots had superior yield with the CMC, RTC lagging by 10 to $40 \%$ for tomatoes and cucumbers. Yield in nonamended plots was reduced considerably more. CMC and RTC are viable options for vegetable growers. The nutrient removal and 0 to $15 \mathrm{~cm}$ soil nutrient levels for these trials will be discussed.

8:00 am-9:45 pm ORAL SESSION 43

$551 \mathrm{~B}$

\section{Horticulture Curriculum and Instruction, Instruction Methods}

Moderator: To Be Announced

8:00 A Cooperative 2+2 Horticulture Program at Southeast Missouri State University

Derald Harp*, Wesley Mueller, Mack Wilson

Agriculture, Southeast Missouri State University, One University Plaza MS6100, Cape Girardeau, MO, 63701

In order to reach the maximum number of students, a cooperative program between Southeast Missouri State University (Southeast), University of Missouri-St. Louis (UMSL), and St. Louis Community College (STLCC) - Meramec Campus was developed. This program gave students, with a completed Associate's Degree in Horticulture at STLCC-Meramec, the opportunity to receive a Bachelor of Science in Agribusiness: Horticulture from Southeast by taking a combination of courses, all of which would be taught either on-line or in St. Louis. The students were required to take 36 hours of senior level support courses at UMSL and 36 hours of major and support courses from Southeast. The Southeast courses were taught by Dept. of Agriculture faculty, and offered on a rotational schedule, two to three courses per semester, with one course taught during the summer. A full-time student would be able to complete their B.S. degree in 2 years. The program mimicked a similar program developed by the Dept. of Industrial Education and Technology (IET). The IET $2+2$ program is very successful, adding an average of 25 new students each year. Unfortunately, the Horticulture program did not experience similar success. Initial results were positive, with 28 students enrolling during year one and departmental credit hour production increasing approximately $15 \%$. Southeast also increased exposure in the St. Louis area. However, student numbers fell drastically during years two and three, with the decision made to terminate the program at the end of year three. Several factors contributed to this including: 1) Unrealized recruitment from Community College students, 2) Poor coordination of programs, and 3) Marketplace difficulties in the St. Louis regional area. The program is currently under review and will be reinstated if programmatic difficulties can be corrected. 
8:15 Hands-on Undergraduate Research, Bridge to Graduate Studies in Agricultural Biotechnology

Eliezer Louzada*1, Allison Abell ${ }^{2}$

${ }^{1}$ Citrus Center, Texas A\&M University-Kingsville, $312 \mathrm{~N}$. International Blvd, Weslaco, Texas, 78596, ${ }^{2}$ Texas Department of Health, Region 11, Texas Department of Health, 601 W Sesame Dr., Harlingen, TX, 78550

The objective of this project was to provide hands-on research experiences for undergraduate students from the highly Hispanic community of the Lower Rio Grande Valley in Texas. The Hispanic community is known by the lower education attainment, compared to the white non-Hispanics, which induces a low household income in communities highly populated by this minority group. The participation of Hispanics in science careers is also very low nationally. Considering that the Hispanics are projected to comprise of the USA population by 2030 , investment needs to be made to attract new scientists from this ethnical group. To address this issue at the local level, Texas A\&M University-Kingsville Citrus Center (TAMUK-CC) initiated an undergraduate research internship in agricultural biotechnology with the objective of attracting undergraduate students from the University of Texas at Brownsville to graduate studies at TAMUK. We provided 15 research internship for 9 undergraduate. Since most of the students are still to graduate in 2003 and 2004, we allowed students to participate more than one time in the research. From the two students already graduated, two are already working on their master s degree. Two students to be graduated are requesting for master degree assistantships. A questionnaire filled by the students after the research experiences demonstrate a radical change in opinion about agricultural related careers. The overall results are very promising for hands-on research as a tool to attract undergraduate students to graduate studies.

8:30 Learning Communities in Horticulture Retain Undergraduate Students and Enhance Their Learning

Gail Nonnecke*, Barb Osborn

Horticulture, Iowa State Univ., Dept. of Horticulture, Ames, IA, 50011

Learning communities, developed for first-year students majoring in horticulture at Iowa State University, have been used in our department since 1998. Learning communities are a curriculum design that schedules and links courses for both students and faculty to encourage community and connections among students, between students and faculty, and among faculty. Learning communities retain students by providing more opportunities for interactions among each other, academic assistance through supplemental instruction and/or group study sessions, and planned horticulture-related activities. First-year students in the horticulture learning community enrolled in the same course cluster and schedule. Faculty and peer mentoring were provided for academics and local field trips to horticultural sites of keen interest to the students. Results of pre- and post-semester assessment surveys for four years showed that student attitudes changed for several factors. Students increased their understanding of the curriculum requirements and plans for graduation. They indicated greater satisfaction with being members of learning communities. Students developed greater abilities to work collaboratively in groups and rated highly their expectations for developing a network of other students as a resource. Iowa State University supports learning communities by providing grants for peer mentors and program activities, facilitating course registration, supplemental instruction for challenging core courses, and academic and student services to strengthen undergraduate teaching programs within and outside of the classroom.

8:45 Horticulture Study Tours: Seeing is Believing-and Learning

Curt Rom*

Horticulture, Univ of Arkansas, PTSC 316, Fayetteville, AR, 72701

This is a descriptive presentation of the use of study tours to supple- ment the in-class educational experience of a horticultural curriculum. During the past 10 years, due to rising costs and other concerns, extended class field trips lasting 1-3 days has reduced in our department. Instead, classes are more likely to take only short, in-class local field trips of 1-2 $\mathrm{h}$ duration. As a result, students in the program have reduced opportunity to see horticulture practiced in a broader range of environments. The faculty believe it is important for students to observe horticulture in different growing environments and of varying scales. Thus, the Horticulture Department at the University of Arkansas started a Horticulture Study Tour program. Study tours have been conducted in 4 of the past 6 years in May immediately following the conclusion of the spring semester. Tours have lasted 5-12 days depending upon the location visited. One Tour was to Scotland and Great Britain. Students may or may not enroll for classroom credit and must complete pre and post tour exercises for the credit. The majority of students do not take the tour for credit due to enrollment costs. Participation in the Tours was greatest when the activity was directly related to student club fund raising programs to reduce the Tour participation costs. Costs for students have also been reduced by inviting local horticulturists and master gardeners to participate at a higher cost rate. Tours have been cancelled due to lack of student participation with the greatest barrier to participation perceived as being the tour costs or interference with enrollment in summer school or summer internships. The most successful tours were tied to club activities supporting travel scholarships.

9:00 Using Video to Enhance Horticultural Education For Extension Clientele

William Hlubik*1, Nicholas Polanin ${ }^{2}$,

Madeline Flahive-DiNardo ${ }^{3}$, Richard Weidman ${ }^{4}$, William Sciarappa ${ }^{5}$, Daniel Kluchinski ${ }^{6}$, David Smela ${ }^{7}$, James Marko ${ }^{8}$

${ }^{1}$ Agricultural and Resource Management Agents, Rutgers, The State Univ., 390 George Street, 8th floor, New Brunswick, NJ, 08901, ${ }^{2}$ Agricultural and Resource Management Agents, Rutgers, The State Univ., RCE of Somerset County, 310 Milltown Road, Bridgewater, NJ, 08807, ${ }^{3}$ Dept. of Agricultural and Resource Management Agents, Rutgers, The State Univ., RCE of Union County, 300 North Avenue East, Westfield, NJ, 07090, ${ }^{4}$ Agricultural and Resource Management Agents, Rutgers, The State Univ., RCE of Middlesex County, 390 George Street, 8th Floor, New Brunswick, NJ, 08901, ${ }^{5}$ Agricultural and Resource Management Agents, Rutgers, The State Univ., RCE of Monmouth County, 20 Court Street, Freehold, NJ, 07728, ${ }^{6}$ Agricultural and Resource Management Agents, Rutgers, The State Univ., RCE of Mercer County, 930 Spruce Street, Trenton, NJ, 08648, ${ }^{7}$ Agriculture, Rutgers Cooperative Extension of Middlesex County, RCE of Middlesex County, 390 George Street, 8th floor, New Brunswick, NJ, 08901, ${ }^{8}$ Agricultural and Resource Management Agents, Rutgers, The State Univ., RCE of Middlesex County, 390 George Street, 8th Floor, New Brunswick, NJ, 08901

Video can provide a very powerful and versatile tool for horticultural and environmental education. In a classroom setting, the combination of personal instruction with properly prepared and edited video can enhance the learning environment. Videos can provide multiple cues to capture students attention and visual cues to demonstrate the topic at hand. Preliminary evaluations indicate that proper use of video may increase retention of subject matter. Video can provide key visual cues for students that can be used independently of the limitations of time, location or expertise of the instructor. Multiple experts can be introduced into the classroom setting with the use of video. Video for class instruction was re-edited from segments and raw footage from the "If Plants Could Talk" NJN PBS television series created by the authors. The video clips were then converted to MPEG for insertion into Power Point presentations on CD ROM.

9:15 Teaching Vegetable Production with Taste David Nagel* 
Plant and Soil Sciences, Mississippi State University, 117 Dorman Hall, Mississippi State, MS, 39762

Vegetable Production is taught as an undergraduate/graduate level course each fall at Mississippi State University.The course is taught as an unofficial capstone course with students required to grow vegetables in self-designed experiments and with test questions requiring the synthesis of cropping systems to meet specific climatic, dietary, and economic situations. The course meets twice a week for lecture and once a week for laboratories. The most popular component with students are the laboratories. Several years ago I started preparing the lab samples for consumption rather than disposal.The only tools required are an electic skillet, a hot pot, and utensils. The food is prepared while and after students complete self-directed lab studies. The influence of vegetable types on quality aspects of prepared food are occasionally incorporated in the lab studies. Students are informed that eating is entirely optional and allowances are made for student dietary requests.

\section{9:30 Constructing Dichotomous Keys - An Exercise in Critical} Thinking

Richard Durham*

Department of Horticulture, University of Kentucky, N-318 Ag. Science North, Lexington, KY, 40546-0091

Introduction to Plant Identification, PLS 220, is a required course for students in the Plant and Soil Science and Landscape Architecture curricula at the University of Kentucky. The three-credit course meets in the fall semester for one hour of lecture and four hours of lab (two, two-hour sessions) each week. One lab session each week focuses on plant morphology while the other lab session introduces the students to a horticulturally diverse group of plants they must learn to identify. The morphology laboratory culminates at the end of the semester in an exercise where the students construct a dichotomous key for a group of plants they have seen in the plant identification lab (herbaceous, woody, fruit and vegetable, weeds and turf grasses, aquatic, or greenhouse/interior plants). Students work in pairs and may refer to their course notes and text when constructing the key. Since they must use morphological terms they have learned during the semester, and many of the plants they have seen previously are available to them for this lab, this exercise is an excellent summary of the plant identification and morphological labs and gives the students an opportunity to review prior to the final laboratory exam. Constructing the key also promotes working in groups, use of critical thinking skills, and reinforces an appreciation for the morphological diversity of horticultural plants.

8:00 am-9:30 am ORAL SESSION 44

\section{Citrus}

Moderator: To Be Announced

8:00 Temperature Affects the Abscission Response of Mature Fruit and Leaves to CMN-Pyrazole and Ethephon in 'Hamlin' Oranges

Jacqueline Burns*, Rongcai Yuan

Citrus Research and Education Center, University of Florida, 700 Experiment Station Road, Lake Alfred, Florida, 33850

The effect of temperature on the ability of CMN-Pyrazole and ethephon to induce ethylene production and abscission of mature fruit and leaves was determined using 3-year-old potted 'Hamlin' orange [Citrus sinensis (L.) Osb.] trees in environment-controlled growth rooms in seasons 2001-02 and 2002-03. Ethylene production and abscission of CMN-Pyrazole or ethephon-treated fruit and ethephontreated leaves were highly temperature dependent. Fruit detachment force (FDF) and fruit ethylene production were not affected by application of ethephon at $200 \mathrm{mg} \cdot \mathrm{L}^{-1}$ or CMN-Pyrazole at $200 \mathrm{mg} \cdot \mathrm{L}^{-1}$ when air temperature was $\# 10^{\circ} \mathrm{C}$ for ethephon treatment or \#15.6
${ }^{\circ} \mathrm{C}$ for CMN-Pyrazole treatment. However, ethylene production of CMN-Pyrazole or ethephon-treated fruit increased sharply, and FDF decreased drastically as temperature increased from 10 to $26.7^{\circ} \mathrm{C}$ for ethephon treatment or from 15.6 to $26.7^{\circ} \mathrm{C}$ for CMN-Pyrazole treatment. At least three days of exposure to $10 \mathrm{~h} / 14 \mathrm{~h}$ temperature regimes of $21 / 10^{\circ} \mathrm{C}$ were required for CMN-Pyrazole to effectively loosen fruit, whereas only one day of exposure to $26.7 / 15.6{ }^{\circ} \mathrm{C}$ was enough to cause similar changes. At $21 / 10^{\circ} \mathrm{C}$, CMN-Pyrazole significantly reduced FDF to $<25 \mathrm{~N}$ and markedly enhanced fruit ethylene production regardless of an occurrence of one day of low temperature at $10 / 10^{\circ} \mathrm{C}$ during the $5 \mathrm{~d}$ experiment. Ethephon had no significant effect on leaf ethylene production and leaf abscission when temperature was $\# 10^{\circ} \mathrm{C}$, but caused a marked increase in both leaf ethylene production and leaf abscission as temperature increased from 10 to $26.7^{\circ} \mathrm{C}$. CMN-Pyrazole did not stimulate leaf ethylene production and leaf abscission regardless of temperature. Chemical names used: 5-chloro-3-methyl-4-nitro-1 H-Pyrazole (CMN-Pyrazole); 2-chloroethylphosphonic acid (ethephon).

8:15 Guanfacine Reduces Ethephon-induced Leaf Abscission by Reducing Expression of Genes Encoding 1-aminocyclopropane-1-carboxylic Acid Synthase and Oxidase In 'Valencia' Orange

\section{Rongcai Yuan*, Jacqueline Burns}

Citrus Research and Education Center, University of Florida, 700 Experiment Station Road, Lake Alfred, Florida, 33850

Guanfacine is a compound that can reduce ethephon-induced defoliation without significantly affecting efficacy of ethephon on mature fruit. We were interested in exploring the mode of action of guanfacine. The effect of guanfacine on ethephon-induced leaf and fruit abscission and associated relationship with ethylene production and expression of ethylene biosynthesis-related genes, 1-aminocyclopropane-1-carboxylic acid (ACC) synthase genes (ACS1\&2) and ACC oxidase gene (ACO), were examined in 'Valencia' orange (Citrus sinensis). Guanfacine effectively reduced ethephon-induced leaf abscission but had a slight effect on fruit loosening caused by ethephon. Ethephon-enhanced ethylene production of leaves and fruit was decreased by guanfacine. Guanfacine suppressed ethephon-promoted expression of ACS1 and ACO genes but not ACS2 in leaf abscission zone and leaf blade. Guanfacine also reduced ethephon-enhanced expression of ACO gene in fruit peel (FP) but had no influence on the expression of ACO in fruit abscission zones (FAZ) or ACS1 in FAZ and FP. Expression of ACS2 promoted by ethephon was slightly reduced by gaunfacine in FB but not in FAZ. These results suggest that guanfacine reduces ethephon-induced leaf abscission by suppressing expression of ACS1 and ACO in 'Valencia' orange.

8:30 Preharvest Applications of 1-MCPControl Unwanted Leaf Abscission Associated with Sprays of Ethephon to Citrus Canopies

Luis Pozo*, Igor Kostenyuk, Rongcai Yuan, Fernando Alferez, Ana Redondo, Jacqueline Burns

Citrus Research and Education Center, University of Florida, 700 Experiment Station Road, Lake Alfred, Florida, 33850

$1-\mathrm{MCP}$ is an ethylene perception inhibitor used to control ethylene-related postharvest problems in horticultural commodities. Our previous work demonstrated that application of gaseous 1-MCP $16 \mathrm{~h}$ prior to ethephon treatment in calamondin orange (Citrus madurensis) greatly reduced leaf drop without affecting the ability of ethephon to cause fruit loosening. We were interested to determine if 1-MCP treatment could also be used to reduce unwanted leaf abscission associated with ethephon applications in the field. SmartFresh (3.3\% 1-MCP; Rohm and Haas) at $0.1,0.5,1.0,2.5$ or $5.0 \mathrm{mM}$ was dissolved in a solution of $200 \mathrm{mg} \cdot \mathrm{L}^{-1}$ ethephon in $0.125 \%$ Kinetic adjuvant immediately before application to canopies of 'Hamlin' or 'Valencia' orange (Citrus sinensis). Five days after application, fruit detachment 
force (FDF) of mature fruit was evaluated. Leaf drop was evaluated at times up to $30 \mathrm{~d}$ after application. Ethephon reduced FDF $65 \%$ as compared with the adjuvant controls $5 \mathrm{~d}$ after application. Reduction in FDF in combination solutions of ethephon + 5 mм 1-MCP was similar to that of ethephon alone. In contrast to mature fruit, leaf drop was strikingly reduced by 1-MCP, and higher concentrations resulted in better control of defoliation. Ethephon alone caused nearly $80 \%$ leaf drop $30 \mathrm{~d}$ after application, whereas control trees lost only $7 \%$. Combining 1-MCP with ethephon reduced leaf drop to $0 \% 14 \mathrm{~d}$ after application, but rose to $20 \% 30 \mathrm{~d}$ after application. Further loss of leaves did not occur up to $60 \mathrm{~d}$ after application in any treatment. Although 1-MCP applications by this method are impractical and inefficient, the results demonstrate that ethephon-induced leaf loss can be controlled with 1-MCP with no loss of fruit loosening. Further, the results suggest that the initiation of mature fruit abscission does not depend on ethylene perception, whereas ethylene perception is important for abscission in leaves. We understand that a sprayable formulation of 1-MCP is being developed. This should increase the efficiency and economy of preharvest 1-MCP applications.

8:45 Effect of 2,4-D and 3,5,6-TPA on Yield, Fruit Size and Fruit Quality of Clementine Mandarin in California

\section{Thomas Chao*1, Louise Ferguson ${ }^{2}$, Carol J. Lovatt ${ }^{3}$}

${ }^{1}$ Department of Botany and Plant Sciences, University of California Riverside, 2137 Batchelor Hall, UC Riverside, Riverside, CA, 925210124, ${ }^{2}$ Pomology Department, University of California Davis, Kearney Ag Center, 9240 South Riverbend Avenue, Parlier, CA, 93648, ${ }^{3}$ Department of Botany and Plant Sciences, University of California Riverside, 4130 Batchelor Hall, UC Riverside, Riverside, CA, 92521-0124

Clementine mandarin (Citrus reticulata Blanco) is a seedless citrus fruit with excellent taste and an easy-to-peel rind of bright orange color. In California, a significant amount of Clementine mandarin acreage has been planted in the past years. As the yields of maturing trees have increased, the problem of small fruit size has also increased. The auxins 3,5,6-trichloro-2-pyridyl-oxyacetic acid (3,5,6-TPA) and 2,4-dichlorophenoxyacetic acid (2,4-D) were applied to 'Fina Sodea' Clementine mandarin at southern Kern County, CA in 2001 and 2002 as a foliar spray to increase yield and fruit size. The 3,5,6-TPA treatment significantly increased yield and fruit size, but reduced juice weight and total soluble solids to acid ratio compared to the untreated control. The 2,4-D treatments also significantly increase the yield and fruit size in early June application, but it did not increase the yield or fruit size in July application. We will discuss the benefit and potential use of plant growth regulators in Clementine mandarin production in California.

9:00 Pre-harvest Application of Harpin Protein Leads to Postharvest Disease Suppression in Commercially Packed Lemons

\section{Glenn Wright*}

Yuma Mesa Agriculture Center, University of Arizona, 2186 W. County 15th Street, Somerton, AZ, 85350

Hypersensitive response protein (Harpin) is a protein that is known to induce a plant to mobilize its own defenses against pathogens. We applied this protein to commercial groves of lemons (Citrus limon Burm.) during the 2001-02 and 2002-03 growing seasons, five days prior to harvest. For the 2001-02 season, harpin protein reduced incidence of blue mold (Penicillium digitatum) in stored fruit by up to $45 \%$, and slowed disease progression in commercially packed lemons. Harpin also reduced incidence of sour rot by as much as $15 \%$. For the 2002-03 season, application of the protein reduced incidence of blue mold by as much as $30 \%$, and sour rot by as much as $50 \%$. Effectiveness of the protein varied, and was dependent upon ripeness of the fruit prior to harvest and storage duration.
9:15 Regeneration of Cybrids Between Microcitrus and Citrus via Electrofusion

Jihong Liu*

College of Horticulture and Forestry, Huazhong Agricultural University, Hongshan District, Wuhan, 430070, People's Republic of China

Embryogenic protoplasts of Microcitrus papuana were electrofused with Citrus aurantium and C. jabhiri, respectively. Only diploid plants were regenerated, as were confirmed by chromosome counting and flow cytometry. RAPD, SSR and CAPs were employed to identify the nuclear and cytoplasmic genomes composition. The results demonstrated that the regenerated plants obtained their nuclear genomes and mt DNA from the leaf and the embryogenic parents, respectively, whereas the cpDNA was inherited from either of the parents.

8:00 am-10:00 am WORKSHOP 20 $555 \mathrm{~B}$

\section{Current Trends in Medicinal Plants and Botanical Supplements Research}

\section{Moderator: Anand K. Yadav}

Sponsor: Herbs, Spices, and Medicinal Plants

Working Group (HSMP)

Objective: The booming popularity of botanical remedies began in 1994, when the US Congress passed the Dietary Supplement Health and Education Act. World trade in medicinal plant products is steadily increasing due to changing perceptions of prescription drugs and preference for herbal remedies without side effects. Thus, the objective of this workshop is to assess knowledge of current trends in medicinal plant bioprospecting, production and management, propagation and improvement, biotechnology and its uses, phytochemical analysis and bioactivity evaluation, and plant/product marketing, before embarking on systematic research on medicinal plants.

Summary: This workshop provides an opportunity to exchange information on medicinal plants bioprospecting, botanical information and population status; natural, conventional and organic production; application of biotechnology for plant regeneration, improvement and preservation; phytochemical analysis, quantification, and bioactivity evaluation in biomedical laboratory; and plant/product marketing prospects. Experts will emphasize their specialty work.

\section{Medicine Hunt-The Search For Cures}

Chris Kilham*

Ethnobotany, Medicinal Plant Program, University of Massachusetts, 15 Trapelo Road, Lincoln, MA 01773

A full eighty-five percent ( $85 \%$ ) of the world's population employs herbs as their primary medicines. And while drugstore shelves in the US are stocked mostly with synthetic remedies, in other parts of the world the situation is quite different. In Germany, pharmacies dispense herbs prescribed by physicians. For 5.1 billion people worldwide, natural plantbased remedies are used for both acute and chronic health problems, from treating common colds to controlling blood pressure and cholesterol. Not so long ago, this was true in the US as well. As late as the early 1950's, many of the larger pharmaceutical companies still offered a broad variety of plant-based drugs in tablet, liquid and ointment forms. Plants are the original source materials for $40 \%$ of the pharmaceuticals in use in the United States today. This is to say that either the drugs currently contain plant-derived materials, or synthesized materials from agents originally derived from plants. Some medicines, such as the cancer drug Taxol (from Taxus brevifolia) and the anti-malarial quinine from Cinchona pubescens and are manufactured from plants. Other medicinal agents such as pseudoephedrine originally derived from ephedra species, and menthol and methylsalicylate, originally derived from from mentha species and wintergreen (gaultheria procumbens) respectively, are now synthesized. Herbal Use Goes Back 60,000 Years. Neanderthals 
lived from about 200,000 years ago until roughly 30,000 years ago in Europe and western Asia. They coexisted with modern humans for most of the period but then mysteriously vanished. Physical evidence of use of herbal remedies goes back some 60,000 years to a burial site at Shanidar Cave, Iraq, in which a Neanderthal man was uncovered in 1960. He had been buried with eight species of plants, seven of which are still used for medicinal purposes today. Plant Medicines, Safer and time-tested plant medicines are far and away safer, gentler and better for human health than synthetic drugs. This is so because human beings have co-evolved with plants over the past few million years. We eat plants, drink their juices, ferment and distill libations from them, and consume them in a thouand forms. Ingredients in plants, from carbohydrates, fats and protein to vitamins and minerals, are part of our body composition and chemistry. In Medicine Hunt, The Search For Cures, we will examine the priniciples and practices of medicinal plant investigation. In the field, medicine hunting is a process of digging into extant traditions of botanical medicine, and learning the traditional knowledge of indigenous medicine men and women. Subsequent to field work, continued investigations in the lab help to establish a scientific basis for the efficacy of traditional plant medicines. By working from field to finish, we can continue to disocover drugs and therapeutic plant-based agents of high value to human health.

\section{Issues in Research For a Traditional Medicinal Plants Company}

Elizabeth K. Lambert*1, Adesoji Adeleja ${ }^{2}$, Dennis Doyle ${ }^{3}$, Arthur Galletta ${ }^{3}$, Geetha Ghai ${ }^{4}$, Amy Howell ${ }^{5}$, Robert Rosen ${ }^{4}$, Brian Schilling ${ }^{6}$, James Simon ${ }^{7}$, Mingfu Wang ${ }^{7}$. David Winston ${ }^{1}$ ${ }^{1}$ Herbalist \& Alchemist, Inc., Washington, NJ, ${ }^{2}$ Rutgers University, New Brunswick, NJ, ${ }^{3}$ Atlantic Blueberry, Hammonton, NJ, ${ }^{4}$ Center For Advanced Food Technology, Rutgers University, New Brunswick, NJ, ${ }^{5}$ Marucci Center for Blueberry Cranberry Research, Rutgers University, Chatsworth, NJ, ${ }^{6}$ Food Policy Institute, Rutgers University, New Brunswick, NJ, ${ }^{7}$ New Use Agriculture Department, Rutgers University, New Brunswick, NJ.

As the medicinal plants industry expands, companies producing commercial products that want to maintain quality and sustain the availability of botanical resources face several challenges. Along with the major issue that these products have not been commercially priced to include a significant margin for research, come some of the following challenges: 1. Cultivated vs. Wild botanicals - As plants "come in" from the wild, that is, are cultivated - this ranges from a replication of natural situation to a more monocropped or row cropped cultivation, we face the issue of what changes, if any occur in these botanicals? Having observed significant organoleptic changes in cultivated Echinacea angustifolia extract--color and odor changed when exposed to light, we investigated this issue with a grant funded by USDA SBIR in conjunction with the Center for Advanced Food Technology at Rutgers University. We present evidence of our results for Echinacea and Goldenseal. 2. Variation in Natural Plant Material - Another issue we face in attempting to meet the "research" market's needs is investigating the feasibility of "standardizing" the naturally occurring phytochemical content ranges of specific botanicals. This is a challenging and controversial issue. Variations in growing conditions, even when dealing with the same plants year to year from the same location can be significant. We present the observations from our Blueberry Health Project - a joint research project among Rutgers University (several research areas including the Food Policy Institute, Marucci Center for Blueberry Cranberry Research and New Use Agriculture Department), the Blueberry Growers of southern New Jersey, and Herbalist \& Alchemist, Inc. 3. Variation in Process Techniques - Clinical literature, research studies, pharmacoepial references and new techniques in botanical processing all offer different methods of processing techniques. Simple variations in alcohol levels, botanical concentration, temperature, motion and processing technique can affect the phytochemical composition of a final product. Part of our USDA SBIR study with Rutgers University was to test the effect of various methods processing on extract of Echinacea angustifolia and Goldenseal. We present the results in this section of our presentation.
We will also present a separate case study on artichoke done with the New Use Agriculture and Natural Plant Products Program. 4. Models for Clinical Efficacy - Traditional herbal medicine treats a patient, not a disease. With a very broad material medica of plants available, a traditional herbalist selects a mix of herbs to address a specific person's condition. In attempting to evaluate the efficacy of botanical medicine, most research is being done by broadly defining a condition and using only one botanical to address that condition. No attention is given to the specific energetics of a situation or to the size or age of the subject. This does not replicate the traditional use conditions. By relying only on this single botanical protocol and trying to standardize dosage, we examine the issue - have we gotten close to the right model for determining clinical efficacy?

\section{Agricultural Wildcatters, Have They Hit a Gusher with Medicinal Plants?}

Randy Beavers*

Sleepy Hollow Medicinal Herbs Organic Farm, 1421 Boyles Mill Road, Dalton, GA 30721

Webster's Dictionary defines a wildcatter as "one who drills wells in the hope of finding oil in territory not known to be productive". Those who collect plants from the wild are known as "wildcrafters". However, growers who attempt to produce medicinal plants often face challenges similar to the traditional wildcatter. Unknown production potential or quality and wildly fluctuating markets present significant risk. Therefore, to coin a phrase, I refer to such grower as an agricultural wildcatter. Medicinal plant agriculture is just beginning to flourish and requires a greater degree of technical knowledge to be successful. However, for those willing to learn the specialized techniques required to produce high quality products, the rewards can be substantial. Several factors make medicinal plant production an attractive crop option, especially for limited resource growers. The market for medicinal plants has been traditionally supplied from wild collected sources. However, over collection from the wild lead to the decimation of several native medicinal plant populations. As a result, many companies which produce herbal products no longer purchase wildcrafted raw material with organically cultivated material commanding premium prices. The current CITES (Convention on International Trade in Endangered Species) regulations require certain listed herbs to be cultivated for a number of years before they can be exported. In addition, many medicinal plants can be produced on farmland not used for crops, such as forestland, and harvested before or after regular crops. Also many of these plants are perennial and once a plantation is properly established and managed, it will self-sustain. Finally, natural herbal products are traditionally criticized for the lack of standard levels of bioactivity from natural raw material. Since wildcrafted plants have uncertain bioactivity blend, their cultivation offers the opportunity to minimize this variation at the point of production. While there remains much work to be done to make medicinal plant production viable for more growers, we believe that the current trends toward increased government regulation of herbal product quality and wildcrafting of medicinal plants coupled with increased consumer awareness of the original source of the products that they consume will effectively mandate the development of cultivated sources of high quality medicinal plants. Will this result in a boom for producers? The answer is still unknown but, for those willing to explore new territory and measure their success in parts per million rather than bushels per acre, the prospects for a gusher are getting more probable everyday.

\section{Analysis of Flavonoid Contents in Scutellaria by HPLC and LC-MS}

Mingfu Wang*1, James E. Simon ${ }^{1}$, Nirmal Joshee ${ }^{2}$, Anand K. Yadav ${ }^{2}$

${ }^{1}$ New Use Agricultural and Natural Plant Products Program, Department of Plant Biology and Pathology, The Rutgers University, New Brunswick, NJ 08901. ${ }^{2}$ Agricultural Research Station, Fort Valley State University, 1005 State University Drive, Fort Valley, GA 31030-4313

The species of Scutellaria Plants contains a lot of phtytochemicals 
including flavonoids, Diterpenes, Triterpenes, ligans and other phenolic compounds. The major compounds were found to be flavonoids and a few of flavonoids have been isolated from Scutellaria including baicalein, baicalin, wogonin, apigenin, luteolin etc. These compounds have a lot of pharmacological activities, especially three compounds, baicalein, baicalin and wogonin have been studied extensively and they have antioxidant activity, anti-hepatitis B virus, anti-inflammatory and anti-HIV activities. In this research, Phytochemicals from different parts (roots, leaves and stems) were extracted using aqueous alcohol solution with the aid of sonication. Then a HPLC method was developed and validated to determine the total flavonoids, the contents of baicalein, baicalein, wogonin and other flavonoids in them. The flavonoids in Scutellaria were identified by retention time of components, on-line UV spectrum, where possible, comparison will be made with authentic standards. LC-MS and LC/MS/MS methods were also developed to identify and analyze the flavonoids in Scutellaria. The structures of unknown compounds were also tentatively given based on the MS and MS/MS data.

\section{Prospects for the Medicinal and Nutraceutical Uses of Orchids}

Nirmal Joshee ${ }^{1}$, Brajesh N. Vaidya ${ }^{2}$, Anand K. Yadav ${ }^{1}$

${ }^{1}$ Agricultural Research Station, Fort Valley State University, 1005 State University Drive, Fort Valley, GA 31030-4313; ${ }^{2}$ Nepal Biotech Nursery, Kathmandu, Nepal

Orchidaceae is the largest family of flowering plants comprising between 17,000 and 20,000 species. The very concept of cultivating plants for health rather than for food and beautification is slowly changing plant biotechnology and medicine. Rediscovery of links between plants and health started a new generation of botanical therapeutics like phytopharmaceuticals, multicomponent botanical drugs, dietary supplements, functional foods and plant recombinant proteins. These products will soon enrich conventional pharmaceuticals in treating, preventing and diagnosing diseases while adding value to agriculture. The $20^{\text {th }}$ century was a triumph for the synthetic pharmaceuticals; however, the developed countries benefitted from modern drugs whereas $80 \%$ of the world population mainly in developing countries continued to rely on ethnobotanical remedies for primary healthcare. We often overlook that our medicines still contain phytochemicals worth $\$ 22,608$ million in 1997 and reaching $\$ 30,690$ million in 2002 with prescriptions and OTC herbal remedies each comprising nearly $50 \%$ of the market. The broken link between plants and health was felt not only in the medicine area but also in agriculture. Although plants are slowly coming back in several areas of human health (functional foods, dietary supplements and recombinant proteins), they are still losing importance in areas of traditional drug discovery process. The Ayurveda, translated as "The Science of Life" originated in India more than 5,000 years ago. Use of medicinal orchids in Ayurveda has been documented in the Vedic religious medical textbooks like Charak Samhita, Susruta Samhita, Astanga Hrdayam Samhita, Bhava Prakash Samhita and Madhava Nidanam Samhita during the period from 3,000 BCE to 1,500 BCE. Rig Veda, which in Sanskrit means "In Praise of Knowledge" is about 5,500 years old. People in the Indian subcontinent still use orchids in Ayurvedic medicine. The materia medica of Ayurvedic system contains a rich heritage of indigenous herbal practices that have helped maintain near perfect health for most of the rural people of India. In the western world, Theophrastus is considered as the pioneer to introduce uses of orchids for medicinal properties around 300 BCE. The ancient Greeks thought that the orchid bulbs did wondrous things to the human body. In Mesoamerica, the ancient Aztecs and Mayans cultivated Vanilla plants and used their pods to flavor their drinks. Vanilla has medicinal properties (carminative and stimulant) and inhibits growth of some bacterial species. Venezuelans use Vanilla pods against fevers and spasms. Yucatanese use Vanilla extract (pod steeped in alcohol) as aphrodisiac and stimulant while Argentinians use it as an antispasmodic, aphrodisiac or emmenagogue. The local tribes and the indigenous people living all over the world use orchids as part of their herbal medicine. In our study carried out in Nepal, Shamans, Jhankri, Vaidyas, and the medicinemen use orchid plant parts for their herbal preparations. The Tibetan medicinemen "Amjis", or priests "Lamas", Newar community medicinemen "Vaidyas" and "Guvajus", Tamang medicinemen "Lamas" and healers "Jhankri", and Tharu priests "Guraun" are the ones who use wild plants including orchids, in their medicine preparations. We present a case study of the uses of orchids as food and medicinal plants in Nepal.

\section{How Molecular Biology Methods Can Be Used in the Authentication of Botanicals}

Brian E. Scheffler ${ }^{1}$, Nurhayat Tabanca ${ }^{2}$, Sara Crockett ${ }^{2}$, Andy Douglas ${ }^{3}$, Natascha Techen ${ }^{2}$, Ikhlas Kahn ${ }^{2}$

${ }^{1}$ USDA-ARS-CGRU, MSA Genomics Laboratory 141 Experiment Station Rd., Stoneville, MS 38776-0038. ${ }^{2}$ National Center for Natural Products Research and ${ }^{3}$ Department of Biology, The University of Mississippi, University, MS 38677

Molecular biology offers an array of methodologies that can be used in the field of botanical supplements. Depending on the process used, it is possible to identify a plant species, characterize and thus protect a variety, or identify contaminants within a sample. These applications require the isolation of DNA from the sample, amplification of specific regions of the DNA using various forms of the technique called PCR (polymerase chain reaction) and, in some instances, the determination of the DNA sequence of the PCR product. Until recently, most molecular biology techniques required a significant investment in equipment and highly skilled trained individuals. With the advent of commercial kits, vendors offering reasonably priced sequencing or fragment analysis services, and development of inexpensive equipment, a small firm could invest approximately $\$ 10,000$ to have a functional molecular biology lab to help in the authentication of botanicals. Commercial kits for DNA extraction and PCR make some of the procedures relatively easy to perform with limited training and they can be reasonably priced to use. They also allow for better reproducibility and standardization of procedures. While all these applications are potentially interesting, there are serious limitations to adapting this technology into the mainstream of botanical supplements: 1. A serious limitation is the absence of standards for the botanicals and potential contaminants. Each molecular biology procedure requires a standard for each desired species to be tested. 2. Presently little effort has been made to standardize the procedures so they can be adapted by many labs and thus, the development of standards is also difficult. $\backslash 3$. Contamination must be defined. Molecular biology techniques can be very sensitive for the detection of a given contaminant, but it is probably an inefficient and expensive tool to characterize all contaminants. 4. The application of all procedures can be limited due to the quality of the products. Harvesting, storage, and processing of botanicals can have a very negative impact on the quality of the DNA, which can in some instances limit the use of molecular biology tools This presentation will provide more information on how of molecular biology techniques cab be used in the authentication of botanicals and the challenges facing the implementation of such techniques into routine analysis.

Studies on the Immuno-modulatory Activities of Isolated Compounds or Extracts Obtained from Select Medicinal Plants

Prahlad Parajuli*1, Nirmal Joshee ${ }^{2}$, Anand K. Yadav ${ }^{2}$

${ }^{1}$ Wayne State University and Karmanos Cancer Institute, Detroit, MI; ${ }^{2}$ Agricultural Research Station, Fort Valley State University, Fort Valley, Georgia

Complementary and alternative therapies are becoming increasingly popular for various diseases, especially cancer, where the standard therapies such as chemotherapy and radiation have failed to yield positive results. A variety of herbal products are being used in laboratories as well as in the clinic with a hope to cure or 'manage' such diseases. Another strategy to fight the menace of diseases like cancer is to boost the body's own immune system, generally referred to as immunotherapy. There have been systematic studies on few of the herbal products, either in the 
form of crude extracts or isolated bioactive compounds, for generating mechanistic evidence for their therapeutic potential. Anti-cancer properties including induction of apoptosis, and anti-inflammatory activities including inhibition of enzyme cyclo-oxygenase-2 (Cox-2) have been demonstrated. However, studies on how these herbal products would affect the immune system have been extremely rare. Our laboratories have a collaborative program for studying the immuno-modulatory properties of one particular herb, namely Scutellaria $s p$. Herein, we report a literature review of studies on anti-cancer and anti-inflammatory activities of Scutellaria in particular with reference to other related herbal products. Preliminary results from our laboratories on immuno-modulatory activities of Scutellaria will also be discussed in connection with it's potential application in immunotherapy of cancer and other diseases.

8:00 am-10:00 am WORKSHOP 21 $552 \mathrm{~A}$

\section{Oxidative Stress: Postharvest Fruits and Vegetables}

Moderator: Gene E. Lester

Sponsor: Postharvest Working Group (PH)

Objective: Oxidative stress of fruits and vegetables reduces product storage quality and marketability. Four international scientists, who are focusing on oxidative stress and its effects on senescence and postharvest disorders of horticultural crops, will present current knowledge on the formation of oxidative stress, on the crucial cycling and interplay of enzymic and non-enzymic antioxidants, on oxidative stress and fruit scald, and on treatments designed to minimize oxidative stress.

Summary: Active oxygen species (AOS) cause oxidative stress when in excess of the tissue scavenging capacity of fruits and vegetables. AOS are linked to postharvest quality issues such as senescence and fruit scald. Knowledge of crucial cycling enzymatic/non-enzymatic antioxidants and treatments designed to reduce oxidative stress will extend postharvest storage quality.

\section{Postharvest Fruit and Vegetables: Effects of Oxidative Stress \\ D. Mark Hodges* \\ Agriculture and Agri-Food Canada}

Regulation of Oxidative Stress in Horticultural Crops Albert C. Purvis*

University of Georgia, Costal Plain Experiment Station

Oxidative Stress and Apple Scald

Bruce Whitaker*

USDA-ARS

Postharvest Storage Procedures and Oxidative Stress Peter Toivonen*

Agriculture and Agri-Food Canada

8:00 am-12:30 pm COLLOQUIUM 4 Ballroom B/C

\section{The U.S. Vegetable Industry Past and Future: Highlighting Advances, Challenges, and Opportunities in Vegetable Crop Management}

\footnotetext{
Moderators: Ted Carey, Matt Kleinhenz

Sponsor: ASHS Vegetable Crop Management Working Group

Abstract: The management of vegetable crops continues to be shaped by on- and off-farm forces. Changes in the availability of land and water for agricultural use, attitudes regarding the role of agriculture
}

in environmental stewardship and diversity and intensifying markets have numerous impacts on vegetable growers and scientists. For growers, these and other factors demand that vegetable crop management be increasingly efficient, tied to market demands, and environmentally friendly. It is also likely that system-oriented strategies, which integrate varying disciplines, may be key to meeting these requirements. With this in mind, the Vegetable Crop Management Working Group in cooperation with six other ASHS working groups is pleased to sponsor a Colloquium entitled "The U.S. Vegetable Industry Past and Future: Highlighting Advances, Challenges, and Opportunities in Vegetable Crop Management." Speakers will outline efforts used to overcome past challenges in key areas of vegetable crop management. And, they will discuss potential strategies for meeting emerging production-related issues. The Colloquium will be a valuable opportunity for participants to address how technical and strategic improvements can be applied to new challenges and opportunities in vegetable crop management, borrowing the insight of recognized experts in key areas.

\section{Introduction}

Matt Kleinhenz*

\author{
Market-production Linkages: Past and Future \\ Tom Karst* \\ The Packer News, Shawnee Mission, KS 66201 \\ Four key issues will be addressed in this presentation: \\ 1. The impact of government regulation and intervention in the \\ fresh produce industry on growers. \\ 2. The role of the government's fight against obesity in the fresh \\ vegetable industry. \\ 3. The impact of mandatory country of origin labeling as an example \\ of how consumer attitudes about vegetables may be shaped by new law. \\ 4. Potential opportunities and problems as a result of coming \\ trade deals.
}

The U.S. Vegetable Seed and Transplant Industries: A Look At The Past, A look Into the Future

Daniel J. Cantliffe*

Horticultural Sciences Department, University of Florida, Institute of Food and Agricultural Sciences, Gainesville, FL 32611

The two industries, seed and plant production, for improvement in stand establishment technology of vegetables crops have traveled long and diverse roads over the past 100 years. The vegetable seed industry has undergone some of the most dynamic changes in American agriculture over the past century. In the first half of the 1900 's many small family owned seed businesses began to enlarge. Fueled by colorful catalogs and local sales, many companies expanded their trial grounds and sales areas. As costs began to climb, mergers started. In the second half of the last century hybrid cultivars, highly trained research breeders, and improved seed production technology greatly improved seed emergence, stand establishment and cultivar performance of many vegetable species. Presently, only a fraction of the seed companies of 100 years ago exist, while those that do, continue to fight for market share via global marketing, heavy research investments and development of superior products. The future will look toward greater emphasis on proprietary research, the adoption and use of GMO's as a means for developing superior proprietary products, and a continued expansion in global marketing.

Similarly, the vegetable transplant industry has gone through dynamic changes including mergers, large companies, use of structures for plant production, adoption of new plug production systems and the development of strategies for seed singulation in cells, use of soilless media and methods to reduce labor inputs. The future will require further development of modernization procedures in both the plant production house and in field planting systems in order to stay 
competitive with direct seeding systems.

\section{Modifying the Microclimate for the Production of Vegetable Crops}

William James Lamont, Jr.*

Dept. of Horticulture, The Pennsylvania State University, University Park, PA 16802

For centuries horticulturists have attempted to modify the environment in which vegetable crops are grown using a wide variety of techniques such as, glass jars, glass cloches, hotcaps, cold frames, hotbeds, and various types of glass greenhouses to extend the production season. The discovery and development of the polyethylene polymer in the late 1930s, and its subsequent introduction in the early $1950 \mathrm{~s}$ in the form of plastic films, mulches, and drip-irrigation tubing and tape, revolutionized the commercial production of selected vegetable crops and gave rise to a system of production known as plasticulture. Simply defined plasticulture is a system of growing vegetable crops where significant benefit is derived from using products derived from plastic (polyethylene) polymers. The later discovery of other polymers, such as polyvinyl chloride, polypropylene, and polyesters, and their use in pipes, fertigation equipment, filters, fittings and connectors, containers for growing transplants, picking and packaging containers, and row covers further extended the use of plastic components in this production system. The complete plasticulture system consists of plastic and non-plastic components: plastic mulches, drip-irrigation, fertigation/chemigation, soil sanitation (fumigation and solarization), windbreaks, stand establishment technology, season-extension technology, integrated pest management, cropping strategies, postharvest handling and marketing. Plastic mulches, drip-irrigation, row covers, low tunnels, high tunnels, plastic covered greenhouses and windbreaks both permanent and annual are the major contributors to modifying the cropping environment of vegetable crops thus enhancing crop growth, yield, and quality. In addition to modifying both the soil and air temperatures, there are also the benefits of protection from the wind and in some instances rain, as well insects, diseases, and predators such as varmints and birds.

\section{Management of Irrigation for Vegetables: Past and Future}

Sal J. Locascio*

Horticultural Sciences Dept., University of Florida, Gainesville,FL32611

Vegetables are grown extensively throughout the United States on various soil types and in various climates. Irrigation is essential to supplement rainfall in all areas to prevent plant water stress for most crops. In the United States, 25.5 million ha of crop land are irrigated. The applied ground and surface water accounts for 80 percent of the nations consumptive water use. Irrigated vegetable production accounts for about 1.9 million ha or 7.5 percent of the irrigated area (including 0.45 million ha potatoes). Irrigation is essential in arid regions of California where 31 percent $(591,000$ ha) of irrigated vegetables are produced as well as humid regions of Florida, second in value of vegetable production with 7 percent $(130,000 \mathrm{ha})$ of the irrigated vegetables. Other states with major irrigated vegetable areas are Idaho (170,000 ha), Washington (163,000 ha), Texas (112,000 ha), Nebraska (94,000 ha), Oregon (74,000 ha), Wisconsin (72,000 ha), and Arizona $(60,000$ ha). These nine states account for 80 percent of the U. S. production of irrigated vegetables. The need for irrigation to reduce plant water stress was recognized as early as 5,000 BC by Egyptians who diverted water from the Nile River to irrigate crops by a system of surface irrigation. In the US, surface and subsurface (seepage) irrigation systems were used initially and are currently used on 45 percent of all irrigated crops. These systems, often called gravity-flow systems, require an abundance of water, gently sloping fields, and the presence of an impervious soil layer at 60 to $90 \mathrm{~cm}$ soil depth. Seepage systems are less expensive and generally are simpler to manage than other systems. However, they use about 5 to 10 percent of the crop land area and have a water use efficiency of about 33 percent or lower. In the 1940's, sprinkler or over-head irrigation systems were developed and are currently used extensively throughout the vegetable industry. Sprinkler systems include solid-set systems, center pivot, lateral moving systems, and portable and traveling gun systems are used on $50 \%$ of the irrigated crop land. The systems are more costly to purchase and operate and more complex to manage than seepage systems. However, they provide better water use efficiency (about 75 percent), and control water applications throughout the field. Water is typically applied on a 5 to 7 day schedule to bring the soil to field capacity in the plant root zone. In addition to being used for irrigation, sprinkler systems are often used for frost control in strawberry and other vegetables. In the late 1960's micro irrigation (drip or trickle) systems were developed and have slowly replaced many of the sprinkler and some of the seepage systems formally used. Micro irrigation is currently used on 5 percent of irrigated crops. With continued concern with water availability and nutrient leaching, particularly $\mathrm{NO}_{3}-\mathrm{N}$ into groundwater, this highly efficient water system ( 90 to 95 percent) is widely used on high value vegetables, particularly polyethylene mulched tomato, pepper, eggplant, strawberry, and open and mulched culture cucurbits. Some advantages of drip irrigation over sprinkler include reduced water use, ability to apply fertilizer throughout the season, precise water distribution, reduced foliar diseases, and the ability to electronically schedule irrigation on large areas with relatively smaller pumps. Systems are complex and require a high level of management. Systems include drip tubing, filters, pumps, back-flow devices, injectors, and timers. Irrigations may be scheduled daily by the replacement of 75 percent of the water evaporated from a Class A Weather Bureau pan or on demand by tensiometers or some other soil water sensor. The $\mathrm{P}$ and micronutrient with 30 to 40 percent of the $\mathrm{N}$ and $\mathrm{K}$ are applied preplant on coarse textured soils with the remaining $\mathrm{N}$ and $\mathrm{K}$ applied in 6 to 10 weekly applications. Daily or weekly applications of nutrients provide similar yields. Most drip lines are placed on the soil surface or at a 2 to $5 \mathrm{~cm}$ depth in the bed. In addition to the application of water and nutrients, drip systems can be used to efficiently apply some pesticides. Another use of drip is as sub-surface drip systems placed at a depth of 60 to 90 $\mathrm{cm}$. These systems are managed to control the watertable similar to that accomplished with sub-surface irrigation systems but with much greater water use efficiency. For efficient use of drip irrigation, water and nutrients must be carefully managed. Over irrigation and poor nutrient application scheduling results in nutrient leaching and reduced yields. Future irrigation concerns include continued availability of water for agriculture, management of nutrients to minimize leaching of nutrients into the ground water, and continue to develop cultural practices that maximize crop water use efficiency.

\section{Mineral Nutrition-Technical and Strategic Advances Charles A. Sanchez*}

Dept. of Soil, Water, and Environmental Sciences and Yuma Agricultural Center, University of Arizona, Yuma, AZ 85364

For centuries it was recognized that plants responded to the addition of certain materials but an understanding of plant nutrition was lacking. Following significant developments in chemistry during the $18^{\text {th }}$ century, the science of plant nutrition evolved considerably in the $19^{\text {th }}$ century. Basic research has and continues to provide fundamental insight into plant uptake, transport, and utilization of nutrients. After it was recognized that plants absorb specific mineral elements from the soil, and various mineral elements were proven essential for plant growth, the benefits of fertilization when these nutrients are deficient was recognized. Over the past century, applied research by horticulturalists and others has focused on fertilizer rates, timing, placement, and methods of application. The integration of soil and plant tissue testing as aids in making fertilizer recommendations also contributed substantially to the efficient utilization of plant nutrients. The implementation of newer evolving technologies, such as site-specific or precision agriculture, and crop production and resource management models, promise to make nutrient management even more efficient. However, challenges remain. This presentation seeks to briefly summarize progress made in the field of plant nutrition over the past century and outline future challenges and opportunities. 
Technical and Strategic Advances in Mechanization

James L. Glancey ${ }^{1}$, Edwin $\mathrm{Kee}^{2}$

${ }^{1}$ Dept. of Bioresources Engineering, University of Delaware, Newark, DE 19716, ${ }^{2}$ Dept. of Plant and Soil Science, Research and Education Center, University of Delaware, Georgetown, DE 19947

At the conclusion of the $20^{\text {th }}$ century, the National Academy of Engineers listed the 20 greatest engineering achievements of the last 100 years. Ranked seventh, among such other accomplishments as electrification, television, automobiles, and computers, was agricultural mechanization. In addition to the often-sited examples of the tractor and grain combine, several significant developments were directly attributable to vegetable production including precision planters, the tomato and potato harvester, and mobile threshing units for pea and bean crops. Together, these innovations have allowed the vegetable industry in the U.S. to plant and harvest significantly more land with higher yields using substantially less labor. Many of the challenges that existed a century ago that led to the mechanical innovations previously sited still exist for some crops. As the production and consumption of most vegetables expands worldwide, many countries are currently struggling with the same basic production issues once faced by U.S. growers. Furthermore, as the vegetable industry continues to experience world-wide consolidation of processors and equipment suppliers, the emphasis on highly efficient, lower cost mechanized production continues to drive research and development in both industry and academia. Several technical and strategic opportunities have the potential to enhance the vegetable industry as it continues to evolve in the $21^{\text {st }}$ century. Short term, intelligent machines capable of operating with minimal operator inputs will provide U.S. growers with rapid and accurate planting, high speed post-planting operations, and improved harvest efficiency. Although the economic and environmental advantages are still uncertain, site-specific technologies may provide a means to improve the production of several vegetables, once sufficient yield and soil data become available. In countries currently developing sustainable production systems that will supply the U.S., the emphasis will be on low-cost mechanization as a replacement for animal power and hand-harvesting. Long term, harvest (separation) mechanisms still need to be designed and tested for many crops. This deficiency exists more for fresh market crop like melons, peppers, squash, but also is true for some processed vegetables. These new harvest systems must recover a significant amount of the crop with minimal mechanical damage. As the ability to introduce genetic modifications to plants continues to expand, significant improvements in mechanized vegetable production may best occur with an integrated approach in which both the machine and crop are designed as a system.

\section{Small Farms, Direct Marketing, and their Roles in the U.S. Vegetable Industry}

Ronald E. Voss*

Dept. of Vegetable Crops, Univ. of California, Davis, Davis, CA95616

At one time in U.S. history, vegetable crops, truck farming and small farms were synonymous. During the past two generations, however, that has changed. As we enter the $21^{\text {st }}$ century, $90 \%$ of the vegetables are produced by large or medium size conventional farms. The role of small farms is still a very significant one, not only to those whose lives are directly dependent upon the individual farms and to the consumers who purchase their produce, but because many of the new industry-wide strategies and philosophies being accepted as cutting-edge have their origin on small farms. Alternative marketing strategies are essential to the economic profitability of small farms, short-term and long-term. The other central theme of successful small farms is alternative production practices. Thus, direct marketing, specialty and new crops and varieties, diversification, value added products, organic production, demand driven by the end-consumer not wholesale buyers or large advertising campaigns, and product branding are among the strategies pioneered by small farmers in the U.S. One by one, most of these strategies have been adopted and/or adapted by larger scale vegetable producers and industry groups. One of the many challenges facing small farmers is how to stay one strategy ahead of their competition - locally, nation- ally and internationally. High quality, capturing a high percent of the consumer expenditures, and maintaining the principles of sustainable agriculture must be components of each of these small farm strategies, individually and collectively. Research and education needs of small farmers and direct marketers may be similar or quite different from larger scale, conventional vegetable farming operations. Education strategies may also vary widely since many clusters or groups of small farmers, and consumers of small farm products, have ethnic or cultural characteristics that do not respond positively to our classical extension education or consumer marketing techniques. Elaboration and examples will be presented.

\section{A Face, A Place, A Taste: The Development of Organic} Agriculture Since 1970

\section{Russell Libby*}

Maine Organic Farmers and Gardeners Association, Unity, ME 04988

From a few scattered farmers selling surplus garden vegetables, organic farming has emerged as one of the few growth sectors in agriculture. While some of the growth is directly related to farmers' decisions about production practices, consumer demand and a perception that there are market opportunities has influenced more change. Even within the organic sector, there are different perspectives on how to approach these consumers. Many farmers in Maine and the Northeast have focused on direct marketing and sales through locally-owned independent retailers, trying to stay outside the traditional commodity marketing system. But as their customer base has grown, and consumers seek organic produce year-round, larger farms in California and other production regions have entered the market, supplying supermarkets and wholesale outlets. As a result, we have the same kinds of divisions in the organic sector as in the conventional - the differences between farmers who know their buyers, and those who are focused on volume marketing.

\section{Concluding Remarks \\ Ted Carey*}

9:00 am-9:30 am COMMITTEE MEETING $555 \mathrm{~A}$

Consumer Horticulture \& Master Gardeners (CHMG) Working Group

Chair: Richard Durham

\section{9:30 am-12:00 am ORAL SESSION 45}

\section{Produce Quality, Safety, and Health Properties}

\author{
Moderator: To Be Announced
}

9:30 Kale Carotenoids Remain Stable while Flavor Compounds Respond to Changes in Sulfur Fertility

David Kopsell ${ }^{* 1}$, Dean Kopsell ${ }^{2}$

${ }^{1}$ Plant Biology, University of New Hampshire, G37 Spaulding Hall, Durham, NH, 03824, ${ }^{2}$ Plant Biology, University of New Hampshire, G48 Spaulding Hall, Durham, NH, 03824

Kale (Brassica oleracea L. Acephala Group) has been reported to contain the highest levels of lutein and $\beta$-carotene carotenoids among green leafy vegetable crops. Dietary intake of certain carotenoids has been associated with reduced risks of specific cancers and chronic eye diseases. However, Brassica vegetables contain glucosinolate (GS) and S-methyl-cysteine sulfoxide (MCSO) sulfur compounds responsible for bitter, acrid flavors that are often regarded as objectionable by consumers. Therefore, the objective of this study was to investigate the influence of increased S fertility levels on: 1) GS and MCSO production; and 2) the accumulation patterns of carotenoid pigments in the leaf tissues of three kale cultivars. 'Winterbor', 'Redbor', and 'Toscano' kale were greenhouse grown using nutrient solution culture with $\mathrm{S}$ treatment concentrations at $4,8,16,32$, and $64 \mathrm{mg} \cdot \mathrm{L}^{-1}$ of $\mathrm{S}$. Sulfur leaf accumulation increased linearly in response to increasing $\mathrm{S}$ in nutrient solution among the cultivars. Levels of GS and MSCO 
also increased linearly in response to increasing $S$ in nutrient solution. However, accumulation of lutein and $\beta$-carotene remained unaffected by $S$ treatment. Therefore, decreasing $S$ fertility in kale production will decrease GS and MCSO compounds responsible for flavor without affecting carotenoid pigments levels. Understanding the combined impact of fertility on flavor compounds and carotenoid pigments may help improve consumer acceptance of phytonutritionally-enhanced vegetable crops.

\section{9:45 Genotypic Variation of Antimutagenicity and DPPH Radi-} cal Scavenging Activity in the Sweetpotato Leaves

Md. Shahidul Islam*1, M. Yoshimoto ${ }^{2}$, M. Jalaluddin ${ }^{1}$, O. Yamakawa ${ }^{2}$

${ }^{1}$ Department of Agriculture, University of Arkansas at Pine Bluff, 1200 North University Drive, Mail Slot 4913, Pine Bluff, Arkansas, 71601, ${ }^{2}$ Upland Farming Research, National Agricultural Research Center, Yokoichi 6651-2, Miyakonojo, Miyazaki, 885-0091, Japan

Antimutagenicity of the water extracts and radical scavenging activity (RSA) prepared from the leaves of sixty genotypes of sweetpotato (Ipomoea batatas L.) were investigated using the Salmonella typhimurium TA 98. The extract from the high polyphenol accumulator genotypes effectively decreased the reverse mutation induced not only by Trp-P-1 and Trp-P-2, IQ, B(a)P, and 4-NQO, but also by dimethyl sulphoxide extract of grilled beef. Comparison of the inhibitory activity of the extracts from the medium and low polyphenol accumulator genotypes suggested that the polyphenol content in the leaves decreases the mutagenic activity of the mutagens as heterocyclic amines. Three constituents of leaves polyphenils, 4,5-di-caffeoylquinic acid and 3,4,5tri-caffeoylquinic acid, effectively inhibited the reverse mutation induced by Trp-P-1 and Trp-P-2. Furthermore, determination of the inhibitory activity of sectional portions using the FV-85 genotypes demonstrated that the inhibitory components are abundant in the leaves, suggesting the involvement of phenolics in the antimutagenicity of the extract from the sweetpotato leaves. The results also suggested that RSA is positively correlated with the total phenolics of sweetpotato leaves.

10:00 Cultivar and Growing Location Effects on Oil and Fatty Acids in Canola Sprouts

\section{Harbans Bhardwaj*, Anwar Hamama}

Agricultural Research Station, Virginia State University, PO Box 9061, Petersburg, VA, 23806

The efforts to increase domestic canola production in the southeastern United States are hindered by lack of processing facilities. Development of alternative uses of canola, such as development of easily marketable products, could help alleviate this problem by establishing the crop and indirectly helping to increase the availability of this crop as an oilseed. Sprouts of alfalfa, mungbean, and many other crops are major component of food consumption in the United States and the world. The current literature lacks detailed information about oil and fatty acids in canola sprouts and about the effects of cultivars and growing locations on quality of canola sprouts. We made sprouts from seeds of seven canola cultivars, grown in replicated experiments at three locations in Virginia (Orange, Petersburg, and Suffolk) during 2001-02 season. Significant variation existed among locations for concentrations of oil, 16:1, 18:1, 18:3, and 20:0 fatty acids in sprouts. Cultivars had significant effects on concentrations of 18:0, 18:1, 18:2, 18:3, 20:0, 20:1, and 22:1 fatty acids in sprouts. The cultivar $\times$ location interactions were non-significant. Canola sprouts, on an average, contained 38.9 percent oil, and 5.0, 0.7, 1.4, 61.5, 18.6, $9.2,0.5,1.8,0.4,0.8,0.1,7.4,92.6,64.8$, and 27.8 percent of $16: 0,16$ : $1,18: 0,18: 1,18: 2,18: 3,20: 0,20: 1,22: 0,22: 1,24: 0$, total saturated, total unsaturated, MUFA, and PUFA fatty acids, respectively in the oil. There was a strong relationship between seed and sprout composition of various fatty acids. Further details of these results would be presented and discussed.
10:15 Determination of Apple Fruit Maturity on the Basis of the Contents of Carotenoids and Chlorophylls during Ripening Sergey Rodikov*

Storage Division, I.V.Michurin Research Institute of Horticulture, Michurin Street, Michurinsk, Tambov Region, 393774, Russian Federation

Reflection index (R678-R485)/R750 was used to investigate the state of apple fruit maturity on the basis of the contents of chlorophylls and carotenoids in their skin. It was shown that air temperature and solar radiation considerably effect the content of skin pigments at the stage of fruit ripening and senescence. Fruit from the part of the tree exposed to light has more heterogeneous degrees of ripeness on its different sides, furthermore the shaded side of the apple is susceptible to skin browning during storage. It was established that the more high levels of reflection of a shaded apple side were observed in the range of $350-440 \mathrm{~nm}$. The lowest levels of reflection in this range was shown in the treatment with sun apple side from the sun side of the tree. Probably it is the effect of phenolic compounds and flavonoids contained in the fruit. Furthermore in seasons with high maximum temperatures fruit on sun side warm up to temperatures resulting in denaturation of protein lipids complex and therefore in scald and tissue breakdown. So as temperature as near UV radiation effect the contents of pigments on the sun side of the apple.

10:30 Volatile Compounds as Markers for Coliforms Inoculated on Strawberry Fruit

Keshun $\mathrm{Yu}^{1}$, Hesham Elgaali ${ }^{2}$, Thomas Hamilton-Kemp*1, Melissa Newman ${ }^{2}$, Randall Collins ${ }^{1}$, Douglas Archbold ${ }^{1}$

${ }^{1}$ Dept. of Horticulture, Univ. of Kentucky, ASC-N 308, Lexington, KY, 40546, ${ }^{2}$ Dept. of Animal Sciences, Univ. of Kentucky, Garrigus Bldg, Lexington, KY, 40546

Previous studies have shown that numerous volatile compounds, including alcohols, ketones, sulfides, and nitrogen compounds, are emitted into the air by Gram-positive and Gram-negative bacteria associated with food. Gram-negative coliforms including Salmonella and Escherichia coli emit a group of characteristic long-chain alcohols including 1-decanol. Moreover, E. coli emits relatively large quantities of indole which is readily detected in the vapor phase. In the present investigations, strawberry fruit was inoculated with strains of $E$. coliincluding the human pathogen $\mathrm{O} 157: \mathrm{H} 7$ and the fruit was rinsed with TSB nutrient broth 24 hours later. The broth was incubated for 24 hours at $35^{\circ} \mathrm{C}$ and volatile compounds produced were collected for 15 minutes using solid phase microextraction SPME. Analysis by gas chromatography revealed the predominant volatile compounds emitted from the broth cultures were 1-decanol and indole. These results provide a basis for developing a nondestructive test for E. coli and other coliform bacterial contaminants of fresh fruits and vegetables. In practice, the method would employ water to rinse the food item and air sampling to detect vapors characteristic of enteric coliforms on food.

10:45 Seasonal Changes in Citrus Limonoids and Their Role in Human Health

Jiaxling Li, Bhimanagouda Patil*

Citrus Center, Texas A\&M University-Kingsville, 312 N. International Blvd., Weslaco, Texas, 78596

Biological activities of citrus functional components such as limonoids, carotenoids, pectin and flavonoids have shown potential benefits to prevention of chronic diseases such as cancer and heart through cell culture and animal studies. Recent studies in our laboratory have demonstrated that limonoids specifically obacunone glucoside against MCF-7 were dose-dependent and the growth-inhibitory effects were significant (Nutrition and Cancer 2001, 40:180-184). Pectin from lemon showed the highest inhibitory effect on the fibroblast growth factor (FGF) signal transduction process (J. Agri. Food Chem. 49:30513057). By considering the synergetic effect of these components on human health, we have initiated investigations on seasonal changes of functional components in grapefruit. Previously, we reported changes 
in lycopene during fruiting season in grapefruit. In present study, the concentration of limonin, including limonoate A-ring lactone (LARL), and its glucoside, limonin 17- $\beta$-D-glucopyranoside (LG) in 'Rio Red' grapefruit were measured during fruit growth and development (July through May of the following year). In the fruit tissues (flesh, segment membrane and albedo), the concentration of LARLdecreased constantly during the fruiting season from July through May of the following year. LG began to appear in the fruit tissues in either September or October, and its concentration steadily increased thereafter. An inverse correlation between LARL and LG was observed, suggesting that LARL was converted to LG during late stages of fruit growth and maturation. In the seeds of 'Rio Red' grapefruit, both LARL and LG concentration increased constantly as the fruit maturation continues. The first appearance of LG in the seeds was observed in August.

11:00 EUREPGAP, Worker Safety and Food Safety in the Ghanaian Pineapple Industry

Donald Humpal ${ }^{* 1}$, Emmanuel Owusu ${ }^{2}$

${ }^{1}$ A\&E, DAI, 4811 Chippendale Drive, Suite 206, Sacramento, CA, 95819, ${ }^{2}$ TIRP, AMEX, House No. 97/4, Labadi Light Industrial Area, PO Box 5196, Accra -North, Accra Region, 5196, Ghana

The European Retail Produce Network's Good Agricultural Practice program is a private, ISO-compliant, third-party auditor certification increasingly required by EU importers of fresh fruits and vegetables. EUREPGAP was developed as a response to consumer and environmental advocates concern over the safety of the human food chain. It is also a response to increasing public pressure on companies in the food chain to demonstrate that they do not benefit from child labor or unfair labor practices. Meeting its threshold standards is challenging even for developed country producers. Environmental, production practice, worker safety, and labor practice standards are bundled together and encompass more than 250 control points. Many of these control points are intended to mitigate the risks of chemical and microbial contamination in human health. This paper outlines the EUREPGAP requirements and how a three-year effort since 2000 has enabled the Ghanaian pineapple industry to meet these exacting management standards.

\section{1:15 Survey of Fruit and Vegetable Growers to Assess on-Farm Food Safety Needs}

Elizabeth Bihn*, Robert Gravani

Department of Food Science, Cornell University, 11 Stocking Hall, Ithaca, NY, 14853

Recent increases in the number of foodborne illnesses associated with fruits and vegetables have resulted in buyers requesting third party audits to insure farms and packinghouses have implemented good agricultural practices (GAPs) to reduce microbial risks. To stay competitive in the marketplace, growers and packers need to know about GAPs and how to implement them. The GAPs Program based at Cornell University has been developing educational materials to assist growers with understanding GAPs and the importance of implementation since 1999. Along with collaborators at 25 Land-Grant Institutions, the program has conducted workshops and exhibited at grower meetings to disseminate this educational information. In order to determine what information and materials growers need as they overcome challenges in the implementation of GAPs, a survey was conducted in New York during the winter of 2002 with 451 growers responding. Preliminary analysis revealed that $49 \%$ of the respondents have started to implement GAPs, but $31 \%$ still were not aware of good agricultural practices. Survey data suggests that implementation may be delayed because growers could not determine which GAPs to prioritize $(16 \%)$ and because of the cost $(18 \%)$. Other responses that will be discussed highlight areas that can be addressed to make GAPs educational programs more effective and meet the immediate needs of growers. Produce food safety is very important because it affects the health of consumers and economic viability of fruit and vegetables growers.
11:30 Wash Operations Affect Efficacy of Chlorine and Ozone on Microbial De-contamination of Fresh-cut Produce Yaguang Luo*1, Ji Gang Kim${ }^{1}$, Yang Tao ${ }^{2}$, James L. McEvoy ${ }^{1}$ ${ }^{1}$ Produce Quality and Safety Lab, USDAARS, 10300 Baltimore Ave., Bldg. 002, Beltsville, MD, 20705, ${ }^{2}$ Biological Resources Engineering, University of Maryland, College Park, MD, 20740

Fresh-cut products are marketed as "washed" and "eady-to-eat". Little information exists regarding how wash operations affect water quality and the efficacy of sanitizers on microbial reduction. The main objectives of this study were to 1) evaluate the effect of fresh-cut wash operations on water quality, and consequently the efficacy of chlorine and ozone on reducing microbial loads on fresh-cut vegetables; and 2) study the effect of wash water quality on microbial growth and sensorial quality of fresh-cut vegetables during storage. Fresh-cut lettuce and carrots were washed in an industrial polywash system using various chlorine and ozone treatments. The products were centrifuged to remove excess water and packaged in bags of selected film oxygen transmission rates according to standard commercial practices. Water quality, as influenced by wash operation and sanitizers, was evaluated for biologic oxygen demand, chemical oxygen demand and heterotrophic bacteria count. Product quality, and microbial loads on the fresh-cut vegetables before and after washing, and during cold storage were also evaluated. Results indicate that water quality and the available chlorine and ozone were significantly affected by the fresh-cut vegetable type, cut size, water to product ratio and the organic load on the product. Wash operations, and the applications of chlorine and ozone also affected specific microbial populations on the fresh-cut produce and product quality during storage.

11:45 Risky Business: Managing Risk in Fresh Produce Operations

Dennis Osborne ${ }^{* 1}$, Douglas Sanders ${ }^{1}$, Donn Ward ${ }^{2}$

${ }^{1}$ Horticultural Science, NC State University, Campus Box 7609, Raleigh, NC, 27695-7609, ${ }^{2}$ Food Science, NC State University, 100 Schaub Hall, Raleigh, NC, 27695

Examples of traditional "Risk Management" tools related to agricultural enterprises include hedging, contracting and insurance. These tools "manage" risk in terms of probability functions. Recently, some new tools have been developed in response to a new American "Homeland Security" consciousness. The new tools address a future not subject to actuarial analysis. The tools were developed because new crops and new farm audiences need tools they can adopt to help address public concerns about food security while simultaneously managing personal liability. While traditional tools help indemnify against loss, the new tools help growers manage potential liability. In form and function such tools differ from loss-indemnification tools. For instance, the authors and co-workers in the South Region have published the first Grower's Recall Plan and developed a risk management training program for the fresh produce industry. This paper reviews our work, some new national efforts in fresh produce-related risk management and discusses some liability concepts related to recall. We also will show how the new USDA GAPs Certification Program should be an effective risk management tool for any scale user.

10:00 am-11:30 am ORAL SESSION 46 $555 \mathrm{~A}$

\section{Postharvest-Cross-commodity}

\author{
Moderator: Adel Kader
}

10:00 Effect of Combination of Delayed Packaging and Film Oxygen Transmission Rate on Quality of Fresh-cut Romaine Lettuce

Ji Gang Kim*, Yaguang Luo, Robert A. Saftner, Kenneth C. Gross

Produce Quality and Safety Lab, USDA ARS, 10300 Baltimore Ave., Bldg. 002, Beltsville, MD, 20705 
Modified atmosphere packaging (MAP) is widely used to maintain quality of fresh and fresh-cut produce by matching the film oxygen transmission rate (OTR) to the respiration rate of the packaged product. However, unlike intact produce, the respiration rates of fresh-cut vegetables follow dynamic patterns with an immediate increase upon processing, followed by sharp and then gradual declines during storage. Commercially, packaging is often delayed; yet its effect on package atmospheres and tissue metabolism has no been reported. The main objective of this study was to evaluate the effect of delayed packaging and its interaction, if any, with film OTR on quality of fresh-cut romaine lettuce. Romaine lettuce leaves were sliced, washed and dried according to standard commercial fresh-cut practices. Samples were held at $5^{\circ} \mathrm{C}$ for $0,4,10$, and 24 hours in air prior to packaging in bags with film OTRs of 1700 and $3500 \mathrm{~mL} \cdot \mathrm{m}^{-2}$ per day. The bags were flushed with $\mathrm{N}_{2}$ to reach an initial headspace $\mathrm{O}_{2}$ partial pressure of $1.5 \mathrm{kPa}$ and hermetically sealed. The packaged samples were stored at $5{ }^{\circ} \mathrm{C}$ for up to 14 days for quality evaluation. Results indicate that delayed packaging significantly $(P<0.001)$ affected $\mathrm{CO}_{2}$, ethanol and acetaldehyde accumulation within the bags, product discoloration and decay. With 3500 OTR film, delayed packaging increased discoloration and reduced overall quality. With 1700 OTR film, delayed packaging maintained product quality by reducing decay, off-odor, and the accumulation of ethanol and acetaldehyde.

\section{0:15 Fatty Acid Composition of tomato Affects Fruit and Leaf} Biosynthesis of C6 Aldehydes and Alcohols

Mauricio Canoles*1, Chuanyou Li², Gregg Howe², Randolph Beaudry ${ }^{3}$

${ }^{1}$ Horticulture, Michigan State University, A28 Plant and Soil Sciences Bldg., East Lansing, MI, 48824-1325, ${ }^{2}$ MSU-DOE Plant Research Laboratory, Michigan State University, MSU-DOE Plant Research Laboratory, East Lansing, MI, 48824-1312, ${ }^{3}$ Horticulture, Michigan State University, A26 Plant and Soil Science Bldg., East Lansing, MI, 48824-1325

Biosynthesis of C6 aldehydes and alcohols by tomato (Lycopersicon esculentum Mill.) leaf and fruit tissue is dependent on fatty acid composition. For tomato fruit, some of the most important aroma 'impact compounds' are cis-3-hexenal, hexanal, trans-2-hexenal, 1hexanol, and cis-3-hexenol, which are produced by peroxidation of linoleic (18:2) and linolenic (18:3) acids through the lipoxygenase pathway. We evaluated the amount of these five compounds in tomato plants cv. Castlemart and in the mutant spr2, which is deficient in a chloroplastic omega-3-fatty acid desaturase (LeFAD7). Wild type and spr2 mutant plants were grown in a greenhouse. Fruits were harvested at various stages of ripeness and pericarp tissue was homogenized. Leaves were taken from individual plants, and then disrupted by freezing and heating. Volatiles were extracted by SPME and analyzed by GC-MS. Lipid composition was determined by fatty acid methyl ester (FAMES) analysis using FID gas chromatography. Fatty acids from leaves and fruit of the LeFAD7 deficient mutant differed dramatically from those of the wild type plants. The mutant had only a fraction of the 18:3 levels of the wild type in both leaves and fruit. Leaves of the spr2 mutant produced significantly lower amounts of cis-3-hexenal, trans-2-hexenal, and cis-3-hexenol, relative to wild type, and higher levels of hexanal and 1-hexanol. When immature green fruit were macerated and the released volatiles measured, the C6 aldehyde and alcohol production was low, and no obvious difference was detected between wild type and mutant. However, when red ripe fruit were macerated, spr 2 mutant fruit produced very low amounts of cis-3hexenal, trans-2-hexenal, but many-fold higher levels of hexanal relative to the wild type. In conclusion, the ratios and amounts of C6 saturated and unsaturated aldehydes and alcohols produced by tomato are dependent on substrate levels, suggesting that practices that alter the content of linoleic and linolenic acids or change their ratios can influence tomato flavor.
10:30 Relative Contribution of Fruit Constituents to Soluble Solids Content Measured by a Refractometer

Adel Kader*1, Betty Hess-Pierce ${ }^{1}$, Eva Almenar ${ }^{2}$

'Department of Pomology, University of California, One Shields Avenue, Davis, CA, 95616, ${ }^{2}$ IATA, CSIC, Apartado de Correos 73, Burjassot (Valencia), 46100, Spain

Soluble solids content (SSC) measured by a refractometer is used as a maturity and/or quality index for many fruits. However, the correlation between sweetness and SSC is not always strong because soluble constituents other than sugars contribute to this measurement. These constituents include organic acids, amino acids, ascorbic acid, pectins, pigments, and phenolic compounds. For example, while SSC of 'Seascape' strawberries averaged 9.2\%, their mean total sugars content was $5.3 \%$ and their titratable acidity was $1.0 \%$. The difference between SSC and sugars plus acids of $2.9 \%$ was attrituable to soluble pectins, anthocyanins, and phenolic compounds. While the ratio between the refractometer reading ( $\%$ or degree Brix equivalent)and concentrations of fructose, glucose, sucrose, citric acid, malic acid, polygalacturonic acid, and pectin was $1: 1$, it was much greater than 1:1 for anthocyanins, such as cyanidin-3-rutinoside and phenolic compounds, such as catechin. Removal of anthocyanins and phenolic compounds from the fruit juice by microfilteration or other means before measuring SSC by a refractometer can increase the reliability of SSC as an indicator of sweetness.

10:45 Volatile Profile, Sensory Attributes, and Quality of Freshcut Cantaloupe is Maturity-at-cutting Dependent

John C. Beaulieu*, Karen L. Bett

Food Processing \& Sensory Quality, Agricultural Research Service, Unites States Department of Agriculture, 1100 Robert E. Lee Blvd., New Orleans, LA, 70124

Maintaining flavor, aroma, postharvest and microbial quality after processing and throughout the distribution chain is a major challenge facing the fresh-cut fruit industry. Melons and fresh-cut melons are rapidly gaining a large share of the produce market and therefore a substantial monetary incentive exists to improve their intrinsic qualities. Flavor and aroma are most often the true indicators of shelf life from the consumer's point of view. Establishing optimum cantaloupe maturity based on end-use, sweetness and quality is often problematic. Changes in post-cutting volatile and sensory differences during fresh-cut storage at $4{ }^{\circ} \mathrm{C}$ in cantaloupe harvested at 4 distinct maturities were subsequently investigated. Volatiles were analyzed by SPME, GC-MS and trained descriptive sensory panelists were utilized. The $1 / 4$-slip harvested fruit were firmer than the other three maturities, and these cubes retained the most firmness through fresh-cut storage. Flavor volatiles increased progressively with increasing maturity, and these trends were conserved through fresh-cut storage almost perfectly in one year, and to a lesser degree in the second year. Nonetheless, flavor volatiles from 1/4-slip cubes were significantly different in cubes prepared from $1 / 2-, 3 / 4-$ and full-slip harvested fruit over the 2 years. Firmness and ${ }^{\circ}$ Brix were also significantly different in $1 / 4$-slip cubes compared to the other maturities. The $1 / 2-3 / 4-$ and full slip cantaloupe did not differ significantly in original flavor and texture attributes. Correspondingly, "fruity" and "sweet" aromatic flavor were less intense in the 1/4-slip cubes compared with the other maturities. "Sweet" taste was consistently less intense in the 1/4-slip cubes during the entire storage period (14 d). "Hardness "was more intense (harder) in 1/4-slip cubes during $0-5 \mathrm{~d}$. Meanwhile, $1 / 4$-slip cubes were less intense in "surface wetness" and "moisture release" at $0 \mathrm{~d}$ and throughout storage. It appears that high quality fresh-cut cantaloupe cubes can be prepared with fruit when harvested $\geq 1 / 2$-slip, but not from $1 / 4$-slip fruit.

11:00 Differential Effects of Ethylene and 1-MCP on Degreening and Ethylene Biosynthesis in Grapefruit

Greg McCollum*, Pilar Maul 
USHRL, USDA, ARS, 2001 S. Rock Rd., Ft. Pierce, FL, 34945

We determined the effects of 1-MCP and ethylene on color change and ethylene production in grapefruit. In the first experiment we determined the effects of 1-MCP applied at $0,5,11,28,56$, or 110 $\mathrm{nL} / \mathrm{L}$ on color change and $\mathrm{C}_{2} \mathrm{H}_{4}$ production. Treatment with 1-MCP inhibited degreening and stimulated $\mathrm{C}_{2} \mathrm{H}_{4}$ production; however, the dose response for color change and stimulation of $\mathrm{C}_{2} \mathrm{H}_{4}$ production differed. Color change was inhibited similarly at all concentrations of 1-MCP tested. In contrast, stimulation of ethylene production was only significantly increased in fruit treated with $110 \mathrm{~nL} / \mathrm{L} 1-\mathrm{MCP}$. Based on results of the first experiment we chose to use 1-MCP at a concentration of $110 \mathrm{~nL} / \mathrm{L}$ and determine the effects alone and in combination with ethylene. Degreening of grapefruit was greatest in fruit treated with ethylene and least in control fruit. Treatment with $1-\mathrm{MCP}$ caused a slight, but significant increase in degreening compared to control fruit. RT-PCR analysis revealed that chlorophyllase transcripts were present in RNA from control, 1-MCP- and $\mathrm{C}_{2} \mathrm{H}_{4}-$ treated fruit $48 \mathrm{~h}$ after treatment, but only in $\mathrm{C}_{2} \mathrm{H}_{4}$-treated fruit $72 \mathrm{~h}$ after treatment. Rates of $\mathrm{C}_{2} \mathrm{H}_{4}$ evolution were ca. $200 \mathrm{~nL} / \mathrm{kg} \mathrm{h}^{-1}$ from control and $\mathrm{C}_{2} \mathrm{H}_{4}$-treated fruit compared to ca. $10,000 \mathrm{nl} / \mathrm{kg} \mathrm{h}^{-1}$ from $1-\mathrm{MCP}$ treated fruit. RT-PCR analysis revealed that ACC synthase (ACS) transcripts were not detectable in fruit that had been treated with ethylene neither 48 nor $72 \mathrm{~h}$ after treatment, but were detectable and similar in control and 1-MCP-treated fruit at both 48 and $72 \mathrm{~h}$ after treatment. ACC oxidase (ACO) transcripts were detectable in all extracts at $48 \mathrm{~h}$ after treatment; $72 \mathrm{~h}$ after treatment ACO transcript was not detected in control fruit, was low in ethylene-treated fruit and was greatest in 1-MCP-treated fruit. Perception of $\mathrm{C}_{2} \mathrm{H}_{4}$ is apparently required for the expression of cholorphyllase in grapefruit flavedo whereas the perception of ethylene results in the inhibition of expression of ACS and to a lesser extent ACO.

\section{1:15 Sweet Corn Pericarp Tenderness as Perceived by Taste Panels}

Teri Hale*, Richard Hassell, Tyron Phillips

Plant and Environmental Science, Clemson University, 2865 Savannah Highway, Charleston, South Carolina, 29414

As the fresh sweet corn market grows in popularity, consumer preferences are gaining more attention. The affect of pericarp tenderness on the consumer's idea of an ideal sweet corn is unknown. The object of our research is to determine if the pericarp tenderness of sweet corn has an effect on consumer preference. A penetrometer is being used to determine the pericarp tenderness of three phenotypes of sweet corn ( $\mathrm{su}, \mathrm{sh}_{2}$ and se). Crunchy, normal and tender varieties of each phenotype were selected according to seed company's recommendations. Our research is being conducted at the Clemson Coastal Research and Education Center in Charleston, S.C. All plots are isolated from each other to reduce cross pollinization and are replicated 4 times. For each variety within each phenotype, the plots contain 4 rows of 40 plants. Plots are being harvested at full maturity, early maturity (five days earlier), and over mature (five days past maturity). Fifteen marketable ears from each plot are used: five for penetromic measurements and 10 for taste panel. The taste panelists are being trained to rate the cobbetts on tenderness and overall flavor. A total of 18 panelists are being used in an incomplete block design in which every panelist rates only 5 samples. The information gained form this experiment will aid both the breeder and grower in producing sweet corn that appeals to the wants of the consumer.

\section{0:00 am-12:00 noon CENTENNIAL SPOTLIGHT} $556 \mathrm{~B}$

Centennial Spotlight: Video Interviews With Noted Horticulturists
10:00 am-12:00 noon WORKSHOP 22

$551 \mathrm{~A}$

\section{Response of Citrus to Salinity: Productivity, Management, and Physiology}

Moderator: Ed Stover

Sponsor: Citrus Working Group (CITR)

Presiding: Ed Stover, University of Florida, Indian River Research \& Education Center, Fort Pierce, Florida

Objective: The goals of the workshop are to provide updates on current research, stimulate meaningful discussion, and foster improved cooperation and progress on addressing problems and opportunities concerning salinity stress of citrus.

Summary: Salinity stress compromises citrus production in many areas. High salinity results from intrusion of saline ground water, use of saline irrigation water, or salt accumulation in arid climates. New research results will be contrasted with published information to stimulate meaningful discussion on problems and opportunities concerning salinity stress of citrus.

\section{Salinity Effects on Florida Grapefruit}

Brian J. Boman*

University of Florida, Indian River Research and Education Center, Fort Pierce, FL

A study was initiated in the $1997 / 98$ production season to evaluate the effects of salinity on grapefruit yield and fruit quality in the Indian River area of Florida. The experiment was conducted on 'Ray Ruby' grapefruit (Citrus paradisi) planted in 1990 on Swingle citrumelo and Carrizo citrange rootstocks. Trees were planted on $15.2 \mathrm{~m}$ wide doublerow beds at a spacing of $4.6 \mathrm{~m}$ in-row by $7.3 \mathrm{~m}$ across-row ( 298 trees $\mathrm{ha}^{-1}$ ). The control treatment was irrigated via microsprinkler emitters with water from a surficial aquifer well with a electrical conductivity (EC) of $0.7 \mathrm{dS} \cdot \mathrm{m}^{-1}\left(500 \mathrm{mg} \cdot \mathrm{L}^{-1}\right.$ total dissolved solids (TDS)). Higher irrigation water salinity levels were achieved by injecting a sea water brine mixture into the supply water to achieve ECs of 2.3,3.9, and 5.5 $\mathrm{dS} \cdot \mathrm{m}^{-1}\left(1600,2700\right.$, and $3800 \mathrm{mg} \cdot \mathrm{L}^{-1}$ TDS). The seasons over which the studies were conducted encompassed a wide range of rainfall and irrigation conditions, with rain totaling 1252, 1336, 1516, and 960 $\mathrm{mm}$ for 1997, 1998, 1999, and 2000, respectively. Salinity level had little effect on internal juice quality parameters (total solids, Brix, acid, or juice content) at time of harvest. One of the most visible effects of irrigation with high salinity water was the damage to leaves, with leaf $\mathrm{Cl}$ levels increasing about $0.20 \%$ for each $1000 \mathrm{mg} \cdot \mathrm{L}^{-1}$ increase in irrigation water TDS for trees on Carrizo citrange and $0.04 \%$ for trees on Swingle citrumelo. For both rootstocks, the number of fruit and the size of the fruit tended to decrease with increasing salinity in the irrigation water. The non-salinized trees had significantly larger fruit compared to the rest of the treatments. In the very dry 2000/01 season, trees on Carrizo irrigated with $500 \mathrm{mg} \cdot \mathrm{L}^{-1} \mathrm{TDS}$ water had about $50 \%$ more fruit size 36 (fruit count per $28 \mathrm{~L}$ carton) or larger than trees watered with 2700 or $3800 \mathrm{mg} \cdot \mathrm{L}^{-1}$ TDS water. For trees on Swingle rootstock, trees irrigated with $500 \mathrm{mg} \cdot \mathrm{L}^{-1}$ TDS water had $1.5-2$ times as many size 36 and larger fruit than trees watered with $\geq 1600 \mathrm{mg} \cdot \mathrm{L}^{-1}$ TDS water. Over the 4 seasons, average yields for Carrizo were reduced about $4800 \mathrm{~kg} / \mathrm{ha}$ per year for each $1000 \mathrm{mg} \cdot \mathrm{L}^{-1}$ increase in TDS of the irrigation water. For Swingle rootstock, the reduction was about $3800 \mathrm{~kg} \mathrm{ha}^{-1} \mathrm{yr}^{-1}$ for each $1000 \mathrm{mg} \cdot \mathrm{L}^{-1}$ increase in TDS of the irrigation water. These reductions averaged 9\% (Swingle) and 11\% (Carrizo) for each $1000 \mathrm{mg} \cdot \mathrm{L}^{-1}$ increase in TDS of the irrigation water.

How Salinity Damages Plants; Specific Ion Damage and Osmotic Stress in Citrus

Louise Ferguson*

Dept. of Pomology, University of California, Davis, CA 95616

There are two ways salinity can damage plants; specific in dam- 
age and osmotic stress. The former is caused by chloride, sodium and boron ion accumulations directly damaging tissue. The damage is visible, and harmful in proportion to the amount of tissue destroyed and not harmful until it becomes growth limiting. Most plants have threshold values. This is the less common form of salinity damage. Osmotic stress is the more common form of salinity damage. It is slow, subtle and often indistinguishable from water stress. If a plant adjusts osmotically the net result is a smaller, less productive, but functional plant. The incidence of these of these two phenomena in citrus will be discussed.

\section{Salinity Interactions with Other Abiotic and Biotic Stress of Citrus}

Jim Syvertsen*1, Yoseph Levy ${ }^{2}$

${ }^{1}$ University of Florida, Citrus Research and Education Center, Lake Alfred, Fla. ${ }^{2}$ Gilat Experiment Station, Agricultural Research Organization, Negev, Israel

We will discuss examples of multiple stresses that almost always have synergistic effects on plants. There are direct and indirect interactions between salinity, soil drainage, drought stress, irradiance, leaf temperature, and atmospheric evaporative demand along with root rot, nematodes and mycorrhizae in citrus trees. Improving tree water relations through optimum irrigation/drainage management, maintaining nutrient balances, and minimizing evaporative demand can alleviate salt injury and prevent toxic ion accumulation. Irrigation with high salinity water not only can have direct effects on root pathogens, but salinity can also predispose citrus rootstocks to attack by root rot and nematodes. Rootstocks known to have tolerance to Phytophthora and nematodes can become more susceptible when irrigated with high salinity water. Conversely, nematodes and mycorrhizae can affect the salt tolerance of citrus roots and may increase $\mathrm{Cl}^{-}$uptake.

Methods to Assess Potential Chloride Stress: Analysis of Roots, Stem-Xylem, Leaves and Fruit

Eran Raveh*

Institute of Horticulture, Agricultural Research Org., Negev, Israel

Chloride stress in citrus is a result of its accumulation in the leaves to a toxic level. The source of the chloride is usually from the soil-solution where it is absorbed by the roots. After being absorbed, chloride flows in the transpiration stream through the stem-xylem to the shoot, where it is accumulated in organs such as leaves and fruit. Monitoring the chloride concentration in these organs can be used to assess its potential stress to the tree. Since some of the above organs tend to accumulate chloride (leaves and fruit) while others do not (root and stem-xylem), care should be taken when interpreting the results. Having a high chloride concentration in roots or in the stem-xylem at a specific sampling time does not necessarily mean that leaves have already accumulated chloride to a toxic level, and a high chloride concentration in fruit or leaf analysis does not necessarily mean that the trees are still exposed to high salinity. The advantages and disadvantages, as well as the limitations, of analyzing different organs, will be discussed.

\section{Methods for Managing Salinity in Citrus Production}

\section{Mongi Zekri*}

University of Florida, IFAS, Hendry County Extension Office, LaBelle, Florida

Salts are a common and necessary component of soils, and many salts are essential plant nutrients. However, when salts are present in relatively large amounts, citrus trees can be damaged or adversely affected. Salt damage is caused by the decrease in the water potential of the soil solution, by the toxicity of specific ions and/or by the nutritional imbalances caused by such ions. Sodium can also cause injury to plants through its deleterious effect on the soil by dispersing clay particles, which block soil pores, thereby decreasing water infiltration and causing poor aeration. Citrus is sensitive to salinity. However, production can be adequate with moderate salinity levels depending on the climate, scion cultivar, rootstock, and irrigation-fertilizer man- agement. Irrigation scheduling is a key factor in managing salinity in areas with salinity problems. Increasing irrigation frequency and keeping the soil moist to reduce salt concentration and applying water in excess of the crop water requirement (ET) to leach the salts beyond the rootzone is recommended. Overhead sprinkler irrigation should be avoided when using water containing high levels of salts because salt residues can accumulate on the foliage and cause serious injury. With micro-irrigation systems, direct foliar uptake of salts, and hence leaf injury, can be reduced. When saline irrigation water is already a potential problem, foliar feeding using saline water should be avoided. High fertilization frequency using low rates through fertigation or dry fertilizers is recommended. Selecting nutrient sources that have a relatively low salt index can reduce salinity problems. Application of fertilizer sources containing chloride and sodium should be avoided. Soil application of calcium sources including gypsum has been found to reduce the deleterious effect of sodium and improve plant growth under saline conditions. Adapting plants to saline environments and increasing salt tolerance through breeding and genetic manipulation is another important method for managing salinity.

10:00 am-12:00 noon WORKSHOP 23 $551 \mathrm{~B}$

\section{Is Bigger Better: Challenges and Benefits Associated with Transplanting Large Trees}

\author{
Moderator: Michael A. Arnold, Texas A\&M Univ. \\ Sponsor: Ornamentals/Landscape/Turf Working Group
}

Objectives: The objectives of this symposium are to summarize the current research related to transplanting various classes of specimen trees, document the potential benefits of transplanting specimen trees for immediate landscape effects, and to identify the challenges associated with establishment and long-term survival of large transplanted trees.

Summary: Across horticultural crops the trend is to transplant larger plants to achieve the intended landscape effect or to produce the desired yield without the long wait associated with direct seeding or small transplant technology. Consumer preference is for immediate gratification with a landscape design that produces the desired effects without the wait for the plants to grow to mature sizes. This trend extends from the use of large herbaceous plants for instant landscape color and transplanting of vegetable plants already in fruit to the home garden for early yield to woody plants. The end result logically culminates in the extension of this process to the transplanting of large specimen trees to create the appearance of a mature landscape. This colloquium will explore the potential benefits of this phenomenon and the challenges facing successful transplant of large trees.

\section{Influence of Tree Size on Transplant Establishment and} Growth

\section{W. Todd Watson*}

Texas A\&MUniversity, Department of Forest Science, 323 Horticulture/ Forest Science Building, College Station, TX 77843-2135

Studies have demonstrated that the size of transplanted trees has a measurable impact on establishment rates in the landscape. Larger trees require a longer period of time than smaller trees to produce a root system comparable in spatial distribution to similar sized nontransplanted trees. This lag in redevelopment of root system architecture results in reduced growth that increases with transplant size. Smaller transplanted trees become established more quickly and ultimately result in larger trees in the landscape in a few years.

\section{A New Look at Transplanting Bare-Root Street Trees}

Nina Bassuk*

Urban Horticulture Institute, Department of Horticulture, 134A Plant Science Building, Cornell University, Ithaca, NY 14853 
Since 1992, most of the street trees in Ithaca, New York have been transplanted using a bare root technology developed by Cornell University. Now, over 10 years later we have a database of over 2100 trees representing 36 genera and hundreds of taxa. This database has yielded information relating to several transplanting questions such as the effects of season of transplanting, production method, soil type and cultivar on transplanting success. Bare root technology whereby the roots of $40-50 \mathrm{~mm}$ caliper trees are dipped in hydrogel at the nursery and bagged, allow city foresters to avoid the effects of root desiccation during handling and storage. These inexpensive, lightweight trees are easily shipped and planted without heavy machinery. Moreover, bare root trees dug by an undercutting 'U' blade have approximately $200 \%$ more root volume than B\&B trees of the same caliper. Data show that fall bare root planting is equally good and more often better than spring bare root transplanting. In many cases, bare root transplanting surpasses B\&B transplanting, although this varies with season and species.

\section{Transplanting Red Oak Using the Missouri Gravel Bed System}

Daniel K. Struve*1, Chris Starbuck ${ }^{2}$, Hannah Mathers ${ }^{1}$

${ }^{1}$ The Ohio State University, Department of Horticulture and Crop Science, 2001 Fyffe Court, Columbus, OH 43210-1096; ${ }^{2}$ University of Missouri, Department of Horticulture, 1-40 Agriculture Building, Columbia, MO 65211-0001

Survival and regrowth potential of transplanted large $(8 \mathrm{~cm})$ and small $(4 \mathrm{~cm})$ caliper red oaks were compared. If confounding factors are eliminated, then large caliper trees have similar re-growth potential as small caliper trees. In a second study, $8 \mathrm{~cm}$ balled and burlapped, and bare rooted red oaks were placed in a Missouri Gravel Bed System in April and transplanted in September. Survival was 100\% for all trees. However, balled and burlapped trees had higher regrowth potential than bare root trees.

\section{Transplanting Specimen Palms: Common Practices and Research-based Information}

Dennis R. Pittenger*, Donald R. Hodel, A. James Downer

University of California Cooperative Extension, Batchelor Hall Extension, Riverside, CA 92521

Mature palms are important and emblematic elements in the landscapes of California, Florida, Hawaii, Arizona, and other Mediterranean or tropical landscape settings. Large specimen palms are often transplanted for instant landscape effects. Although large mature specimens can be transplanted successfully with a relatively small root ball, transplanting failures can result in replacement of $30 \%$ or more of the trees in some installations. To gain a better understanding of how to successfully transplant large palms, we conducted a series of field studies to determine the impacts of common transplanting practices and how palm roots regenerate. We evaluated the affects of removing leaves and tying up the remaining ones, amending the backfill soil of planting holes, and we determined the periodicity and origin of new roots regenerated for several species of landscape palms. Use of organic soil amendments appears to have limited benefit in improving the reestablishment of transplanted palms. Removing and tying up leaves did not improve tree survival or reestablishment after transplanting, and based on the physiological responses of trees these practices may actually hinder palm reestablishment. A 3-year study on root regeneration in mature plants of 16 palm species showed that species vary in the time of year that maximum root growth occurs, although most species produce the greatest number of roots during warmer months.

\section{1:00 am-11:45 am ORAL SESSION 47}

\section{Human Issues}

Moderator: Carl E. Motsenbocker

11:00 A Garden-Based Science Curriculum Can Impact Environmental Awareness of Elementary School Students

Carl Motsenbocker*, Leanna Smith
Horticulture, Louisiana State University AgCenter, 137 Julian Miller Hall, Baton Rouge, LA, 70803

A garden-based science curriculum (chapters 1 to 4, Junior Master Gardener) was introduced into public school fifth grade classes as an informal education program conducted by volunteers. The program was held once a week for two hours during regular school hours the fall semester 2002. Control and treatment class students at three inner city schools were surveyed pre and post with two sections (Pastoralism, Environmental Adaptation) of the Children's Environmental Response Inventory (CERI). CERI is a multidimensional measure of children's environmental dispositions using self-reported questions rated on a five-point Likert scale. Environmental Adaptation reflects a fundamental respect for the physical environment; a lower test score indicates a positive effect for this measure. The implementation of the hands-on science program resulted in a significantly lower $(P$ $<0.01)$ difference in pre and post Environmental Adaptation scores for treatment $(-1.94)$ compared to control classes $(+3.01)$ indicating an enhanced appreciation for the environment and nature of the treatment classes. Pastoralism indicates positive responses to natural environments, outdoors, and open spaces. There were no differences, however, in pre and post Pastoralism test scores due to treatment. The project is continuing in the spring semester with the next 3 chapters of the gardening program.

11:15 The Integration of a Formal Garden Curriculum into Louisiana Public Elementary Schools

\section{Leanna L. Smith, Carl E. Motsenbocker*}

Horticulture, Louisiana State University, 137 Julian C. Miller Hall, Baton Rouge, LA, 70803

School gardens have been and are in use today at schools around the United States to supplement their curriculum. The use of gardens to provide hands-on science activities is not a new concept, but very little research has been conducted to quantify the effect of gardens and their potential benefits. In Fall 2002, the first four chapters of a horticulture based hands-on science curriculum (Junior Master Gardener) along with a small garden plot were introduced into three East Baton Rouge Parish elementary schools. The curriculum was introduced as an informal education program conducted by Master Gardener volunteers and Louisiana State University students once a week for two hours during regular school hours. The effect on the students' science aptitude was quantified using a 40 question multiple choice test developed previously by Texas A\&M University. Statistical analysis using paired t-tests showed a significant difference $(P \leq 0.01)$ between the pre and post test scores of the experimental classes and no difference in test scores of the control classes. Analysis was also performed on test results of individual chapter scores as well as on individual questions related to subject matter of importance. The study is ongoing with three additional chapters of the curriculum being introduced into the schools in the Spring semester of 2003.

11:30 Using Gardening as a Teaching tool for Science Acheivement and Attitudes in Third Grade Classrooms

\section{Kathryn Orvis*, Amy Dirks}

4H Youth and Horticulture and LA, Purdue University, 615 W State St., West Lafayette, IN, 47907-2053

Science education and achievement has been identified as a national concern for United States students. Many educators report the effectiveness of school gardens in their students achievement, attitudes, social interaction and other psychological benefits. School gardens have been shown to be beneficial to elementary school students through several studies and align with the current constructivist theory of learning. Although there are several studies that explore the benefits of school gardening, further research needs to be conducted in this area to fully investigate the effects school gardening have on students. The goal of this study was to investigate the effects of a school gardening curriculum on Indiana third-grade students achievement in and attitudes 
toward science. Several classrooms randomly distributed across the state participated in the school gardening research using a pre-post test approach and the Junior Master Gardeners ${ }^{\circledR}\left(\mathrm{JMG}^{\circledR}\right)$ program. $\mathrm{JMG}^{\circledR}$ is an interdisciplinary curriculum that can easily be incorporated into the school classroom. Students were asked questions regarding their attitudes toward and interest in science, agriculture, and environmental studies and were also asked questions regarding their knowledge of science and agriculture. Test results and responses to attitudinal surveys demonstrate the impact of utilizing gardening as part of school curriculum.

\section{1:00 am-12:00 noon ORAL SESSION 48}

\section{Postharvest-Cross-commodity/Floriculture}

Moderator: Mikal Saltveit

11:00 Effect of Heat-shock on the Chilling Sensitivity of Trichomes and Petioles of African violet (Saintpaulia ionantha)

Mikal Saltveit*

Vegetable Crops, University of California, Mann Laboratory, One Shields Ave., Davis, CA, 95616-8631

Chilling at $6{ }^{\circ} \mathrm{C}$ caused an immediate cessation of protoplasmic streaming in trichomes from African violets (Saintpaulia ionantha), and a slower aggregation of chloroplasts in the cells. Streaming slowly recovered upon warming to $20^{\circ} \mathrm{C}$, reaching fairly stable rates after $4,15,25$, and $35 \mathrm{~min}$ for tissue chilled for $2 \mathrm{~min}$ and 2, 14 and 24 $\mathrm{h}$, respectively. The rate of ion leakage from excised petioles into an isotonic $0.2 \mathrm{M}$ mannitol solution increased after $6 \mathrm{~h}$ of chilling and reached a maximum after 3 days of chilling. A heat-shock at $45^{\circ} \mathrm{Cfor}$ $10 \mathrm{~min}$ reduced chilling-induced rates of ion leakage from excised $1-\mathrm{cm}$ petiole segments to levels near that from unchilled control tissue. Heat-shocks at $45{ }^{\circ} \mathrm{C}$ had no effect on the rate of ion leakage from unchilled petiole segments. Protoplasmic streaming was stopped by 1 min of heat-shock at $45{ }^{\circ} \mathrm{C}$, but slowly recovered to normal levels after about $30 \mathrm{~min}$. Chloroplasts aggregation was prevented by a 1 or $2 \min 45^{\circ} \mathrm{C}$ heat-shock administered $1.5 \mathrm{~h}$ before chilling, but the heatshock only slightly delayed the reduction in protoplasmic streaming caused by chilling.

\section{1:15 Genetic Variation in Postproduction Quality of Regal} Pelargonium

Hye-Ji Kim*, Richard Craig, Kathleen Brown

Department of Horticulture, Pennsylvania State University, 102 Tyson, University Park, PA, 16802

Petal abscission during commercial shipping and handling is a significant problem of Regal Pelargonium(Pelargonium $\times$ domesticum). We have identified two PSU genotypes with about twice the floral longevity of current commercial cultivars. Our results demonstrate that these genotypes still respond to ethylene treatment by abscising petals, but they have significantly reduced rates of ethylene production and reduced ethylene responsiveness. Pretreatment with the ethyleneblocking agent 1-MCP dramatically decreased petal abscission during simulated transport $\left(3\right.$ days, $5^{\circ} \mathrm{C}$ and $\left.95 \% \mathrm{RH}\right)$ in all the tested cultivars, but the extent of the effect varied with genotype. Petal abscission in response to ethylene increases with floret age. Consequently, 1-MCP had a significant effect on petal abscission of old florets, less effect on freshly opened florets, and no effect on the florets that opened after simulated transport. The longevity of whole plants and maximum floret numbers were not affected by the 1-MCP treatment.

11:30 Postharvest and Marketing Internet Site: A Research, Extension, and Teaching Tool

George Staby*

President, Perishables Research Organization, P.O. Box 1552, Healdsburg, CT, 95448
A free floral postharvest and marketing Internet site called Chain of Life NetworkSM was launched on January 1, 2003. Some of the site's many features include detailed information on $445+$ floral crops, answers to frequently asked questions, $1000+$ products/services that can help improve flower/plant longevity, 200+ breeding companies and their good performing species and/or cultivars, and 17,000+ summaries of postharvest research articles including many involving fruits and vegetables. All of the site can be browsed and/or searched in an easy-to-use format. The information contained in this site would compliment many postharvest and floriculture teaching, extension, and/or research activities. The site can be found at http: //www.chainoflifenetwork.org.

11:45 Ultrasonic Wave and Preservative Solution Affects Water Conditions in Cut Rose 'Samantha' Flower

Weiming Guo ${ }^{* 1}$, Xiaoqin $\mathrm{An}^{1}$, Sumei Chen ${ }^{1}$, Zhongchun Jiang ${ }^{2}$ ${ }^{1}$ College of Horticulture, Nanjing Agriculture University, No 1. Weigang, Nanjing, 210095, People's Republic of China, ${ }^{2}$ Dept. of Plant Science, State Univ. of New York, 116 Hodder Hall, Cobleskill, NY, 12043

Effects of pretreatments with the ultrasonic wave or a preservative solution and their combination on water conditions in rose Samantha were studied. The pretreatments significantly improved the water conditions of flower stems during the vase time, including water potential in different parts of flower stems, fresh weight, relative water content, water absorption, water loss; and maintained the water balance, prolonged the vase life of cut flowers to various degrees. Among the pretreaments, the ultrasonic wave combined with the preservative solution was most effective, followed by the preservative solution alone and the ultrasonic wave. The fresh-keeping mechanisms of the pretreatments will be discussed from water conservation aspect.

\section{1:00 am-12:00 noon ORAL SESSION 49}

$552 \mathrm{~B}$

Moderator: Rebecca Darnell

\section{Enzyme Physiology}

11:00 Diurnal Changes of Xanthophyll Cycle and Antioxidant Enzymes in the Peel of Apple Fruit

Fengwang Ma, Lailiang Cheng*

Department of Horticulture, Cornell University, 134A Plant Science, Ithaca, NY, 14853

Xanthophyll cycle conversion and antioxidant enzymes in the peel of apple fruit (Malus domestica Borkh. cv. Liberty) were monitored in the field over a diurnal course at about 3 months after full bloom. Compared with leaves, sun-exposed peel of apple fruit had much lower photosystem II efficiency at any given photon flux density (PFD) and a larger xanthophyll cycle pool size on a chlorophyll basis. Zeaxanthin (Z) level increased with rising PFD, reaching the highest level at noon and early afternoon, and then decreased with falling PFD during the rest of the day. At noon, $\mathrm{Z}$ accounted for over $90 \%$ of the xanthophyll cycle pool in the fruit peel compared with only 50\% in leaves. Efficiency of excitation transfer to PSII reaction centers $(\mathrm{Fv} / \mathrm{Fm}$ ) was negatively related to the level of $\mathrm{Z}$ in the peel, indicating that xanthophyll cycledependent thermal dissipation was operating in the fruit peel in response to prevailing PFD. In apple leaves, activities of superoxide dismutase (SOD), ascorbate peroxidase (APX), and glutathione reductase (GR) did not change significantly during the day; activities of both monodehydroascorbate reductase (MDAR) and dehydroascorbate reducatse (DHAR) were higher in the afternoon than in the morning; catalase (CAT) activity showed a diurnal pattern opposite to that of PFD. In contrast, APX, MDAR, DHAR, and GR of apple fruit peel exhibited a diurnal change similar to that of incident PFD. There was no difference in diurnal patterns between fruit peel and leaves for SOD or CAT. We conclude that both xanthophyll cycle conversion and antioxidant enzymes are up-regulated in apple fruit peel to cope with the excessive absorbed PFD at noon. 
11:15 Effect of Iron Concentration on Ferric Chelate Reductase and Nitrate Reductase Activities in Vaccinium

Rebecca Darnell*, Umpika Poonnachit

Horticultural Sciences, University of Florida, 1131 Fifield Hall, Gainesville, FL, 32611

Production of cultivated blueberry (Vaccinium) species is limited to low $\mathrm{pH}$ soils, which are characterized by high $\mathrm{Fe}$ availability and $\mathrm{N}$ primarily in the $\mathrm{NH}_{4}{ }^{+}$form. These types of soils are limited and there is increasing interest in expanding blueberry production to higher $\mathrm{pH}$ mineral soils, which are characterized by low Fe availability and $\mathrm{N}$ primarily in the $\mathrm{NO}_{3}{ }^{-}$form. However, production of cultivated blueberries on these soils requires high-input approaches, such as extensive soil amendments. A wild species, V. arboreum, grows naturally on these mineral soils. This adaptation of $V$. arboreum to high $\mathrm{pH}$ mineral soils may be related to the ability to assimilate $\mathrm{Fe}$ and/ $\mathrm{orNO}_{3}{ }^{-}$more efficiently than the cultivated blueberry. Both species were grown hydroponically in a complete nutrient solution, using $\mathrm{NO}_{3}^{-}$as the $\mathrm{N}$ source, and varying iron concentrations $(2,22.5$, or $45 \mu \mathrm{MFe}-\mathrm{DTPA})$. Root nitrate reductase activity (NRA) was significantly higher in $V$. arboreum compared with $V$. corymbosum, regardless of Fe concentration. However, there was a significant interaction between species and Fe concentration on NRA. Root NRA in V. arboreum was higher at $22.5 \mu \mathrm{M} \mathrm{Fe}$ compared with any other treatment. Root ferric chelate reductase (FCR) activity was greater in V. corymbosum compared with $V$. arboreum, and was greater at the two higher Fe concentrations compared with the lowest concentration. Leaf FCR activity was consistently greater in $V$. arboreum compared with V. corymbosum, and was not affected by Fe concentration. These results suggest that $V$. arboreum has the potential for greater $\mathrm{NO}_{3}{ }^{-}$assimilation than $V$. corymbosum. However, V. corymbosum is potentially more efficient in Fe assimilation, at least in terms of root FCR activity. On the other hand, leaf FCR activity plays a crucial role in the utilization of Fe transported from the roots to the shoots. Thus, the increased leaf FCR activity in $V$. arboreum may reflect an increased ability to utilize Fe. Both the increased root NRA and leaf FCR activity may partially explain why $V$. arboreum is more widely adapted to mineral soils.

11:30 Pectin Methyl-Esterase Activity in Vivo During Fruit Ripening and the Deciduous Character of Tabasco Pepper Fruit

Ramon Arancibia*, Carl Motsenbocker

Dept. of Horticulture, Louisiana State University Agricultural Center, 137 J.C. Miller Hall, Baton Rouge, Louisiana, 70803

Cell wall degrading enzymes were analyzed in two tabasco pepper (Capsicum frutescens L.) genotypes that differ in the deciduous character of the fruit (ease of separation from the calyx) when ripe. Pectin ultra-degradation that results in tissue disintegration is another characteristic that differentiates the deciduous EZ genotype from the non-deciduous HP genotype. Pectin methyl-esterase (PME) activity was assessed in vivo and in situ by methanol production from fresh and disrupted fruit tissue, respectively. Both genotypes released methanol at all ripening stages from frozen and remoistened freeze-dried tissue. A peak of methanol production in vivo, however, was detected only in EZ ripening tissue when the fruit external color had a hue value (angle in the CIE a* $b^{*}$ chromaticity diagram) between 50 and 40 . Unripe fruit tissue (hue $>55$ ) produced methanol only after reaching the adequate ripening stage 24 to $72 \mathrm{~h}$ later. The $\mathrm{pH}$ of the fruit junction area after separation from the calyx was checked and it decreased only in ripe (hue $<50)$ fruit of the EZ genotype. Fruit detachment force in the EZ line was inversely correlated with methanol production up until the peak and directly correlated with the $\mathrm{pH}$ of the fruit-calyx junction area. Cellulase and polygalacturonase activity extracted from disrupted tissue were the same in both genotypes. The results suggest that PME activity in vivo has a critical role in pectin ultra-degradation by polygalacturonase, and therefore, on the disintegration of the fruit flesh that results in the deciduous character of the fruit. The data also suggests that there is a PME regulatory mechanism that was lost when the tissue was disrupted.
11:45 Isolation and Identification of Cyanogenic Rhizobacteria from the Roots of Peach [Prunus persica (L.) Batsch] Shann Tanner*, Christina Wells, Gregory Reighard, Daniel Kluepfel

${ }^{1}$ Horticulture, Clemson University, Clemson, SC, 29634-0375

Peach replant disorder (PRD) occurs when peach trees are replanted to an orchard previously cropped with peaches: lower growth rates and yields are observed in the replanted trees. Methyl bromide fumigation adequately controls PRD, suggesting that the disorder is the result of harmful interaction(s) between the soil faunal community and peach roots. As methyl bromide fumigation is phased out, the task of determining the specific cause of PRD is now an important goal. One theory suggests that prunasin (D-mandelonitrile $\beta$-D-glucoside), a cyanogenic glycoside found in peach tissues, may play a critical role in replant disorder. Many soil bacteria have the ability to degrade cyanogenic glycosides and release cyanide, a potent respiratory poison. Bacteria capable of degrading prunasin may release cyanide when feeding on decomposing roots of old peach trees, thus inhibiting root growth of the new trees. We examined the rhizosphere bacterial community of peach to determine whether it contained bacteria capable of evolving cyanide from prunasin. Rhizobacteria were isolated from the fine roots of 7-yearold peach trees on M9 carbon source utilization media containing $0.05 \%$ prunasin as the sole carbon and nitrogen source. Five visually distinct colonies were selected and grown-out in pure culture on trypticase soy broth agar (TSBA) plates. The prunasin-degrading rhizobacteria were then tested for their cyanogenic potential using a picrate paper assay. All five prunasin isolates exhibited some cyanogenic potential; two strains were strongly cyanogenic. The cyanogenic isolates were identified using fatty acid methyl ester (FAME) analysis, and the two strongly cyanogenic strains were identified as Arthrobacter globiformis and Cellulomonas cartae. To determine whether cyanogenic bacterial activity can cause growth reductions in peach trees, we are inoculating peach seedlings with the cynanogenic bacterial isolates in the greenhouse and monitoring their growth and root system development.

11:45-12:15 pm WORKING GROUP MEETING

$555 \mathrm{~B}$

Human Issues in Horticulture (HIH) Working Group

Chair: Susan B. Hamilton

12:00 noon-12:30 pm WORKING GROUP MEETING 552B Postharvest (PH) Working Group Chair: Gene Lester

12:00 noon-12:30 pm WORKING GROUP MEETING 551B Ornamentals/Landscape and Turf (O/LT) Working Group Chair: Michael Arnold

1:00 pm-2:00 pm POSTER SESSION 42 Ballroom A

(Location numbers for the posters within the Poster Viewing Area are in parenthesis)

\section{Citrus}

(324) Relationship Between Crop Load, Fruit Size, and Number of Fruit Per Branch of 'Gold Nugget' Mandarin (Citrus reticulata Blanco)

C. Thomas Chao*

Dept. of Botany and Plant Sciences, 2137 Batchelor Hall, University of California Riverside, Riverside, CA, 92521-0124

'Gold Nugget' mandarin (Citrus reticulata Blanco) is a seedless, mid- to late- season mandarin hybrid of 'Wilking' $\times$ 'Kincy' [(Willowleaf $\times$ King $) \times($ King $\times$ Dancy) ] developed at University of California Riverside and released in 1999 (Roose et al., 2000). 'Gold Nugget' is completely seedless even in mixed plantings, and it has nice rind color 
and taste at maturity. Fruits can be harvested as early in late January and the fruits can be stored on the trees without decreasing rind quality till June or July. Since its release in 1999, there is limited production of 'Gold Nugget' in California. However, very limited information is known about this new variety except its fruit quality. This study was conducted in 2001 and 2002 to measure the crop load, the number of fruit per branch, and fruit size of 'Gold Nugget' mandarin. We also determined the relationship between crop load, fruit size, and number of fruit per branch. This information will help growers managing the production of 'Gold Nugget' mandarin and obtain maximum return for the growers.

\section{(325) Reduced Fall and Winter Irrigation Increases Brix and Delays Flowering in Florida Citrus}

Ed Etxeberria*, Lawrence Parsons

Citrus Research Center, University of Florida, 700 Experiment Station Road, Lake Alfred, Florida, 33850

Recent data from young potted 'Hamlin' orange trees in Florida, and from field trials with otherCitrus varieties elsewhere, had indicated that mild water deficits increased fruit Brix content without affecting juice yield. The implications that higher fruit quality can be obtained along with concurrent water savings prompted broader field studies under Florida field conditions. Irrigation on experimental 'Hamlin' and 'Valencia' orange tree plots was stopped at the start of the fall/winter dry season in Florida. For 'Valencia' oranges, an additional plot with water-impermeable Tyvek covering 3 meters on either side of the trees was included. Control trees were irrigated according to commercial irrigation practices. Experiments started on October 15, 2002. After 8 weeks of treatment, fruit from non-irrigated 'Hamlin' orange trees (an early maturing variety) showed a significant increase in Brix of 0.2 units, whereas acid content was unchanged. 'Valencia' oranges, a late maturing variety, were first sampled in Feb. 27 just prior flowering. In agreement with previous studies, fruit from non-irrigated trees had a higher Brix content than irrigated trees, despite the higher than normal rainfall during the fall and winter months in Florida. Fruit from irrigated trees had a Brix of 12.25 and those from non-irrigated trees of 12.45. The highest Brix content of 12.73 was from those trees with roots covered by Tyvek. There was a parallel increase in acid content for all three samples of $0.86,0.88$ and $0.91 \%(w / v)$, respectively. Irrigation regiment also significantly affected flowering time. Full bloom for well-watered trees was estimated to be around March 10 with non-irrigated trees having significantly open blooms at the same time. However, trees with Tyvek had no flowers and only minimal bud swelling at this date. Full bloom for non-irrigated and Tyvek covered trees was estimated to be around March 17th and March 25, respectively. The data from the first year of this multiple year study suggests that withholding irrigation during the cooler fall and winter months saves water and has no effect in fruit quality (possibly even a slight increase in quality).

(326) Foliar-applied Aminoethoxyvinylglycine (AVG) Reduces Albedo Breakdown of Late-harvested Navel Orange Fruit - Preliminary Results

\section{Carmen Gonzalez, Carol Lovatt*}

Botany and Plant Sciences, University of California, 4130 Batchelor Hall, Riverside, CA, 92521-0124

Albedo breakdown (crease) is a rind blemish that occurs on the flavedo (the colored external layer of citrus fruit) when the underlying albedo cells separate (albedo breakdown) causing the flavedo cells to sink and form a crease. Albedo breakdown results in culling of fruit in the packinghouse and a loss in net dollar return to the grower. Prices for navel orange fruit are higher before and after the main harvest period. To increase income, a large percentage of the annual navel orange crop is harvested late. However, both the incidence and severity of albedo breakdown increase as the fruit matures and the peel senesces. Thus, albedo breakdown has become a serious economic problem for California navel orange growers. As citrus fruit age, the capacity of the peel to produce ethylene increases. Ethylene is known to promote senescence in many plant tissues, suggesting that inhibition of peel ethylene biosynthesis might slow peel senescence and reduce albedo breakdown. Amnioethoxyvinyglycine (AVG) inhibits ethylene biosynthesis and is now commercially sold for horticultural use. Foliarapplied AVG (38 mg/L) at 75\% petal fall (26 May) or during June drop (15 June) significantly reduced the incidence and severity of albedo breakdown of 'Washington' navel oranges harvested late in the season (March) compared to untreated control fruit. The June application was more effective than the May application in reducing the severity of albedo breakdown, but a preharvest (Nov.) application of AVG (38 $\mathrm{mg} / \mathrm{L}$ ) was without effect. The petal fall application of AVG had the additional benefit of significantly increasing fruit retention through early January (the mid-harvest period for California 'Washington' navel oranges). However, AVG applied at either stage of fruit development caused a reduction in transverse fruit diameter of approx. $2 \mathrm{~mm}$ that was statistically significant for early-, mid- and late-harvested fruit treated with AVG at petal fall. Fruit treated with AVG during June drop were only significantly smaller at early harvest in Nov. Petal fall, June drop and preharvest foliar applications of AVG at $300 \mathrm{mg} / \mathrm{L}$ were without beneficial effect, but significantly reduced fruit size. Based on the results of this preliminary research, use of AVG to reduce albedo breakdown warrants further testing as a possible management tool to assist the California citrus industry in its continued efforts to provide "picture perfect" navel orange fruit for the fresh fruit market.

1:00 pm-2:00 pm POSTER SESSION 43

Ballroom A

(Location numbers for the posters within the

Poster Viewing Area are in parenthesis)

\section{Propagation}

\section{(404) Asexual Propagation of Bur Oak}

Cheryl L. Moore*1, Tracy A.O. Dougher ${ }^{2}$, Joseph D. Scianna ${ }^{3}$ ${ }^{1}$ Plant Sciences and Plant Pathology, Montana State University, Montana State University, 119 Ag BioScience Building, Bozeman, Montana, 59717, ${ }^{2}$ Plant Sciences and Plant Pathology, Montana State University, 312 Leon Johnson Hall, Montana State University, Bozeman, Montana, 59717, ${ }^{3}$ Bridger Plant Materials Center, USDA NRCS, Route 2 Box 1189, Bridger, Montana, 59014

Bur oak is a long-lived, deciduous tree native to Montana and large areas of North America. It is drought-tolerant, winter hardy, and strongwooded, with few serious pests. It is useful for numerous conservation applications such as windbreaks and shelterbelts, wildlife plantings, native range (woody draw) renovations, and low maintenance landscapes. Although it is easy to grow from seeds, asexual propagation from stem cuttings has been relatively unsuccessful. Identifying efficient methods of vegetative propagation is essential to the success of genetic improvement studies and ornamental production. Asexual propagation of bur oak has received little attention from researchers, limiting our ability to cost-efficiently increase superior clones for research and commercial markets. This study attempts to develop baseline treatments to optimize conditions for conventional rooting of stem cuttings. The more novel approaches investigated included etiolation and banding, blanching, and hedging. Bur oak stem cuttings were harvested from superior seed accessions at the United States Department of Agriculture, Natural Resources Conservation Service Plant Materials Center in Bridger, Montana, USA. Stock plants were selected for superior rate of height growth, high seedling survival, and desirable tree form. Both hardwood and softwood cuttings were taken from these trees. Hardwood cuttings callused, but did not root under any treatment. We then subjected stock plants to three treatments including etiolation and banding, blanching, and hedging. Softwood cuttings were taken from stock plants that underwent these treatments as well as cuttings taken in a more conventional mode from trees not subjected to any treatments. Each cutting was then treated with one of five concentrations of indole3-butyric acid (IBA) in a talc carrier and struck into one of two media 
treatments: peat:perlite 50:50 v/v or sand. Cuttings were placed in a mist chamber in a greenhouse with air temperatures of $24^{\circ} \mathrm{C}$ day / 18 ${ }^{\circ} \mathrm{C}$ night with a 16-hour photoperiod. Cutting bases were examined for the presence of roots after eight weeks. Cuttings from stock plants that were etiolated and banded, or blanched, callused but formed no roots. Approximately $16.7 \%$ of the cuttings taken from hedged plants struck in sand and treated in 7,500 ppm IBA developed roots. Approximately 2\% of the standard cuttings struck in sand and treated in each of 5,000 and $10,000 \mathrm{ppm}$ IBA rooted. No other cuttings rooted. The level of rooting remains commercially impractical. Therefore, future research will focus upon softwood cuttings treated with IBA concentrations above 5,000 ppm, and upon other novel stock plant treatments using sand as a media.

\section{(405) Clonal Propagation of Rubus geoides Sm. Through} Stolons

Gustavo Vater, Miriam Arena*

IPPV, Cadic, Malvinas Argentinas, C.C. 92, Ushuaia, Tierra Del Fuego, 9410, Argentina

Rubus geoides Sm. is a native species of Austral Patagonia, that grows in moist open to partly shaded areas among rocks, grassland, shrub communities, forest clearing and margins. Its stems are slender, creeping, somewhat woody, branched, rooted at several nodes. The orange-red fruits can be eaten fresh or in marmalades and jams. The clonal propagation through stolons was studied in the greenhouse of the experimental field of the CADIC. The nodal segments were obtained from mother plants originated from in vitro propagation and from different sections of their stolons: primary stolons with leaves, primary stolons without leaves, secondary stolons with leaves and secondary stolons without leaves. The nodal segments had 3 buds and each one was potted in May 2001 into a pot $\left(4 \mathrm{~m}^{2}\right)$ filled with a mixture of soil: sand: peat (2: 2: $1 \mathrm{v} / \mathrm{v})$. In May 2002, the rooting percentages of the nodal segments were significant different among sections $(P=0.0000)$. The higher rooting percentage was obtained on nodal segments obtained from primary stolons with leaves $(45.7 \%)$, while on the nodal segments from primary stolons without leaves was $23.9 \%$. The rooting percentage was $10.3 \%$ on secondary stolons with leaves while secondary stolons without leaves did not root. In each nodal segment grew 1.6 shoot of $1.7 \mathrm{~cm}$ length, 1.8 primary stolons of $15.5 \mathrm{~cm}$ length and 1.6 secondary stolons of $7.2 \mathrm{~cm}$ length. None of the secondary stolons formed secondary stolons. The total stolon production was $24.4 \mathrm{~cm}$ and $40.6 \mathrm{~cm}$ for nodal segments obtained from primary stolons with and without leaves respectively. There were not significant differences on the observed responses on the nodal segments coming from different mother plants. The obtained results are the first antecedents on the clonal propagation of Rubus geoides.

\section{(406) Mist Level Influences Cutting Water Potential and Rooting of Stem Cuttings of Loblolly Pine}

Anthony LeBude*1, Barry Goldfarb ${ }^{2}$, Frank Blazich ${ }^{1}$, John Frampton ${ }^{2}$, Farrell Wise ${ }^{3}$

${ }^{1}$ Horticultural Science, N.C. State University, Box 7609, Raleigh, NC, 27695-7609, ${ }^{2}$ Forestry, N.C. State University, Box 8002, Raleigh, NC, 27695-8002, ${ }^{3}$ Vegetative Propagation Research, MeadWestvaco, Corp., Box 1950 MeadWestvaco Rd., Summerville, SC, 29484

Vegetative propagation of loblolly pine (Pinus taeda L.) by stem cuttings is used for multiplying superior full-sib families and elite individuals within superior families. To produce rooted cuttings cheaply and efficiently, propagators must produce rooted cuttings on a large scale. However, this often makes control of the rooting environment a challenge, especially when propagators use rooting environments ranging from greenhouses to direct field setting of cuttings. Therefore, the following research was conducted to define physiological variables that might predict successful rooting among a variety of rooting environments. Specifically, the relationship between mist application and cutting water potential (Y cutting), and the relationship between $\mathrm{Y}$ cutting and rooting percentage of stem cuttings in a polyethylenecovered greenhouse was investigated. Six mist regimes were tested in two experiments. One experiment used dormant, hardwood stem cuttings collected in February, cold-stored, and then set in April, while the other experiment used succulent, softwood cuttings, taken and set in June. Seven, 14, 21, 28 and 35 days after setting (DAS), Y cutting was measured destructively, utilizing a pressure chamber, on two cuttings in each plot every 3 hours between $0500 \mathrm{HR}$ and $2300 \mathrm{HR}$ (seven measurements for each day that measurements were recorded). Rooting success was scored 70 DAS for all cuttings and cuttings were considered rooted when they had at least one root? $1 \mathrm{~mm}$. For both experiments, Y cutting was strongly related to the log of mist application. Mean rooting percentages were $73 \%$ and $63 \%$ for hardwood and softwood cuttings, respectively. Rooting percentage, in both experiments, was related to $\mathrm{Y}$ cutting and the square of $\mathrm{Y}$ cutting. Rooting increased with increased $Y$ cutting (became less negative), however, as $Y$ cutting continued to increase, rooting declined, suggesting that cuttings may need to experience moderate water deficit for optimum rooting. The curves generated defined a range of $Y$ cutting, specific for each cutting type, which corresponded with the greatest rooting in each experiment. Results serve as a step in defining a range of $\mathrm{Y}$ cutting that may be applicable among various rooting environments.

(407) The Effects of Benzyladenine (BAP-10) Concentration \& Application Frequency/Volume on Epimedium $\times$ rubrum \& Helleborus $\times$ hybridus

Mark Brand, Dale Thompson*

Department of Plant Science, University of Connecticut, 1376 Storrs Road. U-67, Storrs, CT, 06269-4067

The purpose of this research is to critically evaluate the use of Benzyladenine (BA) sprays on two ornamental herbaceous species, Epimedium $\times$ rubrum and Helleborus $\times$ hybridus. BA concentration and frequency of BA application are the two variables to be focused upon. Epimedium \& Helleborus are popular herbaceous ornamentals, but are under-utilized in the horticultural trade. This is partly due to slow plant increase and, therefore, limited availability of vegetative propagules. The application of BA could enrich foliar appearance, increasing plant appeal to customers, as well as increasing rhizome branching and meristem production. Single spray applications of five concentrations between 0-6000 ppm BA were applied in May to determine what BA concentration might increase rhizome branching and meristems. In an additional study, BA applications were made at four times during the growing season (May, June, July, August) using 3000 ppm BA sprays or a Tween/water spray. At each spray time, plants were given a Tween/water spray (control), 1, 2, 3, or 4 sprays to provide different volumes of BA. crown size decreased as BA concentration increases from $0 \mathrm{ppm}$ to $6000 \mathrm{ppm} \mathrm{BA}$. Bud number and the number of possible divisions weren't significantly affected by BAconcentration in single spray applications. Foliage appearance actually declined with increasing BA concentration and BA application frequency, but crown size was uniform throughout. Increases in BA application frequency increased bud number and possible divisions substantially. A 150\% increase in bud number and a $50 \%$ increase in the number of divisions was observed for four monthly BA sprays of $3000 \mathrm{ppm}$ in comparison to controls. Helleborus foliage was not damaged by any of the BA spray applications. Increasing concentrations of BA applied as a single increase the number of buds on crowns, but this did not translate into an increase in potential divisions. Monthly applications of four BA sprays increased the number of potential Helleborus divisions from 2.8 (control) to 4.1 divisions per plant.

\section{(408) In Vitro Shoot Proliferation of American Chestnut} Guochen Yang*, Johanna Mearns

Natural Resources and Environmental Design, North Carolina A\&T State University, 1601 E. Market Street, Greensboro, NC, 27411

This research investigated methods for enhancing axillary shoot proliferation of American chestnut. Cultures were established and maintained on woody plant medium (WPM) plus $0.1 \mathrm{mg} / 1 \mathrm{BA}, 3 \%$ sucrose and 
$0.7 \%$ agar at a $\mathrm{pH}$ of 5.8. Micropropagated shoots were used as explant materials for studies involving various plant growth regulators. Kinetin, $\mathrm{N}$-(2-chloro-4-pyridyl)-N'-pheylurea (CPPU), thidiazuron (TDZ), and zeatin at several concentrations were added to the basic WPM to evaluate their effects on in vitro shoot proliferation of chestnut. All cultures were transferred onto fresh media every 4 weeks and maintained at 23 $\pm 3{ }^{\circ} \mathrm{C}$ under a 16 -hour photoperiod at $12.8 \pm 4.8 \mathrm{Mol} \mathrm{s}^{-1} \mathrm{~m}^{-2}$ light provided by cool white fluorescent tube. Differences on number of shoots (primordia) and morphology of micropropagated shoots were observed between the plant growth regulator treatments. Statistical analysis on number of shoots per explant among the concentrations for different plant growth regulators will be presented at the symposium. The long term goal of this research is to establish an efficient micropropagation system for transformation to increase chestnut blight resistance.

\section{(409) Influence of Division Timing and Size on Growth and Propagation of Epimedium}

Jessica Lubell Loavenbruck*, Mark Brand

Plant Science, University of Connecticut, 1376 Storrs Rd., U-67, Storrs, CT, 06269-4067

Epimedium is a genus of shade tolerant herbaceous perennials and groundcovers that are particularly slow growing, and as a result, few propagules (divisions) may be taken from individual stock plants. Our objective is to determine how division timing and size influence the propagation success and growth of E. $\times$ rubrum $(\mathrm{R})$, E. $\times$ versicolor 'Sulphureum' $(\mathrm{V})$, E. pinnatum ssp. colchicum $(\mathrm{P})$, and E. $\times$ youngianum $(\mathrm{Y})$. Uniform divisions of each species were made from 4-Lcontainer-grown stock plants on 5-6 March, 24-26 June, and 28-30 August 2002, and potted in 1.4-L nursery pots. On 17-18 June, large and small divisions, based on number of buds, leaves and crown dimensions, were made for each species. Size divisions of V and P, two species with long rhizomes, were planted in 688-ml square pots, while R, with intermediate-length rhizomes, and Y, a species with short rhizomes, were potted in 307.3mLsquare pots. All divisions were grown outdoors in cold frames with $50 \%$ lath shading, received Peters 20-10-20 fertilizer (at $150 \mathrm{ppm}$ ) every 14 days and were irrigated as needed. Half of the plants were destructively harvested on 16-28 October, while the remaining plants were over-wintered. Over-wintered plants were forced in the greenhouse to study plant growth in a subsequent growing season. Dormant March divisions of $\mathrm{Y}$ and $\mathrm{R}$ produced nearly double the number of final buds per initial bud than June or August divisions. The number of final buds produced per initial bud of $\mathrm{V}$ decreased from March to June to August. March and June divisions of P performed similarly, however August divisions produced significantly fewer final buds per initial bud. For each species, crown and root dry mass (g) decreased from March to June to August. Small divisions of the semi-evergreen species R and the evergreen species $\mathrm{P}$ and $\mathrm{V}$ produced more buds per initial bud than did large divisions. The number of final buds produced per initial bud was the same for large and small divisions of the deciduous Y. Based on data collected thus far, we recommend that propagators trying to maximize the multiplication of epimediums should divide crowns in March (when dormant) to the smallest size possible.

(410) Induction of Better Seedling Growth and Grafting Success of Evergreen Quercus Species by Grafting on Deciduous $Q$. Species

Sang-Yeol Ahn ${ }^{1}$, Sang-Woo Lee ${ }^{2}$, and Zhoo-Hyeon Kim*2

${ }^{1}$ Department of Horticulture, Jinju National University, Jinju 660-758, Korea; ${ }^{2}$ Department of Horticulture, Gyeongsang National University, Jinju 660-701, Korea

Evergreen Q.myrsinaefolia is one of important tall ornamental trees in Southern part of Korea. Evergreen Quercus species show very slow growth pattern than deciduous Quercus species, which it demands to wait a long time to reach to the plant size that are available for decoration of garden, or other uses. A new method, which may be used for growth enhancement of seedlings of Q.myrsinaefolia, was developed during an experiment for graft compatibility test. We grafted reciprocally eight Fagaceae species; Q. acutissima, Q. variabilis, Q. mongolica, Q. aliena, $Q$. serrata, $Q$. myrsinaefolia, $Q$. rubra, $C$. crenata. Also we did that among several land races in $Q$. acutissima and $Q$. serrata. Successful grafting and growth were very closely correlated with the genetic similarity (by RAPD analysis), but not always, especially among land races within same species. In some case, they, heteroplastic graft between species to have very distant similarities, resulted in better growth and higher grafting success rate than those of homoplastic graft, especially in the combination between $Q$. myrsinaefolia and $Q$. variabilis. Ever green species, $Q$. myrsinaefolia, grows very slowly after seeding, and the grafting success rate is very low, even though auto- or homoplastic graft. But transplanting survival, the growth and grafting success rate of the combination of $Q$. myrsinaefolia scion on $Q$. variabilis stock was better 2-3 times, compared to those of seedling and homoplastic graft. For definite judgment of graft compatibility, we must wait more years, but now, 4 years after grafting, they show very good growth, and smooth and very strong graft union in longitudinal section view, appearance and breakage test. Therefore it seems to be there is something affecting to graft compatibility, besides genetic similarity.

(411) Effect of Different Crown Manipulation Treatments on Shoot Production in Four Cultivars of Daylily

Johnny Carter*1, Clarence Johnson ${ }^{2}$

${ }^{1}$ Agricultural Research, Fort Valley State University, 1005 State University Drive, Fort Valley, GA, P.O. Box 4681, ${ }^{2}$ Agricultural Research, Fort Valley State University, 1005 State University Drive, Fort Valley, GA, P.O.Box 4681

During Fall 2002, a study was conducted to determine the effect of crown manipulation on shoot production in four cultivars of daylily. Three crown manipulation treatments: (1) the shoot cut back two centimeters from the crown, (2) the shoot cut back to the crown, and (3) the shoot cut back to the crown and scooped out were compared to a control. The four daylily cultivars, 'Bull Durham,' 'Amber Lamp,' 'Angus McLeod,' and 'Alvatine Taylor' were used in this study. After eight weeks of observations, the results showed that the cut back to crown treatment caused a significant increase in the number of shoots when compared to the control and the other two treatments. Shoot production for the cultivar 'Angus McLeod' was shown to be significantly better than the other cultivars. These results imply that cutting the shoots back to the crown in some daylily cultivars could possibly be used to enhance multiplication of daylilies during propagation.

(412) Alginate Encapsulation of Hardy Hibiscus (Hibiscus Moscheutos Hybr. L.) for Long-term Storage

Todd West*1, John E. Preece ${ }^{2}$

${ }^{1}$ Department of Plant Biology, Southern Illinois University, ${ }^{2}$ Department of Plant, Soil and General Agriculture, Southern Illinois University

The objective of this study was to investigate the use of alginate encapsulation for long-term storage without the need of regular subcultering to reduce high micropropagation labor costs. This study focused on two H. moscheutos cultivars: 'Lord Baltimore' (cutting propagated) and 'Southern Belle' (seed propagated). The alginate matrix medium contained DKW nutrient salts, $10^{-7} \mathrm{M}$ thidiazuron, $3 \%$ sucrose, and had a pH of 5.8. Nodal explants were excised from established Stage II shoot cultures and each explant contained one axillary bud. Experiments were done to determine explant size $(4 \pm 1 \mathrm{~mm}$ vs. $8 \pm 1 \mathrm{~mm} \mathrm{long})$ and sodium alginate concentration $(0,2.0,2.5,2.75,3.0$, or $3.25 \%)$ for use in the long-term storage study. Explants that were $4 \pm 1 \mathrm{~mm}$ long and encapsulated in $2.75 \%$ sodium alginate produced the most viable encapsulated explants. Encapsulated buds were then placed in each of the four treatments; darkness at $5{ }^{\circ} \mathrm{C}$, darkness at $25^{\circ} \mathrm{C}$, light at $5{ }^{\circ} \mathrm{C}$, or light at $25^{\circ} \mathrm{C}$ for 4 weeks. Light had no effect on explants stored at $5{ }^{\circ} \mathrm{C}$, and no bud break was observed. Light affected explants stored at $25^{\circ} \mathrm{C}$. All explants that were in the light had bud break and adventitious rooting. However, explants stored in the darkness had 50\% bud break 
and $0 \%$ rooting. To determine long-term storage effects, encapsulated explants were placed in cold $\left(5^{\circ} \mathrm{C}\right)$ dark storage for up to 6 months. Encapsulated explants were removed from storage every two weeks for 24 weeks and placed on Stage II multiplication medium and placed approximately $30 \mathrm{~cm}$ beneath cool white fluorescent lamps that provide a photon flux of approximately $40 \mu \mathrm{mol} \cdot \mathrm{m}^{-2} \cdot \mathrm{s}^{-1}$ for a 16 -hour photoperiod at $25^{\circ} \mathrm{C}$. There was reduced vigor in both cultivars but both were still able to produce viable axillary shoots and adventitious roots after six months of cold/dark storage.

\section{(413) Breeding for Early Bearing Papayas in the Caribbean} Thomas Zimmerman*, Jacqueline Kowalski

Biotechnology \& Agroforestry, University of the Virgin Islands, Agricultural Experiment Station, RR 2 Box 10,000, Kingshill, VI, 00850, Virgin Islands (U.S.)

The overall goal is to develop papayas that set $1 \mathrm{~kg}$ fruit within one meter from the ground. The local population in the Virgin Islands prefers papayas that are at least $1 \mathrm{~kg}$ in size. However the large fruited varieties generally have the undesirable traits of late flowering, fruit set high on the tree and fruit that lacks the firmness and sweetness of the smaller $(400 \mathrm{~g})$ varieties developed for the export market. $\mathrm{F}_{1}$ hybrid papaya have been have been developed from inbred lines. Crosses were made between early bearing sweet and firm inbred lines were made with large fruited lines to develop the $F_{1}$ hybrid seed. The $F_{1}$ hybrids have been evaluated for plant and fruit characteristics. Thirteen plant and fruit characteristics were measured on the $\mathrm{F}_{1}$ plants. Plants with the greatest positive characteristics were self pollinated to fix the traits and produce $\mathrm{F}_{2}$ seed. Hybrid vigor (heterosis) was obtained from crosses between inbred lines 'Cariflora' $x$ 'Tainung 5' and 'Puerto Rico Dwarf' $x$ 'Yuen Nong 1'. These $F_{1}$ plants produced fruits over a kilogram that set within a meter of the soil surface. Large fruited plants with moderate virus tolerance were also obtained in the 'Cariflora' $x$ 'Solo Sunset' combination. 'Solo Sunset' is very susceptible to the local papaya virus strain.

(414) Carbohydrate Concentration Influences Cassava Acclimatization from Culture

Jay Wiltshire*, Thomas Zimmerman

Biotechnology \& Agroforestry, University of the Virgin Islands, Agricultural Experiment Station, RR 2 Box 10,000, Kingshill, VI, 00850, Virgin Islands (U.S.)

Cassava line TMS 60444 used in genetic transformation studies, has a high mortality rate when being acclimated from tissue culture. Sucrose concentrations during micropropagation were evaluated for their influence on greenhouse establishment. Nodal segments were grown on Murashige and Skoog basal medium with $0 \%, 1 \%, 2 \%$, $4 \%$ or $6 \%$ sucrose for four weeks. Plants from the $1 \%$ to $6 \%$ sucrose treatments were transferred to three in pots containing sterilized ProMix and covered with plastic domes. After one week under lights, all plants survived. The domes were removed after one week. By the end of the second week, only $20 \%$ of the $1 \%$ sucrose treated plants survived while over $95 \%$ of the $4 \%$ and $6 \%$ sucrose remained healthy. Plants were placed in the greenhouse at the start of the third week and placed under $20 \%$ shade for one week. After three weeks in the greenhouse, none of the $1 \%$ sucrose plants remained while over $75 \%$ of the $4 \%$ and $6 \%$ sucrose plants continued to thrive. The higher sucrose concentrations during micropropagation expose the developing plants to a greater osmotic stress and provides for a more metabolic reserves to draw on during acclimatization. Funded by the MBRS-RISE program GM61325

\section{1:00 pm-2:00 pm POSTER SESSION 44}

Ballroom A

(Location numbers for the posters within the Poster Viewing Area are in parenthesis)
Floriculture-Mineral Nutrition and Pest Management

(303) Effects of Calcium, Boron, and Molybdenum on Quality of Poinsettia Plants

Juan Ayala, Ana Maria Castillo*, Maria Teresa Colinas, Joel Pineda

Fitotecnia, Universidad Autonoma Chapingo, Carr. Mexico-Texcoco Km 38.5, Chapingo, Mexico, 56230, Mexic

Poinsettia (Euphorbia pulcherrima) plants cv. Subjibi were grown under greenhouse conditions, in 8 " containers, 14 nutrient treatments were applied ( 10 replicates per treatment), these were formed by three levels of calcium (calcium nitrate 300, 400 and, $500 \mathrm{ppm}$ ), molybdenum (sodium molybdate $0.4,0.5$, and $0.6 \mathrm{ppm}$ ) and boron (borax $0.3,0.4$, and $0.5 \mathrm{ppm}$ ). Plants were sprayed three times during the growing period: 51, 72, and 94 days after transplant which took place on July 29, 2002. Plants were covered with black polyethylene, from $5 \mathrm{pm}$ to 7 am everyday from September 18 to November 6, in order to induce bract development. Chlorophylls a, b and total were evaluated colorimetrically in mature leaves. These same pigments plus carotenoids and anthocyanins were evaluated in bracts from the start of pigmentation until commercialization. The combination of $0.5 \mathrm{ppm}$ boron plus $0.4 \mathrm{ppm}$ molybdenum increased chlorophylls a, $\mathrm{b}$ and total in leaves by $0.341,0.2198$, and $0.1213 \mathrm{mg} / \mathrm{g} \mathrm{FW}$ respectively compared to the control. In the bracts there was an increase in chlorophylls and carotenoids with $400 \mathrm{ppm}$ calcium combined with $0.4 \mathrm{ppm}$ molybdenum. Concentration of anthocyanins was increased by $24.72 \%$ with $0.4 \mathrm{ppm}$ molybdenum compared to the control. As a general conclusion, it can be said that final quality, indicated by bract color, was significantly affected and improved by foliar application of different nutient combinations.

(304) Sunflower (Helianthus annuus) 'Sunbright' Grown as Cut Flowers in Compost Amended Media Respond Differently for Time of Harvest, Growth and Quality as Planting Date Increases From Compost Application

Everett Emino*, Rick Schoellhorn, Becky Hamilton

Environmental Horticulture, University of Florida, 1509 Fifield Hall, PO Box 110670, Gainesville, FL, 32611

Two-week old plug seedlings of 'Sunbright' sunflower (Helianthus annuus) were planted on $15 \mathrm{~cm}$ centers in $1.2 \mathrm{~m}$ wide beds amended with one application of 1.5, 3.0, and 6.0 cubic meters per square meter of cured municipal solid waste/biosolids co-compost in a randomized complete block design at the beginning of the experiment each of two growing seasons. Planting dates were over a nine week period starting $6 / 20 / 2001$ and a six week period starting 6/11/2003. Early planting results showed that increased rates of compost amended media positively influenced growth parameters such as flower diameter, stem length and total fixed carbon. These findings were expected from results reported on other crops in the extensive literature on compost amended media. However, later plantings did not exhibit the same response and a convergence of the results occurred with no significant difference after the fifth week planting date. In addition to the initial enhanced quality aspects of sunflowers harvested from the compost amended beds, the average cropping time was initially reduced by $1.45,2.25$ and 4.90 days respectively with increasing rates of compost compared to the control of 77.75days to flower. These findings have led to further study of timing of compost application and planting date for optimal specialty sunflower cut flower response to compost amendment.

(305) Nitrogen and Potassium Nutrition of Geraniums Grown in Spent Mushroom Substrate (SMS) Fertilized with Leachate from SMS

E. Jay Holcomb*1, Charles W. Heuser ${ }^{1}$, Paul H. Heinemann ${ }^{2}$ ${ }^{1}$ Horticulture, Penn State Univ., 102 Tyson Building, University Park, PA, 16802, ${ }^{2}$ Agricultural and Biological Engineering, Penn State Univ., 
220 Agricultural Engeering Building, Univeristy Park, PA, 16802

Spent mushroom substrate (SMS) can be effectively used as a substrate for crop production if the excess soluble salts are removed by leaching before the crop is planted. The salts in the leachate from SMS are composed of $\mathrm{Ca}, \mathrm{K}, \mathrm{Mg}, \mathrm{NO}, \mathrm{P}$ and other elements. It is assumed that the leachate from SMS could be used as a fertilizer solution for the production of greenhouse crops. The objectives of the research were to determine (1). how $\mathrm{N}$ and $\mathrm{K}$ were leached from SMS, (2) the optimal rate of SMS leachate to mix with water for use as a fertilizer and, (3) the nutrient composition of a crop fertilized with SMS leachate. Cores filled with SMS were leached with deionized water 6 times either once a day for 6 days or once a week for 6 weeks. K leached from the SMS in a linear manner and the rate of leaching was the same whether leached daily or weekly. Nitrate levels were lower than K but the rate of nitrate leaching by daily leaching showed the same trend as $\mathrm{K}$. The weekly leaching of nitrate initially decreased, then increased suggesting that additional nitrate was being released from the SMS as it aged. Geraniums were potted in a growing mix of SMS and peat moss $[1: 1(\mathrm{v} / \mathrm{v})]$. The mix was leached to remove excess soluble salts and the leachate was collected. Four fertilization regimes were established for the geraniums grown on ebb and flood benches. The fertilization regimes were: (1) 1 volume of SMS leachate to 2 volumes of water, (2) 20-4.5-16.6 (NPK) at $200 \mathrm{mg} / \mathrm{LN}$, (3) 1 volume SMS leachate to 4 parts water plus ammonium nitrate at $50 \mathrm{mg} / \mathrm{L} \mathrm{N}$ and, (4) 1 volume of SMS leachate to 4 parts of water. During the production of the geraniums, the nitrate and $\mathrm{K}$ composition of the storage tanks for the subirrigation fertilizer solutions remained stable. Geraniums that were grown in 204.5-16.6 and 1-4 SMS to water plus $50 \mathrm{mg} / 1 \mathrm{~N}$ from ammonium nitrate were similar in fresh weight. Those fertilized with 1-2 SMS to water were slightly smaller, and the smallest plants were fertilized with 1-4 SMS to water. Nutrient analysis of the geranium leaves grown with 4 fertigation regimes determined that $20-4.5-16.6$ produced the highest $\mathrm{N}$ content, 1-4 SMS to water produced the second highest $\mathrm{N}$ content, and 1-2 SMS to water produced the lowest $\mathrm{N}$ content. The $\mathrm{N}$ levels were on the low side of the normal range for $\mathrm{N}$ in geraniums. The $\mathrm{K}$ content of geraniums grown in 1-2 SMS to water were higher than any other treatment. The second highest treatment was 1-4 SMS to water. The other two treatments were lower and similar in K content. K content of all treatments were in the normal range for $\mathrm{K}$ in geraniums. In summary, $\mathrm{N}$ and K can be leached from SMS and that SMS leachate can be diluted and used as a portion of the fertilizer for growing a geranium crop.

(306) Twospotted Spider Mite (Tetranychus urticae Koch) Population Growth on Ivy Geranium (Pelargonium peltatum L.) Under Different Nitrogen and Phosphorus Fertilization Regimes

Yan Chen ${ }^{1}$, George Opit ${ }^{2}$, Kimberly Williams*1, James Nechols², David Margolies ${ }^{2}$

${ }^{1}$ Horticulture, Forestry, and Recreation Resources, Kansas State University, 2021 Throckmorton Hall, Manhattan, KS, 66506-5506, ${ }^{2}$ Entomology, Kansas State University, 123 Waters Hall, Manhattan, KS, 66506-4004

A greenhouse experiment was conducted to determine twospotted spider mite (TSM, Tetranychus urticae Koch) population growth in response to different nitrogen $(\mathrm{N})$ by phosphorus $(\mathrm{N})$ fertilization regimes that produced ivy geraniums (Pelargonium peltatum $\mathrm{L}$.) of commercial quality. 'Amethyst 96 ' plants were fertilized with two $\mathrm{N}(8$ and $24 \mathrm{~mm})$ by three $\mathrm{P}(0.32,0.64$, and $1.28 \mathrm{~mm})$ rates for ten weeks. TSM were artificially infested at week four and allowed to develop for six weeks. Plant growth responses and tissue $\mathrm{N}$ and $\mathrm{P}$ concentrations were determined at weeks four, eight, and ten. TSM number on youngest fully opened (YFO) leaves was non-destructively sampled weekly from week five to ten. No growth differences occurred for no-TSM control plants produced with the different $\mathrm{N}$ by $\mathrm{P}$ fertilization regimes, and premium market quality was achieved. However, tissue $\mathrm{N}$ and $\mathrm{P}$ concentrations among these no-TSM control plants were significantly different: 8 and $24 \mathrm{~mm} \mathrm{~N}$ rates resulted in 4.6 and $6.3 \%$ tissue $\mathrm{N}$ respectively, and tissue $\mathrm{P}$ concentrations from $0.32,0.64$ and $1.28 \mathrm{~mm} \mathrm{P}$ were $0.38,0.61$, and $0.84 \%$, respectively. Thus a range of host-plant nutrient status was provided for TSM feeding and development across treatments. However, no significant difference was found in TSM population size between plants grown with 8 and $24 \mathrm{~mm} \mathrm{~N}$ $(P=0.4904)$. A marginal positive $P$ effect $(P=0.0574)$ was observed in the total number of TSM at week eight such that plants fertilized with $0.64 \mathrm{~mm} P$ had more mites than plants fertilized with $0.32 \mathrm{~mm} P$ $(P=0.0184)$, but mite number was not different from plants fertilized with $1.28 \mathrm{~mm}$ P. TSM did not cause reduction in overall plant quality until three weeks after infestation, and TSM feeding reduced plant dry weight by week eight. These results suggest that growers can use either low or high $\mathrm{N}$ fertilization regimes without concern about increasing TSM problems, but using the low $\mathrm{N}$ rate may slightly reduce production costs. Both 0.32 and $1.28 \mathrm{~mm} P$ could be used for ivy geranium production to result in slightly less problems with TSM than $0.64 \mathrm{~mm}$ $\mathrm{P}$, but further study is needed to explain this pest response.

(307) Evaluation of Microbial Inoculants for Control of Rhizoctonia solani

George Elliott*1, Wade Elmer ${ }^{2}$

${ }^{1}$ Dept Plant Science, University of Connecticut, 1376 Storrs Rd Unit 4067, Storrs, CT, 06269, ${ }^{2}$ Dept Plant Pathology, Connecticut Agricultural Experiment Station, 123 Huntington St, New Haven, CT, 06504

Microbial inoculants (MI) are used as alternatives to chemical fungicides for control of soilborne pathogens in soilless potting mixes (SPM), but few data are available comparing commercial MI. We have conducted several trials evaluating the effect of different MI on the incidence of root and crown rot in flowering vinca (Catharanthus roseus) in different SPM infested with Rhizoctonia solani AG-4 (RS). MI have reduced the incidence of mortality and have increased growth of surviving plants compared to untreated controls. Results have been inconsistent among trials, and statistical interactions among SPM, MI, and RS have been observed within trials. In one trial with a compost-based SPM which proved to be excessively alkaline ( $\mathrm{pH}>7$ ), an MI containing Burkholderia cepacia significantly reduced severity of lime-induced chlorosis and increased final fresh weight compared to an uninoculated control. MI containing either Trichoderma harzianum KRL-AG2 or Gliocladium virens GL-21 reduced chlorosis, but did not improve growth. In a peat-based medium with normal acidity $(\mathrm{pH}<6.5)$, Gliocladium virens GL-21 stimulated growth compared to the control. Results of these trials offer basis for cautious optimism regarding the utility of MI for disease suppression in commercial production, and point to the need for further research on the basis for interactions that affect their efficacy.

1:00 pm-2:00 pm POSTER SESSION 45 Ballroom A

(Location numbers for the posters within the

Poster Viewing Area are in parenthesis)

\section{Floriculture-Propagation and Biotechnology}

(77) Identification of Camellia Varieties Using Randomly Amplified DNA Markers

Rao Mentreddy*1, Soon Park², Shizhou Wang ${ }^{1}$, Lianghong Chen ${ }^{1}$

${ }^{1}$ Agricultural Research Station, Fort Valley State University, 1005, State University Drive, Fort Valley, Georgia, 31030, ${ }^{2}$ Texas Agricultural Research and Extension Center, Texas A\&M University, 2415 E. Highway 83, Weslaco, Texas, 78596

The genus Camellia was introduced to the U.S.A. from China/ Japan via Europe toward the end of $18^{\text {th }}$ century. Camellia sinensis is mainly grown for tea in Asia, but other Camellia species are grown as ornamental and landscape plants. The demand for cultivar registration and patenting is increasing due to increasing economic importance of Camellia sp.as an ornamental crop in Georgia. The American Camellia Society (ACS) alone receives registration/patenting requests for about 30 Camellia varieties per year. The current variety registration criteria based 
on morphological traits, agronomy, location and region- though very exhaustive- are inadequate to supply correct phenotype and genotype of the bloom for registration and patenting. Currently, several molecular marker techniques are used in plant germplasm identification and genetic manipulations. Therefore, more precise and modern diagnostic tools of analysis, such as molecular markers, can be used solely or to supplement the current procedures for reliable identification and registration of new cultivars /flowers. In our preliminary research, ten Camellia species could be identified using randomly amplified polymorphic DNA(RAPD) markers. In the current study, two varieties, Amarie (1A) and Miles Beach (1B) within the species C. reticulata were differentiated using randomly amplified polymorphic DNA (RAPD) markers. Ten random primers were used to characterize the genetic differences between the two varieties. An average of 6.5 amplified DNA fragments, ranging from $400 \mathrm{bp}$ to more $2000 \mathrm{bp}$ in size, was generated per primer. A total of 65 RAPD markers was identified in the two varieties using 10 primers. Six out of ten primers used could differentiate the two varieties indicating that significant genetic diversity exists between the two varieties. The data suggest that each of the two species have unique genomic regions. The study showed that molecular markers could be utilized for the identification of not only inter-specific differences but also intra-specific variation in camellias. This would help accurate variety identification, develop a more efficient registration system and also minimize unnecessary duplications and redundancies within the new and the already registered cultivars.

\section{(78) Paternity Determination of Ornithogalum Seedlings Using DNA Markers}

Mark S. Roh*1, Young Hee Joung ${ }^{2}$

${ }^{1}$ Floral and Nursery Plants Research Unit, USDA, ARS, National Arboretum, B-010A, Rm 238, 10300 Baltimore Ave., Beltsville, MD, 20705, ${ }^{2}$ Korea Research Institute of Bioscience and Biotechnology, Yusong, Taejon, Republic of Korea

This research was initiated to identify the parentage of putative Ornithogalum hybrids using DNA fingerprinting techniques. Seeds were harvested from Ornithogalum thyrsoides hybrid A1, and 5 seedlings (SD1-SD5) were selected and evaluated for growth, flowering, and DNA fingerprinting. Ornithogalum conicum, Bokbaai type of $O$. thyrsoides $7005 \mathrm{~A}, 7005 \mathrm{~B}$ and a seedling from a cross between $O$. conicum $\times 7005 \mathrm{C}$ which were considered as a possible paternal parent of the seedlings were also analyzed. These seedlings varied in scape length, flower shape and color, and the presence or absence of pollen. A total 169 random amplified polymorphic DNA (RAPD) bands were produced, of which 90 (53\%) were polymorphic. Based on the p-distance value, $O$. conicum was excluded as a potential source of pollen and Bokbaai type of Ornithogalum 7005 was considered as pollen source. However, the possibility that all seedlings could result from self-pollinated progenies of A1 was not excluded. Randomly selected five primer pairs for amplified fragment length polymorphism (AFLP) analysis generated total 298 fragments, of which 191 (63.4\%) were polymorphic. The presence of marker 109 in all four seedlings, SD1, SD 2, SD 4, and SD 5 and in $O$. conicum $\times 7005 \mathrm{C}$ concludes that marker 109 was inherited from $7005 \mathrm{C}$. According to the p-distance and nonmaternal band analysis performed with RAPD and AFLP, it was concluded that the seedlings were not the result of self-pollination, and $O$. thyrsoides $7005 \mathrm{C}$ could be the paternal parent. Ornithogalum species or O. thyrsoides, instead of $O$. conicum, should be used in the future breeding efforts to breed a paper white flower with cup-shaped florets.

\section{(79) Paclobutrazol Enhanced the Acclimatization of In Vitro Dendranthema zawadskii Species}

\section{Changhee Lee*, Ki Sun Kim}

Dept. of Horticulture, Seoul National University, 103 Seodun, Suwon, 441-744, Republic of Korea

An efficient and labor-saving method for acclimatization of in vitro Dendranthema zawadskii species was developed through in vitro PBZ treatments. The growth and development were investigated in shoot-tip cultures of five D. zawadskii species on MS medium supplemented with $0,0.3,0.5,0.7,1.0$, and $2.0 \mathrm{mg} \cdot \mathrm{L}^{-1} \mathrm{PBZ}$. Five Dendranthema zawadskii species included $D$. zawadskii ssp. coreanum, D. zawadskii ssp. acutilobum var. tenuisectum, D. zawadskii ssp. yezoense, D. zawadskii ssp. naktongense, and D. zawadskii ssp. lucidum. As PBZ concentration increased plant height and root length in all species were dramatically reduced, whereas leaf thickness and root diameter were significantly increased. PBZ at $0.5 \mathrm{mg} \cdot \mathrm{l}^{-1}$ in all species resulted in the heaviest fresh weight regardless of the part of plantlet. We chose 4 types of acclimatization methods for in vitro plantlet transplanting in greenhouse. Three types of plantlets of in vitro D. zawadskii ssp. coreanum including direct-cut plantlets which were directly excised from multiple shoots (DC), plantlets which grew on MS medium supplemented without PBZ for 3 weeks (HF), and plantlets which grew on MS medium supplemented with $0.5 \mathrm{mg} \cdot \mathrm{L}^{-1} \mathrm{PBZ}$ for 3 weeks (P) were transplanted on plastic container, which was wrapped up with transparent film to retain moisture during the adaptation periods. HF and P-plantlets showed $100 \%$ survival rate, while DC-plantlets showed only $20 \%$ survival rate at 3 weeks after transplanting. P-plantlet without wrapping also showed $100 \%$ survival rate and normal growth like plantlets with wrapping treatment. It was concluded that $0.5 \mathrm{mg} \cdot \mathrm{L}^{-1}$ PBZ treatment to in vitro plantlets was optimal to acclimatize in vitro D. zawadskii plantlet without wrapping a film.

(80) Effect of BAP on the direct shoot proliferation in shoot-tip culture of seven Dendranthema zawadskii species Changhee Lee*, Ki Sun Kim

Dept. of Horticulture, Seoul National University, 103 Seodun, Kwonsun, Suwon, 441-744, Republic of Korea

An efficient and reproducible micropropagation method was developed in seven Dendranthema zawadskii species where heterogeneous seed and the lack of shoot-tip cuttings have been known as major problems in mass propagation. Seven Dendranthema zawadskii species included D. zawadskii ssp. coreanum, D. zawadskii ssp. acutilobum var. tenuisectum, D. zawadskii ssp. yezoense, D. zawadskii ssp. latilobum var. leiophyllum, D. zawadskii ssp. naktongense, $D$. zawadskii ssp. acutilobum and D. zawadskii ssp. lucidum. Highfrequency direct shoots were induced in shoot-tip cultures of seven D. zawadskii species on MS medium supplemented with 0.5-5.0 $\mathrm{mg} \cdot \mathrm{L}^{-1} \mathrm{BAP}$ and $0.01 \mathrm{mg} \cdot \mathrm{L}^{-1} \mathrm{NAA}$. Optimum BAP concentration for multiplication varied among species. BAP at $0.5 \mathrm{mg} \cdot \mathrm{L}^{-1}$ was optimal to produce 65-115 multiple shoots for the first 4 species listed above, whereas BAP at $2.0 \mathrm{mg} \cdot \mathrm{L}^{-1}$ was optimal to produce $10-60$ multiple shoots for the last 3 species after 4 weeks of shoot-tip culture without root formation. The shoot-forming capacity of in vitro shoots was influenced by the number of shoots on the cluster. Three species were tested with propagules (clusters of $1-5$ shoots) and only D. zawadskii ssp. lucidum and D. zawadskii ssp. acutilobum showed higher multiplication efficiency (120\%) using cluster of 2 shoots than using only one shoot $(100 \%)$. Roots were successfully formed without any auxin or 0.3 $\mathrm{mg} \cdot \mathrm{L}^{-1}$ IBA. Plantlets were acclimatized in greenhouse for 2 weeks, followed by normal growth. It was concluded that BAP at 0.5 or 2.0 $\mathrm{mg} \cdot \mathrm{L}^{-1}$ was optimal depending on species to gain high-frequency direct shoots in shoot-tip cultures of D. zawadskii species

\section{(81) Micropropagation for Crop Improvement of Gladiolus} Maria Cantor*1 , Kathryn Kamo ${ }^{2}$, Rodica Pop ${ }^{1}$, Ioana Delia Pop ${ }^{1}$

${ }^{1}$ Department of Horticulture, University of Agricultural Sciences and Veterinary Medicine Cluj, Manastur No. 3, Cluj-Napoca, 3400, Romania, ${ }^{2}$ Floral \& Nursery Plants Research Unit, U.S.D.A., B-010A Room 238 BARC West, Beltsville, Maryland, 20705

Gladiolus hybridus are grown in Romania for cut flower production and gardening. Four Gladiolus cultivars (Speranta, Priscilla, Windsong and H260/2) were used to develop an effective micropropagation method of the new cultivars and novel Romanian hybrids. Callus was induced 
from cormels slices grown in vitro on a Murashige and Skoog's (MS) basal salts medium supplemented with $3 \%$ sucrose, $0,8 \%$ agar and supplemented with $10 \mathrm{mg} / \mathrm{L} \alpha$-naphthaleneacetic acid (NAA), $5 \mathrm{mg} / \mathrm{l}$ indole- 3 acetic acid (IAA), 0,5 mg/1 2,4 D-dichlorophenoxyacetic acid (2,4-D). Regenerated plants were obtained from callus using a medium supplemented with $2 \mathrm{mg} / \mathrm{l}$ kinetin (KIN), $2 \mathrm{mg} / \mathrm{L} 1$ Phenzl-3-1, 2, 3 tria-diazol-5yl urea (TDZ) and 2,5 mg/L zeatin. The rate of vegetative proliferation depends on the cultivars, type of auxins and cytokinins. A high percentage (87\%) of the in vitro grown cormels formed regenerable callus when cultured on $10 \mathrm{mg} / \mathrm{L}$ NAA. Callus maintained in culture on medium containing $2 \mathrm{mg} / \mathrm{L}$ TDZ regenerated a higher number of plants than callus cultured on kinetin or zeatin. Regenerated plants were transferred to MS basal salts medium containing $0,1 \mathrm{mg} / \mathrm{L}$ NAA and $3 \mathrm{mg} / \mathrm{l} \mathrm{kinetin}$ to stimulate bulb development.

\section{1:00 pm-2:00 pm POSTER SESSION 46}

Ballroom A

(Location numbers for the posters within the

Poster Viewing Area are in parenthesis)

\section{Ornamentals/Landscape and Turf-Pest Management/ Environmental Stress Physiology}

\section{(86) Rhapsody ${ }^{\mathrm{TM}}$ as Biofungicide for Control of Diseases of Ornamental Plants}

Paul Walgenbach ${ }^{1}$, Julien Mercier*2

${ }^{1}$ Product Development, AgraQuest, Inc., 1530 Drew Avenue, Davis, CA, $95616,{ }^{2}$ Research and Development, AgraQuest, Inc., 1530 Drew Avenue, Davis, CA, 95616

Rhapsody AS biofungicide is a strain of Bacillus subtilis (strain QST 713) that has exhibited plant safety and control of a broad range of bacterial and fungal pathogens on various ornamental plants. Rhapsody is a protectant-type fungicide with multiple modes of action, formulated as an aqueous suspension. It can be used in greenhouses, shadehouses, nurseries landscapes, interioscapes and home gardens. Applications ranging from $1.0 \%$ solutions to as high as $8.0 \%$ have elicited no plant effects on a wide range of bedding plants, tropical foliage, potted flowers, trees \& shrubs and food crops. Rhapsody will be labeled for use at a range of concentrations from $1.0 \%$ to $2.0 \%$. Thorough coverage of all above-ground plant parts-at initiation or prior to the onset of disease-is required for effective control. Rhapsody controls bacterial pathogens such as Pseudomonas, Xanthomonas and Erwinia. It also controls common fungal pathogens such as powdery mildews (Sphaerotheca, Oidium, Erysiphe, Microsphaeria, Phyllactinia) and Botrytis cinerea. Research continues to expand use patterns and diseases controlled.

(87) Evaluation of Weed Suppressive Perennial Groundcovers for Use Along New York State Roadsides

Seok Hyun Eom*, Leslie A. Weston

Horticulture, Cornell University, 20 Plant Science, Ithaca, NY, 14853

In Fall 200, 21 relatively low growing perennial ornamentals (chosen by past literature and our own visual analysis of growing habits) were planted at the Cornell turf farm in a replicated plot (completely randomized block design). Plots were established at $30 \times 30 \mathrm{~cm}$ or $38 \times 38 \mathrm{~cm}$ on spacing, depending on growth habit. Three weeding regimes were evaluated as treatments for each groundcover species: 1) weeded constantly once per week, 2) weeded once per month, 3) unweeded. Each groundcover was evaluated for its specific growth habit and ability to suppress weeds by collecting weed biomass and weed numbers per plot, light penetration through the canopy at the soil surface and also time required for weed removal by hand. Data were collected during June, July, August, and September of 2001 and 2002. Several species did not overwinter and were injured severely due to winter conditions encountered in 2001. These included Hydrangea anomala, Phuopsis stylosa, Veronica spp., Hypericum moseranum, Imperata cylindrica and Hypericum calcyinum. Once established, three species, (Alchemilla mollis, Nepeta $\times$ faassenii, and Phlox subulata), were extremely suppressive to weed invasion and weed growth, even in unweeded treatments. These plants strongly inhibited light penetration on the soil surface (less than $1 \mu \mathrm{mol}$ light quantity received per plot) during the summer season. When ground covers were managed by hand weeding once a month, nearly all of the groundcovers were rated as well established in 2002 with over 95\% coverage of the soil surface. Exceptions to this were Achillea tomentosa, Houstonia serpyllifolia, and Mazus reptans which never closed their canopies, even with weeding. In 2002, there were no differences between groundcover treatments when managed with hand weeding once a month vs. hand weeding once a week. Groundcovers were generally unaffected by insect or pathogen infestation, with the exception of Fragaria $\times$, which was affected by a bacterial disease.

(88) Suitability of Woody Landscape Plants in the Rhamnaceae as Over-wintering Hosts of Soybean Aphid (Aphis glycines)

William R. Graves*1, David Voegtlin², Robert J. O’Neil ${ }^{3}$

${ }^{1}$ Department of Horticulture, Iowa State University, 129 Horticulture Hall, Ames, IA, 50011-1100, ${ }^{2}$ Center for Economic Entomology, Illinois Natural History Survey, 607 E. Peabody, Champaign, IL, 61820-6970, ${ }^{3}$ Department of Entomology, Purdue University, 901 W. State Street, West Lafayette, IN, 47907-2089

The soybean aphid (Aphis glycines Matsumura), a pest of soybeans in Asia, recently invaded North America. It has spread into regions of the United States where soybean is a major crop and threatens to have an economic impact on producers. The aphid has a complex life cycle that requires surviving winters as eggs on woody plants that serve as primary hosts. Certain Rhamnus L. spp. act as primary hosts where the aphid originated in China and Japan. We sought to determine which taxa of the Rhamnaceae family that are common in North American landscapes and/or horticultural commerce can serve as primary hosts. An experiment was designed to provide aphids the opportunity to develop and deposit eggs on 11 possible host taxa: Rhamnus cathartica L., Rhamnus frangula L., R. frangula 'Asplenifolia', R. frangula 'Columnaris', Rhamnus caroliniana Walt., Rhamnus alnifolia L'Hér, Rhamnus lanceolata Pursh., Rhamnella franguloides Weberbauer, Hovenia dulcis Thunb., Ceanothus americanus L., and Berchemia scandens (J. Hill) C. Koch. A replicated, choice-test protocol was used, and deposition of eggs confirmed which taxa enabled the aphids to over-winter. Observations were made twice a week during the autumn of 2002 of multiple plants of the 11 taxa. Gynoparae, oviparous nymphs, and oviparae were counted, and the presence of eggs was noted until mid-October. Use by fall migrants varied among the taxa and ranged from no use to heavy. On some taxa, oviparous nymphs were deposited but did not develop. Oviparae matured and deposited eggs only on R. cathartica (an invasive species from Europe and Asia) and R. alnifolia (native to North America). All plants on which eggs were deposited were exposed to conditions of the winter of 2002-03, allowing us to gather data on egg hatch and colony development. Our results confirm previous reports that $R$. cathartica is a primary host; indicate that $R$. frangula, its horticultural cultivars, and several other ornamental members of the Rhamnaceae are not primary hosts; and provide the first evidence that $R$. alnifolia is a primary host.

(89) Drought and Inundation Stress Responses of Hornbeam (Carpinus) Species and Hybrids

William R. Graves*, Susan J. Wiegrefe

${ }^{1}$ Department of Horticulture, Iowa State University, 129 Horticulture Hall, Ames, IA, 50011-1100, ${ }^{2}$ Tree Breeder, The Morton Arboretum, 4100 Illinois Route 53, Lisle, IL, 60532-1293

Use of hornbeams (Carpinus) to diversify managed landscapes will be facilitated by information on the resistance of the various taxa 
to water stress. Responses to soil moisture were evaluated with plants on their own roots and as grafts on C. betulus and C. caroliniana. Averaged over plants with drained, partially inundated, and totally inundated root zones for 28 days, photosynthesis of $C$. betulus as a scion was higher than that of $C$. caroliniana, C. caroliniana $\times C$. orientalis, C. caroliniana $\times$ C. laxiflora, and C. caroliniana $\times(C$. betulus $\times$ C. tschonoskii). Rates were especially high when $C$. betulus was grafted on either rootstock. Averaged over scions and treatments, C. caroliniana as a rootstock led to the highest rates. No genotype responded well to total inundation, but data averaged over grafted and own-root plants showed C. betulus had the highest photosynthetic rates after total inundation for 28 days. All genotypes tolerated partial inundation, and the rootstock-by-treatment interaction was significant only on day 8, when rates of plants on C. caroliniana rootstock that was drained or partially flooded were particularly high. In a separate experiment, photosynthetic rate of the same genetic combinations, plus C. caroliniana $\times$ C. tschonoskii as a scion and on its own roots, were examined for responses to drought by modeling changes in photosynthetic rate as soil moisture content by volume decreased from about $55 \%$ to $<5 \%$. Across scions, plants on C. caroliniana rootstock had the highest rates over the entire range of soil moisture, while plants on their own roots had the lowest rates. Across rootstocks, C. caroliniana scions had the highest rates at all soil moistures. We conclude that grafting is advantageous; that scions of C. betulus and C. caroliniana are best adapted to wet and dry root zones, respectively; and that $C$. caroliniana rootstock confers the most vigor of scions regardless of soil moisture.

\section{1:00 pm-2:00 pm POSTER SESSION 47}

Ballroom A

(Location numbers for the posters within the

Poster Viewing Area are in parenthesis)

\section{Ornamentals/Landscape and Turf-Mineral Nutrition}

\section{(90) Effect of Nitrogen Fertilization on Clipping Dry Weight of Six Turfgrasses}

\section{Lawrence Liu, Kent Kobayashi*}

Tropical Plant \& Soil Sciences Dept., University of Hawaii, 3190 Maile Way, St. John 102, Honolulu, HI, 96822

Turfgrass fertilization, particularly nitrogen fertilization, is critical to ensure adequate growth of turfgrasses. A study was conducted on six turfgrasses: Common Bermuda, Wild Bermuda, Seashore Paspalum, El 'Toro', Z-3, and Emerald Zoysia. Fertilizer regimes were $16 \mathrm{~N}-4 \mathrm{P}-4 \mathrm{~K}$ fertilizer at two rates of nitrogen: 7.3 and $14.6 \mathrm{~g} \mathrm{~N} / \mathrm{m}^{2}$ per month. Turfgrasses were grown in a glasshouse in PVC pipe $30.5 \mathrm{~cm}$ high and $15.2 \mathrm{~cm}$ in diameter with four replications of each turfgrass. Potting media mixture was 4 silicon sand : 1 peat moss (by volume). Turfgrasses were watered twice a day with overhead irrigation. From April to September, turfgrasses were clipped twice a month, and dry weights were recorded. Wild Bermuda gave the greatest clipping dry weight, followed by Common Bermuda, Seashore Paspalum, El 'Toro', and Z-3, with Emerald Zoysia having the least dry weight. The high rate of fertilizer generally promoted faster growth compared to the low rate, but the different turfgrasses showed different growth responses. With the fast growing turfgrasses, Wild Bermuda, Common Bermuda, and Seashore Paspalum grew faster as the amount of fertilizer increased. However, for the slow growing turfgrasses, El 'Toro', Z-3, and Emerald Zoysia did not show an obvious response to the fertilizer rates. This study indicated that the different turfgrasses required different rates of fertilizer for adequate growth (clipping dry weight production).

\section{(91) The Use of Expanded Shale in Landscape Mixes}

\section{John Sloan*1, Wayne Mackay², Steve George ${ }^{3}$}

${ }^{1}$ Soil \& Crop Sciences, Texas Agricultural Experiment Station, 17360 Coit Road, Dallas, TX, 75252, ${ }^{2}$ Horticultural Science, Texas Agricultural Experiment Station, 17360 Coit Road, Dallas, TX, 75252, ${ }^{3}$ Horticultural Science, Texas Cooperative Extension, 17360 Coit
Road, Dallas, TX, 75252

Homeowners frequently use organic landscape mixes to improve physical and chemical properties of their gardens and planting beds. The objective of this study was to determine if inclusion of inorganic expanded shale in the mixes would improve their performance. Four basic organic landscape mixes were prepared using traditional and alternative organic materials: 1) $75 \%$ pine bark $+25 \%$ sphagnum peat moss, 2) $50 \%$ pine bark $+50 \%$ wastewater biosolids, 3) $100 \%$ municipal yard waste compost, and 4) $65 \%$ pine bark $+35 \%$ cottonseed hulls. Expanded shale was blended with each of these mixtures at rates of $0,15,30$, and $60 \%$ (v/v). Three sets of pots were planted with Vinca (Catharanthus roseus), Verbena (Verbena hybrida), and Shantung Maples (Acer truncatum). Plant growth was monitored for several months followed by harvest of Vinca and Verbena plants to determine total biomass yield. Vinca plant tissue was chemically analyzed to assess how the landscape mixes affected nutrient and heavy metal uptake. Vinca, grew best in the compost mixture and its performance was improved by blending up to $30 \%$ expanded shale into the mixture. Both the perennial flower, Verbena, and the woody ornamental, Shantung Maple, grew best in the $50 \%$ pine bark $+50 \%$ biosolids mixture, followed closely by the $75 \%$ pine bark + $25 \%$ sphagnum peat moss mix and the $100 \%$ compost mix. For all three species evaluated, plant growth in the $100 \%$ compost mix was improved by the addition of 15 and $30 \%$ expanded shale, but plant growth in the $75 \%$ pine bark $+25 \%$ sphagnum peat moss mix and the $50 \%$ pine bark $+50 \%$ biosolids mix was diminished by including expanded shale in the mix. Expanded shale increased the uptake $\mathrm{Ca}$ and $\mathrm{Mg}$ by Vinca, but decreased the uptake of phosphorus. Decreased Pand trace metal uptake was probably due adsorption by the high $\mathrm{pH}$ expanded shale. Expanded shale can improve the performance of landscape mixes that primarily contain decomposed or composted organic materials. The increased performance is probably due to an improved porosity in the mixtures.

\section{(92) Soil-less Production of Rhododendrons for Export Marketing}

Allen Barker*1, Wayne Mezitt ${ }^{2}$

${ }^{1}$ Plant and Soil Sciences, University of Massachusetts, Bowditch Hall, Amherst, Massachusetts, 01003, ${ }^{2}$ President, Weston Nurseries, Inc., East Main Street, Hopkinton, Massachusetts, 01748

Production of soil-free plants may help to meet phytosanitation requirements for exporting of nursery plants. This research involves developing of specialized facilities and techniques for rhododendron production in hydroponics. Two rhododendron varieties were evaluated, 'Elite' (Rhododendron 'PJM Elite') and 'Aglo' (Rhododendron 'Weston's Aglo'). Rooted cuttings were transferred to 4-inch or 5inch nursery containers filled with coarse-sized, horticultural-grades of perlite or vermiculite. Six nutrient solutions were evaluated. The solutions were a nitrate-based solution with all plant nutrients included at Hoagland's concentrations, this solution modified with ammonium sulfate, the preceding two solutions with additional iron, and these two solutions at half-strength. The rooted cuttings were grown in a plastic-covered greenhouse shaded with 50\% light-transmission cloth. Plants were grown from July until December 2002. Survival rate after transplanting was about $95 \%$. All plants were evaluated for growth and appearance. Variety 'Aglo' was a more vigorously growing plant with more height and branching than 'Elite'. Pot size seemed to have only a slight effect on plant growth, perhaps with a slight growth advantage occurring in the larger than in the smaller pots. The medium also seemed to have little effect on plant growth. However, perlite leaked through holes in the bottoms of the containers. Occasionally, the pots with perlite had to be refilled, and the leaked perlite was unsightly in the system and occasionally gave problems in jamming pumps of the circulation system. Vermiculite did not leak from the pots. Nutrient solutions were about equal in supporting growth of the plants. From a group of 275 plants grown in hydroponics, 25 'Aglo' and 25 'Elite' plants were selected in December for shipment to Japan. The plants were inspected by an agricultural agent and were deemed disease and pest free. The media were removed from the roots, and the plants were 
shipped to Japan, where they also passed quarantine inspections. In Japan, plants will be evaluated in outdoor plots by at least three nursery growers, representing regions of southern, middle, and northern Japan. The remaining plants were kept for evaluation in Massachusetts.

\section{1:00 pm-2:00 pm POSTER SESSION 48}

Ballroom A

(Location numbers for the posters within the Poster Viewing Area are in parenthesis)

\section{Mineral Nutrition}

(235) Boron Analysis of Mehlich No. 3 Extractant with Modified Inductive Coupled Plasma Techniques

Henry Taber*

Horticulture, Iowa State University, 106 Hort Bldg., Ames, IA, 50011

Mehlich No. 3(M-3) has replaced the Bray P1 and ammonium acetate extractants for soil $\mathrm{P}$ and $\mathrm{K}$ determination, respectively, in the Iowa soil testing procedures. Other states have also adopted the procedure with the major benefit of one test across soil types for several nutrients. Correlation of M-3 soil extracted B to the traditional hot water method has been high enough $(r=.82)$ to warrant further investigation. The problem has been suitable analytical procedures to detect $0.01-.02 \mathrm{ppm}$ $\mathrm{B}$ in the extract with high precision. Our instrumentation consisted of a dual-view, charge-injection device fitted with a SeaSpray nebulizer with mass controller set at $0.71 \mathrm{~L} / \mathrm{min}$. The plasma power was $1150 \mathrm{~W}$, $\mathrm{RF}$ at low, and pump speed set at $100 \mathrm{rpm}$. These settings allowed the simultaneous measurement of $\mathrm{P}, \mathrm{K}, \mathrm{Ca}, \mathrm{Mg}, \mathrm{B}$, and $\mathrm{Zn}$. The photodiode detection array has 3 sensitive $\mathrm{B}$ wavelengths that could be utilized, $208.959,249.678$, and $249.773 \mathrm{~nm}$. The 249.678 and 249.773 lines are 2 to 3 times as sensitive and twice the detection limit of the 208.959 line. Preliminary studies showed that $\mathrm{Fe}$ (249.782 line) interfered on the B 249.773 line. The relative standard deviation for B concentrations $<0.1 \mathrm{ppm}$ in $\mathrm{M}-3$ extractant (12 samples) was $1.17 \%$ and $1.15 \%$ for the 208.959 and 249.678 lines, respectively. Recovery of added B from 0.02 to $.09 \mathrm{ppm}$ ranged from 102 to $110 \%$. Either of the two lines proved satisfactory, but the 249.678 line was more sensitive to low B concentrations. A field soil greenhouse experiment showed that M-3 extracted B correlated at $\mathrm{r}=.85, .84$, and .67 with shoot tissue B concentration for cauliflower, sweet corn, and tomato, respectively.

\section{(236) Carbon and Nitrogen Reserve Status and Partition- ing in the Perennial Strawberry}

Laura Acuña-Maldonado*1, Marvin Pritts ${ }^{2}$

${ }^{1}$ Horticulture, Cornell University, 163 Plant Science Building, Ithaca, NY, 14853, ${ }^{2}$ Horticulture, Cornell University, 134-A Plant Science Building, Ithaca, NY, 14853

Two studies were conducted to determine if $\mathrm{N}$ reserves or carbohydrate reserves limit perennial strawberry plant growth and yield in the spring. If $\mathrm{N}$ is limiting, then increasing $\mathrm{N}$ reserves in autumn should increase yield the following spring. If carbohydrates are limiting, then increasing $\mathrm{N}$ reserves in autumn should decrease yield the following spring because additional carbon is required to assimilate $\mathrm{N}$. Plants were grown in pots and fertigated with different $\mathrm{N}$ concentrations ( 0 to 20 $\mathrm{mM}-\mathrm{N}$ ) during the growing season and either water or a 3.0\% urea sol. was sprayed on the foliage in the fall. On 17 April 02, some plants were destructively harvested and separated into major plant components to assess $\mathrm{C}$ and $\mathrm{N}$ reserve status and partitioning. Others were transferred to larger 2-gal pots early in May and grown under a regular $\mathrm{N}$ supply or without $\mathrm{N}$ in the nutrient solution until fruit harvest. Fruit was harvested in June-July 2002. Analysis of carbohydrates and total-N for each plant part (leaves, crowns and roots) were determined. In a second study, carbohydrate reserves were artificially increased through carbon dioxide enrichment and the response to nitrogen application was compared to the response of plants grown under ambient carbon dioxide levels. We hypothesized that yield would respond more strongly to increasing nitrogen reserves when carbohydrate levels are higher. At the end of the growing season, fruit was harvested, plants were de- structively harvested, and carbohydrates and total-N for each plant part determined. Results have implications for grower fertility management.

(237) Changes in Mineral Nutrient Concentrations in Petunia Flower Organs during Development and Senescence Karyn Smith*, Sven Verlinden

Horticulture, West Virginia University, 1090 Ag. Science Building, P.O. Box 6108, Morgantown, West Virginia, 26506

In order to observe changes in nutritional status, several wild-type and transgenic Petunia $\times$ hybrida plants were analyzed for macronutrients $(\mathrm{C}, \mathrm{N}, \mathrm{P}, \mathrm{K}, \mathrm{Ca}, \mathrm{Mg}, \mathrm{S})$, fresh weight, and dry weight of corollas, sepals, pedicles, styles, and ovaries during flower development, age-related and pollination-induced senescence. Comparisons in the nutritional status of these organs were made between two separate sets of wild-type and transgenic petunias. Petunia $\times$ hybrida $\mathrm{cv}$. Mitchell Diploid (wild-type) was compared to CaMV 35S/etr1-1, an ethylene insensitive petunia (transgenic; line 44568); and the inbred 'V26' background petunia (wild-type) to sag12-IPT, an over-producer of cytokinin (transgenic). During age-related senescence of Mitchell, V-26, and sag12-IPT flowers, nitrogen declined gradually during development then decreased dramatically with the onset of the ethylene climacteric. However in etr1-1, which lacks an ethylene climacteric, nitrogen decreased only gradually during development and senescence indicating that ethylene may play an important role in the remobilization of nitrogen. In all four petunia types, phosphorus and potassium declined gradually during development and age-related senescence. However, in sag12-IPT and etr1-1, the decline was more prolonged, which is consistent with the increased corolla longevity observed in these plants. Calcium and magnesium increased steadily during age-related senescence in all plants while carbon declined gradually. Results indicate that remobilization of the macronutrients from corollas occured before and during age-related senescence. Similar results were observed for pollination-induced senescence; however, the pace of remobilization increased dramatically. Our data suggests that remobilization of mainly nitrogen and phosphorus occured during age-related and pollination-induced senescence, each showing its own distinct pattern of remobilization.

\section{(238) Development and Analysis of a Zinc-Contaminated} Soil

Gretchen Bryson*, Allen Barker

Plant and Soil Sciences, University of Massachusetts, Bowditch Hall, Amherst, MA, 01003

For phytoremediation studies, a contaminated soil, with identifiable and consistent properties must be accessible. Utilizing an in-situ $\mathrm{Zn}$-contaminated soil presents many problems, such as a limited range of $\mathrm{Zn}$ concentrations and problems with additional contaminants that may be present in the soil. Therefore, the focus of this experiment was to develop a $\mathrm{Zn}$-contaminated soil that would provide a wide range of $\mathrm{Zn}$ concentrations along with invariable and identifiable properties within one soil type. Concerns in developing a $\mathrm{Zn}$-contaminated soil are determining the amount of $\mathrm{Zn}$ to add and an incubation period for the $\mathrm{Zn}$ to react with the soil. Two soils of the Hadley series (Typic Udifluvents) were used, each being a silt loam. One (Soil 1) had a higher sand content (39\%) than the other (soil 2) (23\%), which had a higher organic matter content (11\%) than soil 1 (4\%). Approximately $1-\mathrm{kg}$ portions of soil were placed into $15-\mathrm{cm}$ plastic pots $(11.5-\mathrm{cm}$ deep), and zinc sulfate was added and mixed with the soil to give 125 , $250,500,1000$, and $2000 \mathrm{mg} \mathrm{Zn/kg}$. Soil samples were taken after 7, 14,21 , and 28 days and were extracted with Morgan's universal solution. Soil samples taken after 7 and 21 days were also sequentially extracted with water, Morgan's solution, and Mehlich 3 solution. All of the extracts were analyzed for $\mathrm{Zn}$ by atomic absorption spectroscopy. Morgan's extractable $\mathrm{Zn}$ increased as the treatment levels increased, ranging from $41 \mathrm{mg} \mathrm{Zn/kg}$, at $125 \mathrm{mg} \mathrm{Zn/kg}$, to $648 \mathrm{mg} \mathrm{Zn/kg}$, at $2000 \mathrm{mg} \mathrm{Zn/kg}$. Morgan's extractable Zn from each soil decreased as the incubation period progressed. Mean Morgan'sextractable Zn 
concentrations were highest at Day 7. The total amounts of extractable $\mathrm{Zn}$, calculated from the sum of the sequential extractions, increased as the treatment levels increased, ranging from $51 \mathrm{mg} \mathrm{Zn/kg}$, at 125 $\mathrm{mg} \mathrm{Zn/kg}$, to $719 \mathrm{mg} \mathrm{Zn/kg}$, at $2000 \mathrm{mg} \mathrm{Zn/kg}$. The removal of $\mathrm{Zn}$ by Morgan's solution or by sequential extraction was not significantly different between the two soils. The mean concentrations of $\mathrm{Zn}$ removed by water, Morgan's, and Mehlich 3 solution were 41, 137, and $112 \mathrm{mg}$ $\mathrm{Zn} / \mathrm{kg}$ respectively. As the incubation period progressed, the percent recoveries of the added $\mathrm{Zn}$ decreased from $44 \%$, on day 7 to $32 \%$ on day 21. Brassica juncea seeds had a $59 \%$ mean germination in soil-Zn additions up to $1000 \mathrm{mg} \mathrm{Zn/kg}$, and Festuca arundinacea seeds had a $92 \%$ mean germination in soil-Zn additions up to $2000 \mathrm{mg} \mathrm{Zn} / \mathrm{kg}$. Mean germination was higher in soil 2 with $77 \%$ than in soil 1 with $73 \%$. It was concluded that an appropriate incubation period was 7 days, since any further incubation periods gave no significant differences in extractable $\mathrm{Zn}$ concentrations. Since B. juncea seeds did not germinate in soil-Zn concentrations greater than $1000 \mathrm{mg} \mathrm{Zn} / \mathrm{kg}$, it was determined that soil- $\mathrm{Zn}$ concentrations up to $1000 \mathrm{mg} \mathrm{Zn} / \mathrm{kg}$ would be suitable for phytoextraction studies with B. juncea or F. arundinacea.

(239) Effect of Reserved Nitrogen and Current Season Uptake Nitrogen on Gala/M26 Apple Fruit Development Pinghai Ding*, Leslie H. Fuchigami

Horticulture, Oregon State University, ASL 4017, Corvallis, OR, 97331

4-year-old pot-in-pot Gala/M26 apples grown at the Lewis-Brown Farm of Oregon State University were sprayed twice at one week interval with $3 \% 15 \mathrm{~N}$-urea and $14 \mathrm{~N}$-urea in October, 2001. Before bud break the trees were repotted into nitrogen-free medium (perlite: vermiculite 1:1) to study the effect of reserve and current nitrogen uptake on fruit development. The effect of current nitrogen uptake on fruit development was discriminated against the reserve nitrogen by applying single applications of $15 \mathrm{~N}$-urea to each treatment at different stages from March 15 to August 15. The results showed that fall foliar urea application significantly increased spur reserve nitrogen and tended to increase new shoot nitrogen content but not significantly. Fall urea application significantly increased tree and cluster fruit set and tended to increase tree fruit yield. The soil $15 \mathrm{~N}$-urea application significantly increased more fruit total $15 \mathrm{~N}$ content than the fall foliar $15 \mathrm{~N}$-urea application. Among current season $15 \mathrm{~N}$-urea application at different growth stages, the applications in May and June significantly increased total fruit $15 \mathrm{~N}$ content in comparison with the other period of application. This result showed that May and June nitrogen application was important for Gala apple fruit development.

\section{(240) Effect of Season and Fertilization on Amino Acid} Composition of Leafy Greens

\section{Martin Gent*}

Forestry \& Horticulture, CT Agr. Expt Stn, PO Box 1106, New Haven, CT, 06504

Amino acid composition of leafy greens is likely to be affected by the wide variation in light and temperature when grown in high tunnels, as well as by method of fertilization. To test these hypotheses, seven species of salad greens were grown in spring and fall using organic or conventional fertilization. Unheated high tunnels had plots with perlite fertilized with a complete soluble fertilizer, or with $1: 1 \mathrm{v} / \mathrm{v}$ leaf compost:perlite fertilized with cotton-seed meal. Three harvest dates were analyzed using HPLC and fluorescence to detect phthaldialdehyde derivatives of free amino acids. The concentration of free amino acids in leaf tissue varied from 60 to 150 micromoles per gram dry weight. In general, the concentration of amino acids in leaves varied with that of total nitrogen, but the coefficient of variation for amino acids was much larger than for total nitrogen. The variation between harvests was greater than between methods of fertilization. There was no consistent difference in growth within harvests due to the method of fertilization. The species varied in nitrate; Brassica rapa, Brassica juncea, and Plantago corynopsis had high nitrate levels, but only Plantago corynopsis had a high concentration of free amino acids, compared to the other species. Glutamine was the predominant amino acid in leaves of all species. As a fraction of all free amino acids, Plantago corynopsis had the most glutamine, about $55 \%$ compared to a low of $25 \%$ for Spinacea oleracea. Brassica oleracea had relatively more arginine than other salad greens. Spinacea oleracea had relatively more valine and phenylalanine. Plantago corynopsis had more asparagine. Over all harvests, Brassica rapa had low amounts of all amino acids.

(241) Effects of Solution Calcium Level and Bulb Calcium Level on The Development of Upper Leaf Necrosis on Lilium cv. Star Gazer

Yao-Chien Chang*,William B. Miller

Dept. of Horticulture, Cornell University, Ithaca, NY 14853-5904

Upper leaf necrosis (ULN) on Lilium cv. Star Gazer is a result of localized calcium (Ca) deficiency in the upper leaves. In the current study, we investigated the effects of solution Ca level and bulb Ca content on the development of ULN. Studying this way, we were able to examine the role of the bulb on ULN symptomatology. Bulbs (14-16 cm circum.) were planted in pure sand, and fertigated with nutrient solutions with 0 , 0.2 , or $4 \mathrm{mM} \mathrm{Ca}$. The Ca concentrations of all organs were positively correlated, and ULN was negatively correlated, with solution Ca level. Regardless of nutrient $\mathrm{Ca}$ level (even $\mathrm{Ca}$ free), necrosis symptoms appeared only on the upper leaves. When leaves senesced, the bulbs (with various internal Ca concentrations) were harvested. Upon forcing these bulbs with extremely low internal Ca concentration $(0.009 \%$ DW) in the next season, we found prominent necrosis symptoms on the lower and middle leaves. These results demonstrate ULN is primarily caused by an insufficient Ca supply from the bulb. The bulb is able to translocate limited Ca to the shoot; this is why ULN only shows on the upper leaves. Data suggest the lower and middle leaves rely more on Ca supply from the bulb, the upper leaves and flowers rely more on $\mathrm{Ca}$ uptake from the roots. 'Star Gazer' lily partitioned most Ca to leaves, little to bulb scales. However, the proportion of Ca partitioning to leaves decreased when solution $\mathrm{Ca}$ level was reduced, indicating that leaf $\mathrm{Ca}$ is very plastic, and depends on $\mathrm{Ca}$ availability to the roots.

(242) Effects of Supplemental Calcium on Yield and Quality of 'Sweet Charlie' Strawberry

Camille Esmel*, John Duval

Horticultural Sciences, University of Florida, 13138 Lewis Gallagher Rd., Dover, FL, 33527

Supplemental $\mathrm{Ca}$ is used on various fruit crops to maintain or increase commodity quality. Strawberries are a high value crop with a short shelf life. Many Florida growers apply supplemental Ca to their crop despite lack of conclusive evidence of an increase in berry quality. In the 199899 season, 'Sweet Charlie' was grown on $>50 \%$ of the strawberry acreage in Florida however, during the 200203 season, the cultivar accounted for only $2 \%$. Easily bruised and soft fruit of 'Sweet Charlie' are ascribed as reasons for the decline in acreage. Supplemental $\mathrm{Ca}$ applied to 'Sweet Charlie' during production may help increase fruit shelf life and increase firmness. Applications of supplemental Ca were made using two methods: a pre-plant soil amendment of calcium sulfate and a weekly foliar application of two Ca salts. The pre-plant soil amendment treatments are $0 \mathrm{~kg} / \mathrm{ha}, 224 \mathrm{~kg} / \mathrm{ha}$, and $448 \mathrm{~kg} / \mathrm{ha}$ of Ca. The foliar applied Ca treatments are a water spray-control, $400-\mathrm{mg} / \mathrm{L}$ for $\mathrm{CaSO}_{4}$, $400-\mathrm{mg} / \mathrm{L}$ calcium chloride $\left(\mathrm{CaCl}_{2}\right)$, and $800-\mathrm{mg} / \mathrm{L} \mathrm{CaCl}{ }_{2}$ at the rate of $935 \mathrm{~L} / \mathrm{h}$. All treatment combinations were assessed for differences in marketable yield, calcium concentration, firmness and shelf life.

(243) Foliar Symptomology and Tissue Concentrations of Nutrient Deficient Angelonia

Amy Williams*, Paul V. Nelson, Brian E. Whipker, John M. Dole, Brenda R. Cleveland, F.R. Walls

Horticluture, North Carolina State University, 4706 G Bluebird ct, 
Raleigh, NC, 27606

Foliar analysis standards have not been published for Angelonia angustifolia 'Carita Purple'. Deficiency symptoms do not exist for many nutrients in this crop. Angelonia plants were grown hydroponically in a glass greenhouse. Treatments consisted of a complete Hoagland's all nitrate macronutrient solution with altered micronutrient content and 11 related solutions, each devoid of one essential nutrient. Visual symptoms were chronologically recorded and photographed. Angelonia appeared to be most sensitive to Ca deficiency due to the appearance of symptoms at day $12 . \mathrm{N}, \mathrm{P}, \mathrm{K}$ and $\mathrm{Fe}$ followed at day 16 , and $\mathrm{S}$ at day $20, \mathrm{Cu}$ and $\mathrm{Zn}$ at day 24 , followed by $\mathrm{B}$ on day $26, \mathrm{Zn}$ on day 31 and $\mathrm{Mg}$ on day 37 . Unique deficiency symptoms included the following: there was considerable upward rolling of the margins and twisting of the young and recently mature leaves on $\mathrm{Cu}$ and $\mathrm{Zn}$ deficient plants and dark green pigmentation preceded symptoms of $\mathrm{P}$ and $\mathrm{Cu}$ deficiencies. Minimal critical leaf concentrations for $\mathrm{N}, \mathrm{K}, \mathrm{S}, \mathrm{Fe}, \mathrm{Mn}$ and $\mathrm{Zn}$ were in the ranges formerly reported for other crops while for $\mathrm{P}, \mathrm{Ca}, \mathrm{Mg}, \mathrm{Cu}$ and $\mathrm{B}$ the minimal critical nutrient concentrations were unusually low. These low values may be do to the young growth stages of these plants compared to the older, more reproductive stages, that are associated with traditional standards in the literature for ornamental crops. Detailed descriptions of the chronological development of deficiency symptoms are presented along with associated early and advanced stage leaf nutrient concentrations.

(244) Influence of Nitrogen Fertilization on Broccoli Yield, Disorders, Disease, and Ascorbic Acid Content

Cathy Bakker*1, Alan McKeown ${ }^{1}$, Clarence Swanton ${ }^{2}$, Ivan O'Halloran ${ }^{3}$, George $\mathrm{Chu}^{4}$

${ }^{1}$ Plant Agriculture, Univ. of Guelph, Box 587, Simcoe, Ontario, N3Y 4N5, Canada, ${ }^{2}$ Plant Agriculture, Univ. of Guelph, 50 Stone Rd., Guelph, Ontario, N1G 2W1, Canada, ${ }^{3}$ Ridgetown College, Univ. of Guelph, 120 Main St. East, Ridgetown, Ontario, NOP 2C0, Canada, ${ }^{4} \mathrm{Plant}$ Agriculture, Univ. of Guelph, 50 Stone Rd., Guelph, Ontario, N1G 2W1

Current information on the response of broccoli yield and quality to nitrogen fertilization is lacking for southern Ontario. In addition, relevant data is required due to nutrient management legislation. Nitrogen $(\mathrm{N})$ was applied to two broccoli cultivars (Brassica oleracea var. italica 'Captain', 'Decathlon') at 0, 50, 100, 150, 200, 300, $400 \mathrm{~kg} \cdot \mathrm{ha}^{-1} \mathrm{~N}$ as a broadcast application of ammonium nitrate before transplanting. Yield and quality was assessed based on the presence of defects and diseases such as loose or misshapen florets, hollow stem, and bacterial head rot. Crop marketable yield increased with increasing $\mathrm{N}$ rates reaching a maximum of $17 \mathrm{t} \cdot \mathrm{ha}^{-1}$ at $\mathrm{N}$ rates of $296-335 \mathrm{~kg} \cdot \mathrm{ha}^{-1} \mathrm{~N}$. Yield of misshapen, loose heads decreased with increasing $\mathrm{N}$ rates. The percent of heads with hollow stem increased with increasing $\mathrm{N}$ rates from $0 \%$ to $3 \%$ at $0 \mathrm{~kg} \cdot \mathrm{ha}^{-1} \mathrm{~N}$ to $46 \%$ to $66 \%$ at $400 \mathrm{~kg} \cdot \mathrm{ha}^{-1} \mathrm{~N}$. The yield of heads with bacterial head rot increased proportionately with increasing $\mathrm{N}$ rates from $0 \mathrm{t} \cdot \mathrm{ha}^{-1}$ at $0 \mathrm{~kg} \cdot \mathrm{ha}^{-1} \mathrm{~N}$ to $0.1-0.6 \mathrm{t} \cdot \mathrm{ha}^{-1}$ at $400 \mathrm{~kg} \cdot \mathrm{ha}^{-1} \mathrm{~N}$. Total ascorbic acid (AA) content decreased proportionately with increasing $\mathrm{N}$ rates from 108.3 to $96.9 \mathrm{mg}$ AA per $100 \mathrm{~g}$ fresh weight. Visual quality decreased rapidly at $\mathrm{N}$ rates less than $150 \mathrm{~kg} \cdot \mathrm{ha}^{-1} \mathrm{~N}$. There is a tradeoff between yield and quality for although visual quality of the head increases at higher $\mathrm{N}$ rates, undesirable characteristics such as hollow stem, bacterial head rot may be worsened.

\section{(245) Photosynthetic and Morphological Characteristics of Three Spathiphyllum Cultivars Subirrigated with Different Concentrations of Nitrogen}

\section{Q. Wang ${ }^{1}$, Y. Li' ${ }^{2}$, R.D. Caldwell ${ }^{1}$, J. Chen*1}

${ }^{1}$ Mid-Florida Research and Education Center, 2725 Binion Road, Apopka, FL 32703, ${ }^{2}$ Tropical Research and Education Center, 18905 SW 280 St. Homestead, FL 33031

Spathiphyllum had been obscure for more than a century since its first introduction in 1874 but now is one of the most popular ornamental foliage plants in the market. More than 50 cultivars with different growth habits and sizes are available and used widely for interior plantscap- ing. However, leaf photosynthetic and morphological characteristics in relation to different rates of nitrogen $(\mathrm{N})$ supply have not been well documented. In this study, three genetically related Spathiphyllum cultivars, 'Claudia', 'Double Take', and 'Petite' with similar initial sizes and biomass, were potted in $15-\mathrm{cm}$ containers filled with Vergo Container Mix A. Plants were grown in a shaded greenhouse and fertigated with a constant supply of nitrogen at $50,100,200$, and $400 \mathrm{mg} \cdot \mathrm{L}^{-1}$ using an ebb-and-flow fertigation system. Based on growth indices and dry weights, the optimal $\mathrm{N}$ rate for three cultivars were $200 \mathrm{mg} \cdot \mathrm{L}^{-1}$. However, 'Claudia' and 'Double Take' had plant sizes and dry weights significantly greater than 'Petite' when grown under this optimal $\mathrm{N}$ rate. Leaf photosynthetic and morphological comparisons indicated that the stomatal conductances of 'Claudia' and 'Double Take' were 30\% greater, thus net photosynthetic rates $(\mathrm{Pn})$ were significantly higher, than 'Petite'. In addition, the leaf areas of 'Claudia' and 'Double Take' were 60\% larger than 'Petite'. Since Pn is expressed based on leaf surface area, the greater the leaf surface area is, the more $\mathrm{CO}_{2}$ is fixed. Thus, the differences in plant size and biomass production of 'Claudia' and 'Double Take' compared to 'Petite' are attributed to high Pn and increased leaf area.

(246) Response of Two Container-grown Ornamental Grasses to Fertilizer Variables

Christopher Catanzaro*, Sarabjit Bhatti

Cooperative Agricultural Research Program, Tennessee State University, Box 9610, 3500 J.A. Merritt Blvd., Nashville, TN, 37209

Two cultivars of container-grown ornamental grasses (Calamagrostis acutiflora 'Karl Foerster', Phalaris arundinacea 'Strawberries and Cream') were evaluated during summer 2002 for response to two placements (topdressed vs. incorporated) of a 3-4 month formulation of controlled release fertilizer $(14 \mathrm{~N}-6 \mathrm{P}-11.6 \mathrm{~K})$ and three rates (low, medium, high) based on label recommendations. Plant height, width and dry weight increased with increasing rate, but did not differ by fertilizer placement. Weekly effluent collection revealed that electrical conductivity (EC) of effluent dropped rapidly, with readings below 0.6 $\mathrm{dS} / \mathrm{m}$ by week 5 . Differences in EC were not detected among rates or delivery methods. Although growth and nutrient use efficiency were not affected by the fertilizer delivery methods tested, results suggest that grasses require high rates of macronutrients during summer months to maximize growth.

(247) Selenium Source and Concentration in Nutrient Solution Affect Growth and Quality of Leaf Lettuce (Lactuca sativa L.) and Garland Chrysanthemum (Chrysanthemum coronarium L.) in Hydroponic Culture

Hyung Kweon Yun ${ }^{1}$, Young Cheol Kim¹ ${ }^{1}$ Tae Chul Seo ${ }^{1}$,

Sang Gyu Lee*1, Hyo Duk Suh ${ }^{1}$, Jun Gu Lee ${ }^{2}$,

Chiwon W. Lee ${ }^{3}$

${ }^{1}$ Vegetable Cultivatioin Division, National Horticulture Research Institute, 475 Imok-dong, Changan-gu, Suwon, 440-310, Republic of Korea, ${ }^{2}$ Horticultural Division, National Highland Agr. Res. Ins., Heongkye, Pyungchang-gun, 232-955, Republic of Korea, ${ }^{3}$ Dept. of Plant Sciences, North Dakota State University, Loftsgard Hall 266F, Fargo, ND, 58105

Changes in selenium uptake by leaf lettuce (Lactuca sativa L.) and garland chrysanthemum (Chrysanthemum coronarium $\mathrm{L}$.) as influenced by the source $\left(\mathrm{Na}_{2} \mathrm{SeO}_{3}, \mathrm{Na}_{2} \mathrm{SeO}_{4}, \mathrm{Se}\right.$-amino chelate) and nutrient solution concentration $\left(0,2,4,8,16 \mathrm{mg} \cdot \mathrm{L}^{-1}\right)$ of Se during hydroponic culture were investigated. When treated for 7 days prior to harvest, fresh weight and leaf area decreased as Se concentration exceeded $8 \mathrm{mg} \cdot \mathrm{L}^{-1}$ in both species. Among the Se sources tested, sodium selenite $\left(\mathrm{Na}_{2} \mathrm{SeO}_{4}\right)$ was most influential in reducing plant growth in leaf lettuce, especially at $16 \mathrm{mg} \cdot \mathrm{L}^{-1} \mathrm{Se}$ with 2.3 and 1.8 fold reduction of fresh weight and leaf area, respectively, as compared to the control. Garland chrysanthemum showed a similar growth response. Tissue vitamin C content was highest ( $14.1 \mathrm{mg}$ per $100 \mathrm{~g}$ f.w.) when lettuce was grown with $8 \mathrm{mg} \cdot \mathrm{L}^{-1} \mathrm{Se}$ from selenite. Total tissue mineral contents in leaf lettuce were unaffected by Se source but slightly decreased as Se concentration in nutrient solution 
increased. While similar Se influence on vitamin $\mathrm{C}$ and mineral content was observed, garland chrysanthemum accumulated less nitrate in the tissue when grown with elevated levels of Se in the nutrient solution as compared to leaf lettuce. Tissue Se contents in both species were enhanced as nutrient solution Se concentration increased. Leaf lettuce and garland chrysanthemum, respectively, accumulated $79.3 \mathrm{Se}$ and $89.0 \mathrm{Se}$ per $\mathrm{kg}$ d.w. when grown at $16 \mathrm{mg} \cdot \mathrm{L}^{-1} \mathrm{Se}$ in the nutrient solution containing selenite. The visual quality of both vegetables was the best when grown with 2 or $4 \mathrm{mg} \cdot \mathrm{L}^{-1} \mathrm{Se}$ in the nutrient solution.

(248) Spring Soil Nitrogen Application in Relation to Nitrogen Remobilization, Uptake and Partitioning for New Growth in Almond Nursery Plants

Guihong Bi*1, Carolyn Scagel ${ }^{2}$, Leslie Fuchigami ${ }^{1}$

${ }^{1}$ Horticulture, Oregon State Univ., 4017 ALS, Corvallis, OR, 97331, ${ }^{2}$ USDA-ARS, Horticultural Crops Reseaarch Laboratory, 3420 NW Orchard Street, Corvallis, OR, 97330

One-year-old 'Nonpareil' almond [Prunus dulcis (Mill) D.A. Webb] trees on 'Lovell' rootstocks were used to evaluate the effects of soil nitrogen $(\mathrm{N})$ availability in the spring on $\mathrm{N}$ remobilization, uptake, partitioning, and tree growth. After being transplanted to a $\mathrm{N}$-free medium, the trees received a modified Hoagland solution, with or without $\mathrm{N}$ from ${ }^{15} \mathrm{~N}$-depleted $\mathrm{NH}_{4} \mathrm{NO}_{3}$, twice a week for 12 weeks. During the first 4 weeks, the $\mathrm{N}$ used for new shoot and leaf growth mainly came from the nitrogen that had accumulated in storage tissues. There was no significant difference in the amount and duration of $\mathrm{N}$ remobilization between $\mathrm{N}$-fertilized trees and those that received no N. However, trees that were fertigated in the spring had significantly more new shoot and leaf growth. Uptake of ${ }^{15} \mathrm{~N}$ by the roots began two weeks after transplanting. Nitrogen was rapidly taken up from the soil during the period of greatest shoot and leaf growth; leaves were the major sink for $\mathrm{N}$ from both root uptake and storage. Six weeks after transplanting, the whole-tree $\mathrm{N}$ content was significantly higher in fertilized trees than in the controls. We conclude that the remobilization of $\mathrm{N}$ for spring new growth takes place irrespective of the current-year external $\mathrm{N}$ supply. However, the new growth in young almong trees is highly dependent on soil $\mathrm{N}$ availability, which demonstrates the importance of Spring $\mathrm{N}$ fertilizer applications following transplantation.

(249) Effects of the Fall Foliar Urea Application on N Reserves and Fruiting of High-density Cameo/M9Apple Trees

Shufu Dong ${ }^{1}$, Pinghai Ding ${ }^{2}$, Lailiang Cheng*3,

Leslie H. Fuchigami

${ }^{1}$ Pacific Agri-Food Research Center, Agriculture and Agri-Food Canada, 4200 Highway 97, Summerland, British Columbia, V0H 1Z0, Canada, ${ }^{2}$ Horticulture, Oregon State Univ., ALS 4017, Corvallis, OR, 97331, ${ }^{3}$ Horticulture, Cornell Univ., 134A Plant Sci. Bldg, Ithaca, NY, 14853

Reserve nitrogen is an important factor for plant growth and fruiting in tree fruit crops. The fall foliar urea application appears to be an efficient method of increasing $\mathrm{N}$ reserves. Effects of fall foliar urea application on $\mathrm{N}$ reserves were studied with high-density bearing apple trees at Fleming's orchard, Orondo, WA. Three classifications of Cameo/M9 (vigorous, moderate and weak) trees were selected and treated with either $0,1,2$, or 3 times of $3 \%$ urea foliar application after harvest. Shoot and spur samples were taken at the dormant season for reserve $\mathrm{N}$ analysis. Growth performance and fruiting were recorded in the following season. The fall foliar application significantly increased $\mathrm{N}$ levels in both shoots and spurs, but there was no significant difference in spur $\mathrm{N}$ content between 1,2 and 3 urea applications, indicating saturation of spur $\mathrm{N}$ level. Fruit number and yield were generally increased with the fall foliar urea application except the vigorous trees with two urea applications. Fruit size were a little bit increased in vigorous and moderate trees by the fall foliar urea application.
1:00 pm-2:00 pm POSTER SESSION 49

Ballroom A

(Location numbers for the posters within the Poster Viewing Area are in parenthesis)

\section{Postharvest-1-MCP and Ethylene}

(93) Delay in Color Changes and Softening in Breaker- and Turning-stage Tomato Fruit Treated with 1-Methylcyclopropene

Brandon Hurr *1, Donald Huber ${ }^{2}$

${ }^{1}$ Horticultural Sciences Department, University of Florida, 1213 Fifield Hall, PO Box 110690, Gainesville, FL, 32611, ${ }^{2}$ Horticultural Sciences Department, University of Florida, PO Box 110690, 1143 Fifield Hall, Gainesville, FL, 32611-0690

1-methylcyclopropene (1-MCP) is an effective inhibitor of ethyleneregulated developmental processes including ripening. In climacteric fruits, 1-MCP effectively delays pigment changes, softening, ethylene production and, to a lesser extent, respiration. In this study, ripening characteristics including color changes and softening were determined for breaker and turning tomato fruit (cv. Florida 47) in response to 200 $\mathrm{ppb}$ or $1 \mathrm{ppm} 1-\mathrm{MCP}$. Fruit were sealed in 17-L containers and given either air or a $200 \mathrm{ppb}$ or $1 \mathrm{ppm} 1-\mathrm{MCP}$ treatment. Color and firmness measurements were taken every other day until the fruit became unmarketable, either from oversoftening or pathogen infection. 1-MCP significantly delayed color changes and softening in both breaker and turning fruits, with differences being evident within $24 \mathrm{~h}$ after 1-MCP treatment. Initial hue angle measurements were $120^{\circ}$ and $60^{\circ}$ for breaker and turning fruit, declining to $40^{\circ}$ within 15 days and 10 days of storage, respectively. After 7 days, at which time control fruit were fully ripe (hue angle ca $45^{\circ}$ ), the color change of 1-MCP-treated fruit accelerated, reaching rates similar to those exhibited during ripening in control fruit. Softening followed a parallel pattern; however, the $200 \mathrm{ppb} 1-\mathrm{MCP}$ treatment was more effective at inhibiting color change than softening compared with the treatment at $1 \mathrm{ppm}$, which suppressed both to similar degrees. Interestingly, 1-MCP caused a transient increase (32\% in breaker fruit; $11 \%$ turning) in whole fruit compression values in the first 5 to 7 days following treatment. Pericarp disks prepared from fruit during storage did not show this firmness increase, suggesting that the increase in whole fruit firmness reflected changes occurring in internal fruit tissues. 1-MCP-treated fruit softened to acceptable values but did not soften to the extent of controls. Loss of marketability in control fruit was due to oversoftening whereas 1-MCP-treated fruit remained acceptable through 27 (fruit initially at breaker stage) and 20 days (turning), limited eventually by pathogen proliferation.

(94) 1-Methylcyclopropene (1-MCP) for Extending Shelflife and Maintaining Quality of Fresh-cut Tomato

Jiwon Jeong*, Jeffrey Brecht, Donald Huber, Steven Sargent ${ }^{1}$ Horticultural Science, University of Florida, 1213 Fifield Hall, P.O. Box. 110690, Gainesville, FL, 32611-0690

A study was conducted to determine the effect of 1-methylcyclopropene (1-MCP) on changes in pericarp firmness, electrolyte leakage, and watersoaking of intact vs. fresh-cut tomato (Lycopersicon esculentum Mill.) during storage at $5{ }^{\circ} \mathrm{C}$. $1-\mathrm{MCP}$ was applied directly to tomato slices as well as to intact tomatoes before slicing. In addition, the relationship between the development stage of tomato fruit and watersoaking symptom development was determined. Significantly less pronounced changes were observed for 1-MCP treated tomato slices. Slicing increased softening of control slices compared to intact fruit, and 1-MCP treatment overcame this effect, maintaining slice pericarp firmness that was equal to that of slices from intact fruit. 1-MCP treatment did not significantly affect electrolyte leakage of fresh-cut tomato slices or slices from intact fruit during $8 \mathrm{~d}$ storage at $5{ }^{\circ} \mathrm{C}$. Pericarp firmness of fresh-cut tomato slices treated with $1 \mu \mathrm{L}^{\circ} \mathrm{L}^{-1} 1$-MCP for 24 h at $5{ }^{\circ} \mathrm{C}$ decreased by about $7.6 \%$ of the initial day 0 value after $10 \mathrm{~d}$ storage at $5{ }^{\circ} \mathrm{C}$ while the firmness decrease of fresh-cut tomato slices 
without 1-MCP was 29.6\%. 1-MCP treatment did not have a significant effect on the respiration pattern of fresh-cut tomato slices, but the application of 1-MCP at $5{ }^{\circ} \mathrm{C}$ significantly increased the magnitude of the ethylene production peak in fresh-cut tomato slices. 1-MCP treatment reduced the development of watersoaking on fresh-cut tomato slices; and fresh-cut tomato slices with higher initial firmness values showed less watersoaking development during $8 \mathrm{~d}$ storage at $5^{\circ} \mathrm{C}$.

(95) 1-Methylcyclopropene Extends Postharvest Quality of Grape Tomato Fruit Harvested at Advanced Ripeness Stages

Muharrem Ergun, Steven Sargent*, Donald Huber

Horticultural Sciences Dept., University of Florida, 1301 Fifield Hall, PO Box 110690, Gainesville, FL, 32611-0690

Grape tomato fruit (Lycopersicon esculentum Mill., cv. Santa) harvested at light-red and full-red stages, were randomized into rigid, vented clamshell containers ( $473 \mathrm{~mL}$ volume; $\mathrm{n}=20$ ), treated with 1 $\mu \mathrm{L} \cdot \mathrm{L}^{-1}$-methylcyclopropene (1-MCP) for $24 \mathrm{~h}$ at $20^{\circ} \mathrm{C}$ and stored at $20^{\circ} \mathrm{C}$. Light-red harvested fruits treated with 1-MCP had $56 \%$ lower respiration rate $(3.8 \mathrm{~mL} / \mathrm{kg} / \mathrm{h})$ than untreated fruits on day 1of storage; by day 7 these rates had converged at about $2 \mathrm{~mL} / \mathrm{kg} / \mathrm{h}$. Ethylene production from light-red harvested tomatoes treated with 1-MPC was $24 \%$ lower $(2.3 \mu \mathrm{L} / \mathrm{kg} / \mathrm{h})$ than untreated, with rates converging by day 11 . For full-red harvested tomatoes, 1-MCP had similar effects on respiration and ethylene production, although convergence occurred earlier, by day 5. Fruit harvested at light-red stage had lower soluble solids content $(4.3 \%)$ than fruit harvested at full-ripe stage (5.5\%). In a second test, full-red harvested tomatoes were treated with several combinations of 1 -MCP concentrations $\left(\mu \mathrm{L} \cdot \mathrm{L}^{-1}\right)$ and exposure times (h), namely $1 / 24$, $5 / 6,5 / 12,25 / 6,25 / 12,50 / 6$ or $50 / 12$, and stored at $20^{\circ} \mathrm{C}$. There were no treatment effects on surface and locular gel hue angle (38 and 57 degrees, respectively), pulp soluble solids content $(6.6 \%), \mathrm{pH}(4.3)$, total titratable acidity $(0.65 \%)$ or firmness. Marketable life ( $>15 \%$ of fruits soft, decayed and/or shriveled) for untreated and treated tomatoes was 6 and $7 \mathrm{~d}$, respectively. In a third test, full-red harvested tomatoes were treated with $1 \mu \mathrm{L} \cdot \mathrm{L}^{-1}-\mathrm{MCP}$ for $24 \mathrm{~h}$ at either 13 or $20^{\circ} \mathrm{C}$, stored for 4 $\mathrm{d}$ at $13{ }^{\circ} \mathrm{C}$ then transferred to $20^{\circ} \mathrm{C}$ to simulate commercial practices. Marketable life for 1-MCP untreated and treated tomatoes was 7 and $8 \mathrm{~d}$, respectively; treatment temperature had no effect.

(96) 1-Methylcyclopropene (MCP) Does Not Influence Physiological Peel Disorder and Decay Development in White 'Marsh' Grapefruit

Huating Dou*1, Mark Ritenour ${ }^{2}$, Shelley Jones ${ }^{1}$

${ }^{1}$ Citrus Research \& Education Center, FL Dept. of Citrus, 700 Experiment Station Road, Lake Alfred, FL, 33850, ${ }^{2}$ University of Florida, Indian River Research and Education Center, 2199 S. Rock Road, Ft. Pierce, FL, 34945

The effect of MCP on postharvest pitting (PP), chilling injury (CI), and decay development of various citrus cultivars has been studied in our laboratory since 1998. The results of studies using white 'Marsh' grapefruit are presented here. Grapefruit were harvested early, mid and late season and handled under simulated commercial conditions. All storage conditions had $92 \% \mathrm{RH}$. Early-season fruit were treated with five different MCP concentrations $(0,5,50,500$, and $5000 \mathrm{ppb})$ at 22 ${ }^{\circ} \mathrm{C}$ for 7 hours. Fruit exposed to $5000 \mathrm{ppb}$ MCP and then stored 4 weeks at $22^{\circ} \mathrm{C}$ had increased decay compared to the control, but the development of PP was not affected. There was also no effect of MCP on the development of $\mathrm{CI}$ on fruit stored at $4{ }^{\circ} \mathrm{C}$ for 2 months. Mid-season fruit were exposed to air or air plus 5000 or $10000 \mathrm{ppb} \mathrm{MCP}$ for 7 hours at 22 ${ }^{\circ} \mathrm{C}$. Compared to the control, MCP treatments resulted in no significant differences in decay development or $\mathrm{CI}$ when fruit were stored at $4{ }^{\circ} \mathrm{C}$. However, $\mathrm{PP}$ was higher in $\mathrm{MCP}$-treated fruit stored at $22^{\circ} \mathrm{C}$ compared to the control. In late-season fruit exposed to air or air plus $1000 \mathrm{ppb}$ $\mathrm{MCP}$ and then washed and waxed with shellac or carnauba waxes, there were no differences in $\mathrm{CI}$ or decay when fruit were stored at 4
${ }^{\circ} \mathrm{C}$, and no differences in PP and decay when fruit were stored at $22^{\circ} \mathrm{C}$. Generally, MCPapplication did not reduce fruit peel disorder incidence.

(97) Comparison of 1-Methylcyclopropene and Controlled Atmosphere for Maintaining Quality of Apples During Refrigerated Storage and Subsequent Marketing

Elizabeth Baldwin*1, Jinhe Bai ${ }^{2}$, James Mattheis ${ }^{3}$, Jeffrey Brecht ${ }^{4}$

${ }^{1}$ Citrus \& Subtropical Products Laboratory, USDA/ARS, 600 Ave. S N.W., Winter Haven, FL, 33881, ${ }^{2}$ Horticulture, University of Florida, 1207 Fifield Hall, University of Florida, Gainesville, FL, 32611, ${ }^{3}$ Tree Fruit Research Laboratory, USDA/ARS, 1104 N. Western Ave, Wenatchee, WA, 98801, ${ }^{4}$ Horticulture, University of Florida, 1207 Fifield Hall, Gainesville, FL, 32611

Apples ('Gala', 'Delicious', 'Granny Smith', and 'Fuji') +/ pretreatment with 1-methylcyclopropene (1-MCP, $18 \mathrm{~h}$ at $\left.0.6251 .0 \mu \mathrm{L} \cdot \mathrm{L}^{-1}\right)$ were stored in controlled atmospheres $\left(\mathrm{CA}: 1-1.5 \mathrm{kPa} \mathrm{O}_{2} ; 1-2 \mathrm{kPaCO}_{2}\right.$ ) or in regular atmosphere (RA) for up to 8 months at $1^{\circ} \mathrm{C}$. Firmness, titratable acidity (TA), soluble solids (SS), and volatiles analyzed via gas chromatograph (GC), and electronic nose ('Gala' only) were monitored every month directly or after transfer to air at $20^{\circ} \mathrm{C}$ for 1 week to simulate marketing conditions. CA and/or 1-MCP + RA treatments delayed ripening and prolonged storage life as indicated by decreasing loss of firmness and TA in all four varieties during storage. CA and/or 1-MCP + RA also slightly decreased the loss of SS for 'Gala' but had no effect on the other varieties. There were differences among treatments for firmness and levels of TA (1-MCP + RA > CA) for 'Gala', 'Delicious' and 'Granny Smith' apples (especially after transfer of fruit to $20^{\circ} \mathrm{C}$ ), however, the reverse was found for 'Fuji' . A combination of $1-\mathrm{MCP}+\mathrm{CA}$ was best (1-MCP + CA > 1-MCP + RA or CA) for maintaining 'Delicious'firmness and acidity. CA and 1-MCP inhibited 'Gala' volatile production similarly at low temperature, but the effect of 1-MCP was greater at room temperature. Canonical discriminant analysis of electronic nose data separated the storage treatments (1-MCP + CA, 1-MCP + RA, CA, RA), indicating that the volatile profiles were different in fruit from each treatment (confirmed by GC analysis). The differences in volatile profiles by treatment increased with increasing storage time, and especially after transfer to $20^{\circ} \mathrm{C}$. For inhibition of 'Gala' volatile production, $1-\mathrm{MCP}+\mathrm{CA}>1-\mathrm{MCP}+\mathrm{RA}$ or CA. Therefore, 1-MCP + RA was the best treatment for storing 'Gala' apples with minimal loss of volatiles, while maintaining firmness and acidity. The results indicate that the efficacy of 1-MCP and $\mathrm{CA}$ in maintaining apple quality factors is variety dependent based on one season's data.

(98) Quality Changes During Refrigerated Storage of Araza Fruit Treated with 1-MCP

Maria Hernandez ${ }^{* 1}$, Lina Gallego ${ }^{1}$, Jaime Barrera ${ }^{1}$,

Orlando Martinez ${ }^{2}$, Juan Pablo Fernandez-Trujillo ${ }^{3}$

${ }^{1}$ Instituto Amazonico de Investigaciones Cientificas SINCHI, , Bogota, 02, Colombia, ${ }^{2}$ Genetics Institute, Universidad de los Andes, Carrera 1ENo18-20, Bogota, 02, Colombia, ${ }^{3}$ Dept. of Agricultural \& Food Engineering, Universidad Politecnica de Cartagena-España, Paseo Alfonso XIII. ETSIA (Edif. Agrónomos). 30203, Cartagena, Murcia, 30203, Spain

Arazá fruit harvested at two maturity stages (green mature and mature) in Caquetá (Colombia) were treated according with manufacturer's instructions with 0 (control in air) or $1000 \mathrm{ppb} 1-\mathrm{MCP}$, either for 1 or 6 hours at $20^{\circ} \mathrm{C}$. The fruit were stored at $10^{\circ} \mathrm{C}$ and $90 \% \mathrm{RH}$ to determine the effect of 1-MCP treatment on quality parameters (weight loss, respiration rate, firmness, skin colour, juiciness, anthracnose, shrivelling and skin scald). Fruit were inspected after 1 or 2 weeks at $10^{\circ} \mathrm{C}$ with or without a shelf life period ( 3 days at $20^{\circ} \mathrm{C}$ and $70 \% \mathrm{RH}$ ). 1-MCP delayed respiration rate and colour changes in green mature fruit treated for 1-hour, although shrivelling and skin scald were unaffected by the treatment. When extending 1-MCPexposure for 6 hours in mature green fruit, the treatment also delayed other ripening associated events as 
flesh softening but differences were not significant to privilege longer exposures. Mature fruit showed higher weight loss compared with green mature fruits irrespective of duration of exposure to 1-MCP, and similar quality loss in terms of anthracnose, skin scald, and shrivelling. These results confirm that $1 \mathrm{MCP}$ preserved araza fruit quality particularly when harvested in a green mature stage. However, noticeable weight loss, softening and anthracnose developed after 1 week of storage particularly in mature fruit or after a shelf-life period. This fact limits the use of 1-MCP treatments alone for prolonging storage life of arazá fruit without coadjutants as modified atmosphere packaging.

(99) Variation in Apple Flavonoid Levels During Cold Storage in Relation to Harvest Maturity and 1-MCP Treatment

Dan MacLean*1, Dennis Murr ${ }^{1}$, Jennifer DeEll ${ }^{2}$

${ }^{1}$ Dept. of Plant Agriculture, Bovey Building, Univ. of Guelph, Guelph, Ontario, N1G 2W1, Canada, ${ }^{2}$ Plant Agriculture, Ontario Ministry of Agriculture and Food, HES, Box 587, Simcoe, Ontario, N3Y 4N5, Canada

The ethylene antagonist 1-methylcyclopropene (1-MCP) was investigated for its potential impact on the synthesis of beneficial flavonoid compounds in apples during storage. Numerous anthocyanins, flavonols, flavan-3-ols and hydroxycinnamic acids in skin tissues of 'Empire', 'Delicious' and 'McIntosh' apples from three different harvest maturities treated with $1.0 \mu \mathrm{L} \cdot \mathrm{L}^{-1} 1$-MCP were monitored using LC/DAD analysis during a 120 -day storage period in air at $0-1{ }^{\circ} \mathrm{C}$. 'Delicious' fruit contained the highest content of total flavonoids (including simple phenols) with $4602 \mu \mathrm{g} \cdot \mathrm{g}^{-1} \mathrm{f}$.w., followed by 'McIntosh' red and green tissues at 3380 and $2551 \mu \mathrm{g} \cdot \mathrm{g}^{-1}$ f.w., respectively, and finally 'Empire' with $2340 \mu \mathrm{g} \cdot \mathrm{g}^{-1}$ f.w.. Cyanidin 3-galactoside was the predominant anthocyanin, accounting for approximately $90 \%$ of the total anthocyanin content. It varied with harvest maturity and duration of storage, but not with 1-MCP treatment. Flavonol levels varied significantly with harvest maturity, but remained relatively stable for the duration of the storage period, and were also unaffected by 1-MCP treatment. Red skin tissue of 'McIntosh' had a nearly 3-fold greater content of total flavonols when compared to green skin tissue from the same fruit. Flavan-3-ol content varied significantly with storage duration, but was unaffected by maturity or 1-MCP treatment. Total chlorogenic acid content varied significantly with removal time from storage, but did not vary with maturity or 1-MCP treatment. Treatment with 1-MCP had no apparent beneficial nor detrimental effect on flavonoid metabolism in apple tissues. Therefore, it did not compromise the potential human health benefit obtained from consuming these groups of compounds found in apples.

(100) Lipase Activities and Phospholipid Degradation in Watermelon (Citrullus lanatus) Fruit Exposed to Ethylene and 1-Methylcyclopropene

Lin-Chun $\mathrm{Mao}^{1}$, Yasar Karakurt ${ }^{1}$, Donald Huber*2

${ }^{1}$ Horticultural Sciences Department, University of Florida, 1213 Fifield Hall, PO Box 110690, Gainesville, FL, 32611, ${ }^{2}$ Horticultural Sciences Department, University of Florida, PO Box 110690, 1143 Fifield Hall, Gainesville, FL, 32611-0690

The ethylene-induced watersoaking of watermelon (Citrullus lanatus, Matsum and Nakai) fruit involves the up-regulation of a number of genes and the accumulation of several classes of hydrolases targeting membranes and cell walls. Electrolyte leakage is an early response to ethylene, occurring prior to detectable changes in cell wall metabolism. In this study, we investigated the involvement of phospholipase C(PLC), phospholipase D (PLD), and lipoxygenase (LOX), and analyzed phospholipids and phospholipid degradation products in ripe watermelon fruit exposed to $50 \mu \mathrm{L} \cdot \mathrm{L}^{-1}$ ethylene. Water soaking symptoms were observed by the second day of ethylene exposure, and were accompanied by increased activities of PLC (13.8\%), PLD (21.5\%) and LOX (10.0\%), an increase (26.3\%) in phosphatidic acid (PA), and decreases in phosphatidylcholine (17.8\%) and phosphatidylinositol (22.5\%). PLC and LOX activities, and PA and diacylglycerol (DAG) levels, changed little during 8 days storage in air. The inductive role of ethylene in the enzyme increases (PLC, PLD, LOX) was investigated by treating fruit with 1-methylcyclopropene (1-MCP) at $5 \mathrm{ppm}$ for $18 \mathrm{~h}$ prior to ethylene exposure. 1-MCP completely prevented water soaking in fruit exposed to $50 \mu \mathrm{L} \cdot \mathrm{L}^{-1} \mathrm{C} 1$ ethylene for as long as 8 days. Increases in PLC, PLD and LOX activities were suppressed by $50 \%$ to $75 \%$ in 1-MCP-treated fruit. Watersoaking was noted to occur sporadically in watermelon fruit stored for prolonged periods (2-3 weeks) in air, and in each case the affected fruit had produced transient, elevated levels of ethylene. These results, along with the observed prophylactic effects of 1-MCP, suggest that watersoaking in watermelon fruit is an ethylene-dependent phenomenon involving, in part, enhanced phospholipid hydrolysis and peroxidation. The ensuing membrane damage likely contributes to turgor loss, efflux of cytosolic fluid into the apoplast, and accelerated cell wall degradation, culminating in the development of watersoaking.

(101) Characterization of Ethylene-responsive Genes in Ripe Watermelon (Citrullus lanatus) Fruit

Yasar Karakurt ${ }^{1}$, Donald Huber*2

${ }^{1}$ Horticultural Sciences Dept., Univ. of Florida, 1213 Fifield Hall, PO Box 110690, Gainesville, FL, 32611, ${ }^{2}$ Horticultural Sciences Dept., Univ. of Florida, PO Box 110690, 1143 Fifield Hall, Gainesville, FL, 32611-0690

Watermelon fruit demonstrate acute symptoms of softening and water soaking following short periods of exposure to ethylene. mRNA differential display strategy was utilized to isolate and characterize genes associated with the ethylene-induced disorder. Watermelon fruit were harvested at the full-ripe stage and exposed to 50 micro L/L ethylene for $12 \mathrm{~h}$, and 1,3 and 6 days at $20 \mathrm{C}$. DNA-free total RNA ( 0.2 micro $\mathrm{g}$ ) isolated from fruit treated with air or ethylene for $24 \mathrm{~h}$ was reverse transcribed using three different one-base-anchored oligo dT primers. High stringency PCR was performed using eight different 18-mer arbitrary primers in combination with the flourescent-labeled one baseanchored oligo dT primers. The PCR fluorescent-labeled products were separated on a $6 \%$ polyacrylamide sequencing gel and differentially expressed bands were isolated. Confirmation of true positive bands was performed by Northern blotting. The comparison of mRNA transcripts between ethylene- and air-treated fruit revealed that 78 genes were differentially expressed, of which 15 partial cDNAs were isolated and characterized. BLAST search results revealed significant homologies to ethylene biosynthesis and signal transduction pathway genes, allene oxide synthase, radical scavenging enzymes, hydroperoxide lyases, expansin, and ATPases. Northern blot analysis of RNA isolated from air- and ethylene-treated fruit stored for $12 \mathrm{~h}, 1,3$ and 6 days with a probe of the partial cDNAs revealed a high level of expression of each of the corresponding genes in ethylene-treated fruit. The data are consistent with the view that softening and water soaking of ethylenetreated watermelon fruit involve a rapid up-regulation of oxidative and hydrolytic enzymes targeting membranes and cell walls.

(102) Inhibition of Ethylene Action in Cherimoya Fruit is Effective in Blocking Autocatalytic Ethylene Production and Prolonging Postharvest Life

Julio Retamales ${ }^{1}$, Bruno Defilippi*2, Daniel Manriquez ${ }^{3}$, Reinaldo Campos ${ }^{1}$

${ }^{1}$ La Platina, Institute for Agricultural Research, INIA-Chile, Casilla 439/3, Santiago, P.O. Box 439/3 Santiago, Chile, ${ }^{2}$ Department of Pomology, University of California-Davis, One Shield Avenue, Davis, CA, $95616,{ }^{3}$ Biotechnologie, ENSAT/INP, Toulouse, France, P.O. Box 439/3, Santiagos, P.O. Box 439/3, Chile

Inhibition of ethylene action in fruits has been carried out within the framework of a research project (FONDECYT 1010258) in Chile. Two trials in consecutive years (2000 and 2001) were conducted on Concha Lisa cherimoya (Annona cherimoya Mill.) fruit by applying 1-methylcyclopropene (1-MCP), an ethylene action inhibitor. Fruit were applied right after harvest with 1-MCP at different concentrations $(0$, 
600 , and $1200 \mathrm{ppb}$ in the first year; $0,75,150,300$, and $600 \mathrm{ppb}$ in the second year). Fruit was stored at $10{ }^{\circ} \mathrm{C}$ followed by shelf life periods at $20^{\circ} \mathrm{C}$, evaluating fruit firmness, soluble solids content, titratable acidity, peel color, ethylene production and respiration together with development of physiological disorders and weight loss. Inhibition of ethylene action by 1-MCP resulted in marked effects according with the applied dosage, with fruit showing reduced autocatalytic ethylene production, respiration and softening, both during cold storage and in shelf life. High incidence of decay and senescence limited postharvest life in cherimoya and could be effectively controlled by 1-MCP. Thus, fruit treated with 1-MCP could be stored for 21 and 28 days in 2000 and 2001, respectively, allowing subsequent shelf life and ripening, while fruit from control treatment was already in advanced ripeness at 21 and 14 days and could not withstand any further shelf life after such periods.

(103) Modulation of Nitric Oxide-Induced Flower Abscission and Senescence in Cut Racemes of Big Bend Bluebonnet by Sucrose and 1-MCP

Narendra Sankhla, Wayne Mackay*, Tim Davis

TAES-Dallas, Texas A\&M Univ., Dallas, 17360 Coit Rd., Dallas, TX, 75252-6599

Nitric oxide (NO*) is an endogenously produced highly bioactive molecule in plants. It has been suggested that $\mathrm{NO}^{*}$ acts as a natural senescence-delaying growth regulator and a part of its action are mediated via ethylene metabolism. Therefore, $\mathrm{NO}^{*}$ may have potential for extending the storage and marketing life of flowers, vegetables and fruits. Herewith, we report the effects of $\mathrm{NO}^{*}$ on parameters related to postharvest performance of cut racemes of a Lupinus havardii Wats. cultivar Texas Sapphire (TS) and advance breeding line Blue Select (BS). Freshly prepared sodium nitroprusside (SNP) solution (10-200 M) was used as the source of NO*. In TS, SNP presence affected both flower abscission and senescence. Relatively low concentrations of SNP (10-20 M) promoted flower abscission, while higher concentrations $(>50$ $\mathrm{M}$ ) induced flower senescence. In contrast to TS, the cut racemes in BS show very little abscission. Therefore, in BS only flower senescence was promoted by SNP. Early visible signs of flower senescence were reflected in the change of the color of the banner spot from light yellow to muddy-brown/black and wilting of the standard petal. Inclusion of sucrose $(2 \%)$ in the vase solution resulted in the reduction of flower abscission caused by SNP and also delayed the change of banner spot color. Similarly, the pretreatment of racemes with either 1-MCP or STS, completely suppressed the induction of flower abscission. Sucrose and 1-MCP/STS additively reduced the response of SNP on flower abscission and senescence.

(104) Role of Ethylene in Regulating Aroma Biosynthesis of Greensleeves Apples

Bruno Defilippi*1, Abhaya Dandekar ${ }^{2}$, Adel Kader ${ }^{2}$

${ }^{1}$ Department of Pomology, University of California-Davis, One Shield Avenue, (Wickson Hall), Davis, CA, 95616, ${ }^{2}$ Department of Pomology, University of California-Davis, One Shield Avenue, Davis, CA, 95616

The role of ethylene on aroma biosynthesis was investigated on apple fruits. In order to demonstrate this role, ethylene production and action were reduced using apple trees lines transformed for suppressing ACC-synthase and ACC-oxidase enzymes activity and an ethylene action inhibitor (1-MCP), respectively. In fruits derived from these treatments, a notorious reduction on ethylene biosynthesis and respiration rate was measured. As expected, results showed differential level of dependence of ripening parameters to ethylene biosynthesis and action revealing either ethylene-non-associated events as acidity and soluble solids, or ethylene-associated events including flesh firmness and aroma production. Regarding aroma production, head space analysis showed a reduction in ester production in the ethylene-suppressed lines and in the fruit treated with two concentrations of 1-MCP. On the other hand, no major differences were measured in alcohol and aldehydes volatiles. In the biosynthetic pathway of aroma compounds, alcohol acyl-CoAtrans- ferase (AAT) activity, a key enzyme in ester biosynthesis, was partially reduced when ethylene biosynthesis and action was affected. On the contrary, no differences were observed in the activity of alcohol dehydrogenase (ADH). These results suggest that the regulatory mechanisms of aroma biosynthesis in apple are under partial ethylene regulation.

(105) Synergestic Effect of Retain $^{\mathrm{TM}}$ and 1-MCP on Internal Ethylene Content, Fruit Firmness and Superficial Scald in 'Cortland' and 'Mcintosh' Apples

Sastry Jayanty*, Melissa Butkiewicz, Katie Schwallier, Phil Schwallier, Randy Beaudry

Horticulture, Michigan State University, A26, PSSB, East Lansing, MI, 48824

ReTain $^{\mathrm{Tu}}$ is a preharvest treatment for apples that inhibits ethylene biosynthesis and slows the rate of maturation, improving harvest management. ReTain $^{\text {Th }}$ delays firmness loss and slows color development. 1-Methylcyclopropene (1-MCP) is a gaseous ethylene action inhibitor applied post-harvest that markedly retard fruit ripening. While most fruit respond well to 1-MCP, 'McIntosh' fruit have exhibited variable and sometimes marginal responses to 1-MCP. The reason for the lack of predictable responses may be related to the accumulation of very high internal ethylene levels in the fruit. We attempted to improve 'McIntosh' response to 1-MCP by inhibiting ethylene accumulation via a pre-harvest application of ReTain ${ }^{\text {Tx }}$. We studied effects of ReTain ${ }^{\text {Tw }}$ and 1-MCP, singly and in combination, on the internal ethylene concentration (IEC) and fruit firmness of 'Cortland' and 'McIntosh' apples harvested on different dates. Evaluations were performed for fruit held up to six months in refrigerated air storage. Both 1-MCP and ReTain ${ }^{\text {Tu }}$ treatments reduced the IEC of stored fruit by 10 - to 100 -fold compared to untreated controls. The combination reduced IEC to a greater extent in 'McIntosh' compared to 'Cortland', resulting in an approximate 1000- to 5000-fold reduction relative to controls. Fruit firmness retention best maintained across all harvest dates for both 'Cortland' and 'McIntosh' apples by the combination treatment. Superficial scald was controlled by 1-MCP and the $1 \mathrm{MCP}+\operatorname{ReTain}^{\mathrm{Tu}}{ }^{\text {combination treatments but not by ReTain }}{ }^{\mathrm{Tu}}$ alone.

1:00 pm-2:00 pm POSTER SESSION 50

Ballroom A

(Location numbers for the posters within the Poster Viewing Area are in parenthesis)

\section{Herbs, Spices, and Medicinal Plants}

\section{(336) Callus Induction in Origanum Species}

Houchang Khatamian*, Mustafa Ozden

Horticulture Forestry and Recreation Resources, Kansas State University, 2021 Throckmorton Hall, Manhattan, Kansas, 66506

Oregano is one of the commercially important medicinal plants in the world. Oregano oil has antibacterial, antifungal, antimicrobial, and antioxidant properties, due to presence of major two phenols (Carvacrol and thymol). Until now, there is no report on callus culture of $O$. hirtum and $O$.onites. The objective of this study was to identify the best explant and media for callus induction of Origanum hirtum and $O$. onites. The explants (leaf-base, nodal, stem, cotyledon, hypocotyl, and root segments) were cultured onto Gamborg's B5 or Murashige and Skoog (MS) medium supplemented with 2,4-D, and TDZ individually and in various combinations of 2,4-D with kinetin. The best explant for callus induction was leaf-base section for both Origanum species. The best medium for callus formation and proliferation for $O$. hirtum was MS or B5 medium containing $0.01 \mathrm{mg} / \mathrm{L} \mathrm{TDZ}$. Also, the best callus formation and proliferation for $O$. onites was obtained with MS or B5 medium containing $1 \mathrm{mg} / \mathrm{L} 2,4-\mathrm{D}+0.5 \mathrm{mg} / \mathrm{l}$ kinetin. During subcultures of the calli, an apparent build-up of phenols caused brown necrotic areas on upper and lower sides of the callus. This browning of the cell inhibited callus growth, later it extended over the entire surface of the callus, and led to callus decline and death. To control oxidation caused by phenols, ascorbic acid (vitamin C) and Polyvinyl-pyrrolidone (PVP) were added to liquid cultures. Callus growth of Origanum species was responded 
well in liquid culture. Unlike that of $O$. onites, addition of vitamin C to liquid culture, prolonged the callus growth of $O$. hirtum.

\section{(337) Freeze Damage to North American Ginseng}

Jan Schooley ${ }^{1}$, John T.A. Proctor*2

${ }^{1}$ Agr. and Rural Division, Ont. Ministry of Agr and Food, Hwy.3 / Blueline Rd., Simcoe, Ontario, N3Y 4N5, Canada, ${ }^{2}$ Plant Agr., Univ. of Guelph, Bovey Bldg., Univ. of Guelph, Guelph, Ontario, N1G 2W1, Canada

The Lake Erie counties of southern Ontario, Canada are the major producers of ginseng in North America. In this area there is about 1740 ha of ginseng and an annual production of $1455 \mathrm{t}$. Spring freeze damage to the crop is rare as the mean date of last freeze in spring is May 12. On May 21, 2002, following 3 to 6 nights when air temperatures dropped below freezing, extensive damage to the crop was evident. A survey by the Ontario Ginseng Growers Association showed that $78 \%$ of growers had gardens showing freeze damage. The extent of the damage was variable across the growing area, and on individual farms. Most damage to plants occurred in low-lying areas where heavy cold air collected. Recently germinated plants (seedlings) that were exposed above the straw mulch were severely damaged, and many did not survive because they did not have leaves and no perennating bud was formed. Damage to two-year-old plants was expressed as leaves wilting and turning black. In some cases stems froze and the plants toppled. In three-year-old, and older plants, damage was very variable with some leaf collapse and stems broken, or damaged with corking-over taking place. Damage to inflorescences ranged from death and abscission, to distorted flowers and shriveled and split peduncles. Plant health was a concern following the freeze episode, and throughout the subsequent growing season. The fungicide Elevate (fenhexamid) received emergency registration to combat recurring problems in Botrytis control. The seed crop for 2002 was light. Damaged seedling gardens were replanted. Older gardens will undergo a period of adjustment. Crop yield in 2002 was reduced by $30 \%$, a $500 \mathrm{t}$ loss. The full extent of the damage and associated financial implications are unknown and could impact the industry until 2005.

\section{(338) Genetic Variability of an Endangered Medicinal Plant, Hydrastis canadensis L.}

\section{Kerry J. Kelley ${ }^{1}$, Amy Frary ${ }^{2}$, Lyle Craker*1}

${ }^{1}$ Plant and Soil Sciences, University of Massachusetts-Amherst, Stockbridge Hall, Amherst, MA, $01003,{ }^{2}$ Biological Sciences, Mount Holyoke College, Clapp Lab, South Hadley, MA, 01075

Hydrastis canadensis L. (goldenseal) is an endangered species of perennial wildflower native to eastern North America and is harvested for its root that contains the alkaloids berberine, hydrastine and canadine. Studies have shown this herb to have anti-inflammatory, antibiotic and anti-pyretic effects. Today, the number of wild goldenseal populations is on the decline, to the point of extirpation in some states, thought to be largely due to over-harvesting and exacerbated by the plant's reproductive strategy. Goldenseal reproduces by both vegetative and sexual means. Juvenile plants reproduce clonally and it takes two to three years for a plant to reach sexual maturity. At this stage the root is considered large enough to harvest. Thus, as wild harvesters collect mature plants, the probability of sexual reproduction is reduced. Consequently, it is thought that there is little genetic diversity within those wild populations that are subject to wild harvesting on a regular basis. Understanding germplasm diversity is critical for crop improvement and breeding programs for endangered species. This information also helps conservation efforts by offering data that can support preservation of habitat, collection monitoring and genetically sound reintroduction strategies. In this study we analyzed several populations of Hydrastis canadensis for genetic diversity within and among populations. The samples are from cultivated populations in Kentucky, Massachusetts, New York and Canada and wild populations from Kentucky, Ohio, West Virginia and New York. We used the Random Amplified Polymorphic
DNA (RAPD) analysis technique to generate DNA profiles from our samples and to estimate genetic relatedness among and between populations. RAPD analysis is a relatively simple technique and offers the ability to compare numerous sites within the genome with just a few primers. The results for the cultivated material show $72-86 \%$ similarity among the populations tested and the similarity for the wild populations of 20-67\%. These numbers are in line with expected results when comparing a clonaly propagated group with the wild type.

\section{(339) Growth and Podophyllotoxin Content of Mayapple Under Sun or Shade}

Kent Cushman*1, Muhammad Maqbool ${ }^{1}$, Ebru Bedir², Ikhlas Khan ${ }^{2}$, Rita Moraes ${ }^{2}$

${ }^{1}$ North Mississippi Research \& Extension Center, Mississippi State University, 5421 Hwy 145 S, Verona, MS, 38879, ${ }^{2}$ National Center for Natural Products Research, University of Mississippi, Thad Cochran Research Center, University, MS, 38677

Leaves of American mayapple contain podophyllotoxin, a compound used as a precursor of several pharmaceuticals. We are investigating domestication of this species as a source of podophyllotoxin and its potential as a crop for growers of medicinal herbs. Mayapple rhizome segments were harvested from a single colony of plants in the wild and transplanted into raised beds in Fall 2001. Sunlight exclusion treatments of $0 \%, 30 \%, 55 \%$, and $80 \%$ shade were tested in a randomized complete block design with four blocks and 20 rhizome segments per experimental unit. Shade treatments were applied on 27 Mar. 2002, at the time of shoot emergence. Data were collected for air and soil temperatures, shoot longevity (days from emergence to senescence), leaf area, leaf dry mass, and lignan content (podophyllotoxin, $\alpha$-peltatin and $\beta$-peltatin). Air and soil temperatures were slightly higher under $0 \%$ and $30 \%$ shade than $55 \%$ and $80 \%$ shade. Shoot longevity and leaf area increased in the following order: $0 \%<30 \%<80 \%$ shade, with $55 \%$ shade equal to that of $30 \%$ shade. Leaf dry mass was lowest for $0 \%$ shade and similar for $30 \%, 55 \%$, and $80 \%$ shade. Podophyllotoxin content $\left(\mathrm{mg} \cdot \mathrm{g}^{-1}\right)$ of leaves under $0 \%$ shade was higher than that of $30 \%$ or $80 \%$ shade. Podophyllotoxin content of leaves under $55 \%$ shade was similar to that of $0 \%$ and $30 \%$ shade and higher than that of $80 \%$ shade. Podophyllotoxin yield $\left(\mathrm{mg} \cdot \mathrm{m}^{-2}\right)$ of leaves under $0 \%$ and $55 \%$ shade was similar to that of $30 \%$ shade and higher than that of $80 \%$ shade. Podophyllotoxin yield of leaves under $30 \%$ shade was similar to that of $80 \%$ shade. $\beta$-peltatin content was higher at $0 \%$ shade than at $30 \%, 55 \%$, or $80 \%$ shade. Shade did not affect $\alpha$-peltatin content. Generally, these data indicate that when grown under increasing levels of shade mayapple shoots produce leaves of increasing size, mass, and longevity and of decreasing podophyllotoxin content.

\section{(340) Isolation and Purification of Crucifer Glucosinolate Degradation Products}

\section{Steven Vaughn*, Mark A. Berhow}

National Center for Agricultural Utilization Research, USDA, ARS, 1815 North University Street, Peoria, IL, 61604-3902

The crucifer family, Brassicaceae, is an economically important family for its many food crops. Crucifers are characterized by the presence of a group of secondary compounds called glucosinolates, which with their degradation products are primarily resonsible for the characteristic aromas and flavors of crucifers. Glucosinolate degradation products include substituted isothiocyanates, nitriles, thiocyanates, epithionitriles and oxazolidinethiones, which vary depending on the plant species studied, side-chain substitution, cell $\mathrm{pH}$ and cell iron concentration. Many of these degradation products have biological activity ranging from insect attractants to suspected human health benefits, but are not commercially available. We have developed methods for isolation and purification of several of these degradation products, including the isothiocyanates erucin, iberin, cheirolin, hesperin, and lesquerellin (as well as most of the corresponding nitriles) using seed from several different genera within the Brassicaceae as the source of parent glucosinolates. 
By manipulating seed source, reaction conditions (e.g. temperature, $\mathrm{pH}$ ) and through solvent partitioning, relatively pure $(>95 \%)$ compounds can be isolated without necessitating any chromatographic separation.

(341) Mulch Type, Mulch Depth, and Rhizome Planting Depth for Field-grown Mayapple

Muhammad Maqbool*, Kent Cushman

North Mississippi Research \& Extension Center, Mississippi State University, 5421 Hwy 145 S, Verona, MS, 38879

Leaves of American mayapple contain podophyllotoxin, a compound used as a precursor of several pharmaceuticals. We are investigating domestication of this species as a source of podophyllotoxin and its potential as a crop for growers of medicinal herbs. Mayapple rhizome segments were harvested from a single colony of plants in the wild and transplanted into raised beds in Fall 2001. Two types of organic mulch (bark or wheat straw), two depths of mulch ( 8 or $16 \mathrm{~cm})$, and two planting depths of rhizome segments $(0$ or $5 \mathrm{~cm})$ were examined. The experimental design was a randomized complete block with four blocks, using a $2 \times 2 \times 2$ factorial arrangement of treatments and 12 rhizome segments per experimental unit. Data were collected for air and soil temperatures, shoot emergence, leaf area, leaf dry mass, weed species, weed dry mass, and retention of mulch depth. The combination of $16 \mathrm{~cm}$ of bark mulch and $5 \mathrm{~cm}$ planting depth provided rhizomes far greater insulation from fluctuations in air temperature than the combination of $8 \mathrm{~cm}$ of straw mulch and 0 $\mathrm{cm}$ planting depth. All other combinations were intermediate between these two treatments. There was an interaction between mulch type and planting depth for shoot emergence, with fewer shoots arising from straw in combination with $0 \mathrm{~cm}$ planting depth than from any other combination of mulch type and planting depth. Plant growth (shoot emergence, leaf area, leaf dry mass, and plant height) was not affected by mulch depth. Regardless of mulch type, shoots arising from rhizomes planted $5 \mathrm{~cm}$ deep produced more leaf area and leaf dry mass than those planted $0 \mathrm{~cm}$ deep. There was an interaction between mulch type and planting depth for shoot height. Shoots arising from bark, regardless of planting depth, were taller than those arising from straw. With straw, however, shoots arising from rhizomes planted 5 $\mathrm{cm}$ deep were taller than those planted $0 \mathrm{~cm}$ deep. Straw performed better than bark for weed control of grass species and for retaining mulch depth over time. Overall, plant growth was superior with $5 \mathrm{~cm}$ planting depth than with $0 \mathrm{~cm}$ planting depth. Bark was only slightly better than straw for plant growth, but straw was slightly better than bark for weed control and retention of mulch depth.

\section{(342) Phenological Growth Stages of North American Ginseng}

John T.A. Proctor*1, Martine Dorais ${ }^{2}$, Hermann Bleiholder ${ }^{3}$

${ }^{1}$ Plant Agr., Univ. of Guelph, Bovey Bldg., Univ. of Guelph, Guelph, Ontario, N1G 2W1, Canada, ${ }^{2}$ Centre de Recherche en Hort., Laval Univ., Pavillion de l'Environtron, Laval Univ, Quebec, Quebec, G1K 7P4, Canada, ${ }^{3}$ Basf Ag, Limburgerhof, Carl-Bosch-Str. 64, D-67117, Limburgerhof, LI 444, Germany

Work is underway to evaluate and conserve native ginseng germplasm and to conserve, evaluate and use germplasm found in cultivation. A first step in this work will be to identify highly heritable phenotypic markers such as phenological events (e.g. shoot emergence and flowering periods). Also, a major constraint to ginseng production is the prevalence of pests, particularly fungal diseases. A description of the developmental stages of ginseng would be useful in recording phenological events, in making pest control recommendations and in the timing of cultural practices. The $\mathrm{BBCH}$ (Biologische Bundesanstalt, Bundessortenamt, Chemische Industrie) scale is used to describe the phenological growth stages of North American ginseng (Panax quinquefolius L.). Eight principal growth stages for germination and bud development, leaf development (crop cover), root and perennating bud formation, peduncle elongation and inflorescence development, flowering and fruit set, development of fruit, ripening of fruit and senescence, and 42 secondary growth stages are described. A practical use of the scale is proposed with reference to the timing of application of agrochemicals for disease control.

\section{(343) Soil Applied Calcium Influences Growth, Root Yield, and Alkaloid Content of Goldenseal}

Jeanine M. Davis*

Horticultural Science, North Carolina State University, Mountain Horticultural Crops Research and Extension Center, 455 Research Drive, Fletcher, NC, 28732

Goldenseal (Hydrastis canadensis L.) is a highly valued North American forest botanical that has traditionally been collected from wild populations. The increasing popularity of goldenseal root as an herbal medicine and food supplement threatens the continued existence of wild goldenseal, particularly in public forests. Cultivation of goldenseal is now encouraged but little research has been done on the most efficient and effective ways to do this. As a result, many growers follow production recommendations for ginseng to grow goldenseal. Recent research shows that ginseng growth and root yield is best in soils with high calcium levels. This study was conducted to determine how goldenseal would respond to increasing levels of calcium. Three treatments of 0,2802 , and $5605 \mathrm{~kg} \cdot \mathrm{ha}^{-1}$ of calcium were applied in the form of gypsum to the soil surface of beds containing established goldenseal plants. The gypsum was incorporated into the top 3 to 5 centimeters of soil and then covered with hardwood bark mulch. Data were collected for three years on plant survival, plant growth and health factors, disease incidence, slug damage, and fruiting. Each growing season, plants were less vigorous and foliage color was lighter with the highest calcium rate compared to the no calcium treatment. Incidence of foliar diseases and slug damage increased dramatically with increasing calcium but plant survival, plant height, and leaf size were unaffected. After three seasons of growth the roots were harvested and dried. Root fresh weight and dry weight decreased as the soil calcium rate increased. Root alkaloid content was also affected. This study suggests that cultivated goldenseal will not benefit from additional soil calcium.

\section{1:00 pm-2:00 pm POSTER SESSION 51}

Ballroom A

(Location numbers for the posters within the Poster Viewing Area are in parenthesis)

\section{Postharvest-Cross-commodity}

(112) Chlorophyll Fluorescence Imaging as a Means to Investigate Citrus Rind Injury Following Postharvest Quarantine Treatments

David Obenland*, Paul Neipp

Postharvest Quality and Genetics, USDA/ARS, 9611 S. Riverbend Ave., Parlier, CA, 93648

Chlorophyll fluorescence in plants has been found to be very sensitive to stress and has been proposed as a means of predicting stress-induced tissue injury. Development of injury to the rind of citrus following postharvest quarantine treatments is often not uniform and may be difficult to assess using standard hand-held fluorometers due to limited coverage of the surface area of the fruit. In this study we have utilized an imaging fluorometer to quantify chlorophyll fluorescence over large surface areas of the fruit to determine the relationship between rind injury induced by high temperature treatment and changes in rind fluorescence. Limes were immersed in $55^{\circ} \mathrm{C}$ water for $0,1,3$ and 5 $\mathrm{min}$ and both sides of the fruit imaged for chlorophyll fluorescence following $24 \mathrm{~h}$ and $1 \mathrm{wk}$ of storage at $5^{\circ} \mathrm{C}$. Following $1 \mathrm{~min}$ of hot water treatment and $24 \mathrm{~h}$ of storage maximum fluorescence yield $\left(\mathrm{F}_{\mathrm{m}}\right)$ dropped by $36 \%$ while after 3 and 5 min $\mathrm{F}_{\mathrm{m}}$ declined by $55 \%$. In contrast, initial fluorescence $\left(\mathrm{F}_{0}\right)$ increased by $26 \%$ after 1 min of treatment and by $60 \%$ following 3 and $5 \mathrm{~min}$. Fluorescence images taken after a 
week of storage indicated that some recovery of $F_{m}$ occurred while $F_{0}$ continued to increase. The ratio of $\mathrm{F}_{0} /\left(\mathrm{F}_{\mathrm{m}}-\mathrm{F}_{0}\right)$ increased most dramatically between 1 and $3 \mathrm{~min}$ and was associated with the occurrence of rind injury in the treated limes.

\section{(113) Biochemical Changes in 'Fuji' Apple Fruit Peel Induced by UV-B Irradiation}

Yiping Gong*, James P. Mattheis

Tree Fruit Research Laboratory, USDA/ARS, 1104 N. Western Ave., Wenatchee, WA 98801

Exposure to ultraviolet-B (UV-B) irradiation in the field or after harvest can induce peel disorders in 'Fuji' apples. Harvested 'Fuji' apples were used to determine if development of peel disorders is accompanied by changes in activity of enzymes involved in oxidative and secondary metabolism. Apples were exposed to UV-B irradiation or held in the dark (control) at $20^{\circ} \mathrm{C}$ for five days then stored at $0{ }^{\circ} \mathrm{C}$ for 90 days to allow development of disorders. Analysis of enzyme activity was conducted at the end of the five day irradiation period. Exposure to UV-B induced development of both stain and sunburn, and irradiated fruit had increased NADH oxidase and NADPH oxidase activities compared to controls. Fruit exposed to UV-B had higher phenylalanine ammonia-lyase (PAL) activity compared to controls, but UV-B exposure did not alter the activity of 4-coumarate: coenzyme A ligase (CL) relative to activity at harvest. Activities of PAL and CL from control fruit were lower and higher, respectively compared to values at harvest. Superoxide dismutase (SOD) activity was not impacted by UV-B irradiation and SOD activity for controls and UV-B irradiated fruit was lower than activity at harvest. Catalase activity in controls and UV-B irradiated fruit increased relative to activity at harvest, but was slightly lower in UV-B irradiated fruit. Treatment of fruit at harvest with the SOD inhibitor N, N,-diethyldithiocarbamate (DE) plus UV-B irradiation resulted in a higher occurrence of sunburn in fruit, but UV-B irradiation alone did not. The occurrence of stain was not affected by DE treatment. The results indicate SOD activity may be important for avoiding UV-B-induced sunburn, while stain is accompanied by enhanced activity of NADH oxidase and PAL and reduced $C L$ activity.

(114) Capsaicinoids Content of Five Hot Pepper Accessions From a Germplasm Bank of the Colombian Amazonic Region

Maria S. Hernandez ${ }^{* 1}$, K. Jaramillo ${ }^{1}$, L. Aponte ${ }^{1}$, L.M. Melgarejo ${ }^{2}$, J. Barrera ${ }^{1}$, J.P Fernandez-Trujillo ${ }^{3}$

${ }^{1} \mathrm{New}$ Technologies, Instituto Amazonico de Investigaciones Cientificas SINCHI, Calle 20 No5-44, Bogota, Cundinamarca, 02, Colombia, ${ }^{2}$ Biology, Universidad Nacional de Colombia-Sede Bogota, Ciudad Universitaria-Biologia, Bogota, Cundinamarca, 02, Colombia, ${ }^{3} \mathrm{De}-$ partment of Agricultural \& Food Engineering, Universidad Politecnica de Cartagena-España, Paseo Alfonso XIII. ETSIA(Edif. Agrónomos)., Cartagena, Murcia, 30203, Spain

The capsaicin and dihydrocapsaicin are key components responsible of flavor of native hot peppers. This work describes the evolution of capsaicinoids during fruit development in five accessions of hot pepper species (Capsicum annuum, Capsicum bacatum and Capsicum chinense, respectively) coming from the amazonic pepper germplasm bank collection from the SINCHI institute. Fruits from all accessions were weekly harvested from set to ripening stage in orchards from Leticia in the Colombian amazonic region. The goal is to assess local growers in order to harvest the fruit with maximum capsaicinoids content similar to commercial varieties. In general, capsaicinoids were more abundant in fruits from $C$. annuum followed $C$. baccatum and $C$. chinense. Concentrations of capsaicin and dihydrocapsaicin increased continuously throughout development and ripening in these accessions under field conditions ranging from 0.72 to $1.63 \mathrm{mg} \cdot \mathrm{g}^{-1}$, and from 0.18 to $0.61 \mathrm{mg} \cdot \mathrm{g}^{-1}$ (on a fresh weight basis), respectively. In C. baccatum a maximum capsaicin content reached after $19 \mathrm{~d}$ of development (around $170 \mathrm{~mm}$ longitudinal diameter) with minimum changes thereafter irrespect of an increase in fruit diameter up to $150 \mathrm{~mm}$. In. C. chinense capsaicinoid levels peaked after $41 \mathrm{~d}$ of development (full ripe fruit, $250 \mathrm{~mm}$ longitudinal diameter). Capsaicin was higher than dihydrocapsaicin in the five accessions, which are in agreement with others hot pepper trends as Habañero and Piquin varieties, commercial varieties ("ajís"), or the Cayenne and Tabasco fruit. In summary, regarding alkaloid content this native chilli peppers harvested in full mature stage of maturity (evaluated by visual color) can be recommended for the hot pepper market.

(115) Changes in L-Phenylalanine Ammonia-lyase Activity and Gene Expression During Storage of Asparagus Spears

PankajKumar Bhowmik*, Toshiyuki Matsui

Dept. of Bioresource Production Science, Faculty of Agriculture, Kagawa Univ., Kita-Gun, Miki-Cho, Ikenobe, Kagawa, 761-0701, Japan

Phenylalanine ammonia-lyase (PAL, EC 4.3.1.5) the first enzyme in the phenylpropanoids metabolism in plants catalyzes the elimination of ammonia from L-phenylalanine to form trans-cinnamic acid. The changes in PAL activity in relation to fiber development in harvested green asparagus were investigated during storage. We held asparagus (Asparagus officinalis L.) spears at $20^{\circ} \mathrm{C}$ up to 48 hours and examined the changes in PAL activity in both top and bottom portions of spears. In both top and bottom portion enzyme activity started to increase after harvest and reached maximum at 24 hour. Thereafter, the level of activity started to decline although the toughness determined as the value of breaking force was still increasing. Both the toughness and PAL activity were found higher in the bottom portion than in the top. Northern blot analysis showed increase level of pAS-PAL mRNA until 24 hour, which coincided well with PAL activity. The increase in fiber content after 24 hours might be due to the activity of other lignin-specific enzymes like peroxidase and cinnamyl alcohol dehydrogenase. Further research is necessary to investigate the role of other lignin-specific enzymes controlling the toughness of asparagus.

(116) Changes in Soluble Sugar Content and Composition of Cell Wall Carbohydrates In Muskmelon (Cucumis Melo L.) Fruit During Development And Senescence

Soo-Hee Kim ${ }^{1}$, Jongkee Kim*11, Won Moon ${ }^{2}$, Yeo-Hoon Kim ${ }^{1}$ ${ }^{1}$ Dept. of Horticulture, Chung-Ang University, Nairi 72-1, Daedukmyun, Ansung, Kyounggi-do, 456-756, Republic of Korea ${ }^{2}$ Dept. of Agriculture, Korea National Open Univ, Dongsoong-dong 169, Chongro, Seoul, 110-791, Republic of Korea

A commercial muskmelon (Var. 'Sunpower') fruit were grown in a plastic film house and harvested every 5 days until 55 days after anthesis(DAA), when a visual sign of fruit abscission in the peduncle was noticed. An increase in ripening-related ethylene production was observed beginning $45 \mathrm{DAA}$ and showed a peak in $50 \mathrm{DAA}$, however, a rapid loss in tissue firmness occurred prior to an increase in total soluble solids content. The concentration of sucrose showed a basal level till 25 DAA, thereafter increased throughout maturation and senescence, ranging 75 to $140 \mu \mathrm{mol}$ per gram fresh weight. On the other hand, the content of glucose and fructose remained fairly high in the middle of the fruit growth and followed by a gradual decrease during maturation and senescence. Compared to these soluble sugars, raffinose and stachyose maintained low levels during fruit development and followed by a sharp upsurge during senescence. During fruit development, there was a slow but steady increase in soluble galactose content in the tissue, followed by a slight decrease during senescence. Composition of cellulose and polyuronides was increased quickly between 0 and 10 DAA, and maintained rather constant during fruit growth, 25 to $30 \%$ for cellulose and 30 to $35 \%$ for polyuronides in cell walls, and followed by a gradual decrease 
during senescence. However, after 10 DAA the amounts of noncellulosic neutral sugars(NCNS) including galactosyl residues, the most abundant sugars, decreased sharply during fruit development and remained relatively unchanged during senescence.

(117) Comparison of Electrolyzed Strong Acidic and Weak Acidic Water on Microbicidal Effect for Fresh-cut Vegetables

Hidemi Izumi*1, Yoshiki Dohi ${ }^{1}$, Motomasa Ohara ${ }^{1}$, Mio Nagano ${ }^{1}$, Nobuo Achiwa ${ }^{2}$

${ }^{1}$ School of Bio-Oriented Sci. \& Tech., Kinki University, 930 Nishimitani, Uchita, Naga, Wakayama, 649-6493, Japan, ${ }^{2}$ Specialized Engineering Development, Hoshizaki Electric Co., Ltd., 3-16 Minamiyakata, Sakae, Toyoake, Aichi, 470-1194, Japan

Ministry of Health, Labor and Welfare of Japan approved electrolyzed strong acidic and weak acidic water as food additives in June 2002. The antimicrobial activities against various bacteria in-vitro and effectiveness as a disinfectant on fresh-cut vegetables in-vivo were compared between electrolyzed strong acidic water $(\mathrm{pH} 2.7,25$ and $50 \mathrm{ppm}$ available chlorine) and weak acidic water ( $\mathrm{pH} 6.5,25$ and 50 ppm available chlorine). Electrolyzed acidic water was produced by electrolysis of $\mathrm{NaCl}$ solution using electrolyzed acidic water generator. The antimicrobial activities of electrolyzed acidic water against gram-negative bacteria ( 4 strains) and gram-positive bacteria ( 2 strains) were investigated. Minimum inhibitory concentration was lower with electrolyzed weak acidic water than with electrolyzed strong acidic water against Enterobacter cancerogenus, Pantoea stewartii, Escherichia coli and Leuconostoc mesenteroides. For bacterial isolates from indigenous microflora of sliced cucumber, both electrolyzed acidic water were more effective against gram-positive bacteria including Staphylococcus spp. than against gram-negative bacteria including Pseudomonas spp.. The effectiveness of electrolyzed strong acidic and weak acidic water as disinfectant was similar when treatment was made by dipping or rinsing sliced cucumber, trimmed spinach leaves and shredded carrots. The treatments reduced the total microbial count by about 1 to $3 \operatorname{logs} \mathrm{CFU} / \mathrm{g}$ relative to non-treated samples. The degree of reduction was dependent on type of fresh-cut vegetables, method of treatment and concentration of available chlorine.

(118) Effect of Naturally Occurring Substances on Postharvest Quality of Raspberries

Chien Wang*

Produce Quality and Safety Laboratory, U. S. Department of Agriculture, Bldg. 002, 10300 Baltimore Ave., Beltsville, MD, 20705-2350

The postharvest quality of raspberries (Rubus idaeus L.) was evaluated after treatment with several natural volatile compounds and storage at 0,10 or $20^{\circ} \mathrm{C}$. At high storage temperature $\left(20^{\circ} \mathrm{C}\right)$, raspberries deteriorated rapidly and none of the natural volatile compounds used were effective in extending storage life of the fruit. At low storage temperature $\left(0^{\circ} \mathrm{C}\right)$, little difference could be discerned among the various volatile treatments. However, at $10^{\circ} \mathrm{C}$ storage, raspberries treated with methyl jasmonate (MJ), allyl isothiocyanate (AITC), tea tree oil (TTO), or absolute ethyl alcohol (AEA) had less decay. MJ- and TTO-treated fruit also maintained higher levels of sugars, organic acids, and oxygen radical absorbance capacity (ORAC) compared to untreated fruit. Samples treated with acetic acid (AA) or vinegar vapor did not differ from control fruit. Measurement of oxygen and carbon dioxide concentrations within the containers during storage revealed that none of the treatments caused accumulation or depletion of these gases to a level that would be harmful to raspberries. Color measurements of the berries showed that all raspberry fruit became darker and less red after storage, but fruit treated with MJ were found to have the highest intensity of red color while AITC application caused the berries to appear lighter in color.
(119) Effect of Sucrose and CPPU on Postharvest Performance of Cut Phlox Inflorescences

Wayne Mackay*, Narendra Sankhla, Tim Davis

TAES-Dallas, Texas A\&M University-Dallas, 17360 Coit Rd., Dallas, TX, 75252-6599

A superior selection of perennial phlox (Phlox paniculata 'John Fanick') bearing attractive and long-lasting flowerhead clusters was recently identified for Texas landscapes. Some of the important parameters affecting postharvest performance are reduced flower abscission, retention of flower color, opening of additional flower buds, and the quality of leaves on the inflorescence axis during vaselife. CPPU ( (2-chloro-4-pyridyl)-N -phenylurea), a non-purine cytokinin type plant growth regulator not only reduced the abscission of flowers, but also significantly enhanced the opening of more flower buds than the control in cut flowerheads of 'John Fanick' phlox. Additionally, as evidenced by visual evaluation of leaf color, analysis of leaf pigments and soluble proteins, CPPU strongly retarded the senescence of leaves. During vaselife of 'John Fanick' phlox, the color of the petals gradually changes from the initial deep pink-white to an overall uniform pale blue or white. Addition of sucrose to the vase solution substantially improved the maintenance of the deep pink-white petal color. CPPU and sucrose, in combination, further improved the display life and longevity of the flowerheads. Previously we observed that thidiazuron, another non-purine type cytokinin, was also highly effective in improving postharvest performance of phlox inflorescences. Overall, these results suggest an important role of phenylurea derivatives and sucrose in postharvest floriculture of phlox.

(120) Effect of Thidiazuron and Abscisic Acid on Flower Abscission and Senescence in Cut Racemes of Big Bend Bluebonnet

Narendra Sankhla, Wayne Mackay*, Tim Davis

TAES-Dallas, Texas A\&M University-Dallas, 17360 Coit Rd., Dallas, TX, 75252-6599

Attractive racemes of Big Bend bluebonnet (Lupinus havardii Wats.) borne on a long axis have shown immense potential as a novel cut flower crop. This study was undertaken to evaluated the effects of thidiazuron (TDZ) and abscisic acid on two key components (viz., flower abscission and senescence) which affect the display life and longevity of cut racemes. Both the naturally occurring [(+)-, trans-] as well as the synthetic $[( \pm)$-cis, trans) $\mathrm{ABA}$, when supplied through the cut raceme axis, promoted flower abscission and to a lesser degree flower senescence in cut racemes. On the other hand, TDZ (5-50 M) positively enhanced the overall functional display of the racemes by substantially reducing the flower abscission and delaying flower senescence. Simultaneous addition of TDZ and ABA in the vase medium, resulted in the reversal of the effect of the latter hormone on display life. The response of ABA was also considerably minimized by AVG and 1-MCP indicating that the ABA response is at least partially mediated by ethylene. We also observed that like 1-MCP, TDZ also prevented the abscission accelerating the effect of CEPA. These results suggest that in bluebonnet, TDZ may also impair ethylene sensitivity, albeit much milder than either STS or 1-MCP.

(121) Field Solar Radiation Influences Expression of Chilling Injury During Postharvest of Tomatoes

Christian Krarup*, Carolina Henriquez, Rodrigo Gonzalez

Depto. Ciencias Vegetales, Universidad Catolica de Chile, Proyecto Fondecyt 1020882, Santiago, 22, Chile

Field solar radiation has been reported to affect development of chilling injury symptoms in various and sometimes contradictory ways in different fruits. There no known reports of the response in tomato. Studies carried out using variable shading in commercial tomato cultivars (Alboran, FA-870, FA-1404, Melissa, R593 and Syta), grown for summer harvest at an intermediate latitude $\left(33^{\circ} 25^{\prime} \mathrm{S} 71^{\circ} 11^{\prime} \mathrm{W}\right)$, indicate 
that incident solar radiation has significant effects on chilling injury expression. After storage of fruits for 18 days at $0^{\circ} \mathrm{C}$, mild to severe symptoms of chilling developed in fruits that grew either completely exposed or shaded with a dark bag in the field, while fruits that grew under a net that allowed passage of about 50\% PAR suffered little or no injury. Although this effect was general, susceptibility of the cultivars to the disorder varied significantly. These results suggest that the effects of solar radiation on chilling injury will probably vary according to cultivar, position of fruits in the plant, and growing season, which could explain some of conflicting reports of the literature.

\section{(122) Intensity and Stability of Color in 'Michigan Purple' Potato}

Elzette Van-Rooyen*, Deirdre Holcroft

Horticulture, Michigan State University, Plant and Soil Sciences Building, East Lansing, Michigan, 48824

The objective of this study was to provide preliminary data on factors affecting the intensity and stability of color in 'Michigan Purple' potato, a new purple-skinned tablestock cultivar bred by Michigan State University. 'Michigan Purple', 'Dakota Rose', 'Norland' and 'California Red' were stored at $10{ }^{\circ} \mathrm{C}$ and hue angle of the skin was measured fortnightly. The hue angle of 'Michigan Purple' increased from $0^{\circ}$ to $13.9^{\circ}$ after 22 weeks of storage while the hue angles of the red-skinned cultivars, 'Norland', 'Dakota Rose' and 'California Red', increased by $7.2^{\circ}, 4.8^{\circ}$ and $4.3^{\circ}$, respectively. Hence, the rate of loss was greater in 'Michigan Purple' although all the cultivars in this experiment lost color during storage. We found no clear correlation between intensity of color (hue angle) and size of 'Michigan Purple' potatoes within the range of $70 \mathrm{~g}$ to $307 \mathrm{~g}$. The rate of color loss was similar in 'Michigan Purple' potatoes grown in either muck or mineral soils and stored at $10^{\circ} \mathrm{C}$ for 22 weeks, despite very different initial hue angle values $\left(350^{\circ}\right.$ and $30^{\circ}$, respectively). Therefore, according to this preliminary data, preharvest factors that affect color intensity at harvest will have a significant influence on color after storage.

\section{(123) Lanthanum Effects on Gravitropic Response of Cut Tulip Flowers}

Hye-Ji Kim*, E. Jay Holcomb, Kathleen Brown

Department of Horticulture, Pennsylvania State University, 102 Tyson, University Park, PA, 16802

One of the major postharvest problems of cut tulip flowers is their stem curvature when placed in a horizontal orientation during transport or in flower arrangements. The $\mathrm{Ca}^{2+}$ blocker $\mathrm{LaCl}_{3}$ (lanthanum chloride) was tested for prevention of stem bending in cut tulip flowers. Our results indicate that stem bending varies with cultivars and is positively correlated with stem elongation rate. $\mathrm{LaCl}_{3}$ prevented stem bending by reducing stem elongation. However, $\mathrm{LaCl}_{3}$ treated flower stems failed to maintain straight stems when positioned vertically. Further, the gravitropic response of the tested cultivars varied with growing conditions, implying significant environmental effects on this response. $\mathrm{LaCl}_{3}$ did not affect stem bending during simulated dry transport ( 3 days, $5 \mathrm{C}$ and $95 \% \mathrm{RH}$ ), but cold-stored flowers exhibited less bending compared to fresh flowers held at room temperature. Further, flower longevity was reduced $20 \%$ to $40 \%$ by the $\mathrm{LaCl}_{3}$ treatment with or without simulated transport. Consequently, $\mathrm{LaCl}_{3}$ would not be useful to prevent stem bending of cut tulip flowers in commercial horticultural practice.

\section{(124) Low Oxygen Storage Affects the Carbohydrate Status of Asiatic Hybrid Lily Bulb Scale and Shoot Tissues}

Garry Legnani*, Anil P. Ranwala, Christopher B. Watkins, William B. Miller

Horticulture, Cornell University, 20 Plant Science Bldg. Tower Road, Ithaca, NY, 14853

Storage of Asiatic hybrid lily bulbs in humidified $1 \% \mathrm{O}_{2}$ controlled atmospheres (CA) has been shown to inhibit shoot elongation and flower bud development under "dry sale" conditions of warm temperatures $\left(22-26^{\circ} \mathrm{C}\right)$ and low light $\left(\mathrm{ca} .40 \mu \mathrm{mol} \cdot \mathrm{m}^{-2} \cdot \mathrm{s}^{-1}\right)$, thus prolonging shelf life when compared with storage of bulbs in air. Results suggest that modified atmosphere packaging (MAP) technology may be useful to extend the shelf life of "dry sale" lily bulbs. To better understand the physiological implications of low $\mathrm{O}_{2}$ storage on lily bulbs, the effects of a $1 \% \mathrm{O}_{2}$ atmosphere on the carbohydrate status of bulb scale and shoot tissues were investigated. Asiatic hybrid lily 'Marseille' bulbs were stored in darkness in humidified atmospheres of $1 \% \mathrm{O}_{2}$ or air for 4 weeks at $22^{\circ} \mathrm{C}$. Mother scale (MS), daughter scale (DS), and shoot tip tissues (1-2 mm segments including meristem) were harvested at weekly intervals and sucrose, reducing sugar, and storage carbohydrate (starch and glucomannan (GM)) concentrations were determined using HPAEC-PAD. High initial sucrose concentrations in MS and DS (180.3 and $138.1 \mathrm{mg} \cdot \mathrm{g}^{-1}$ dry wt. respectively) steadily declined in air-stored bulbs over time but remained relatively unchanged in $1 \%$ $\mathrm{O}_{2}$-stored bulbs. MS reducing sugar concentrations increased ca. 3-fold in both air and $1 \% \mathrm{O}_{2}$, reaching maximum levels after weeks 1 and 2 respectively, while DS reducing sugar concentrations were unaffected over time and between CA treatments. DS had greater initial GM and starch concentrations compared to MS. Both MS and DS showed little change in GM levels over time and between CA treatments. Similarly, MS starch concentrations showed little change. Daughter scale starch concentrations increased sharply in air-stored bulbs between weeks 3 and 4 , while concentrations in $1 \% \mathrm{O}_{2}$-stored bulbs remained close to initial levels. Shoot tip sucrose concentrations of air-stored bulbs increased 1.4-fold in week 1 then remained unchanged, while sucrose concentrations of $1 \% \mathrm{O}_{2}$-stored bulbs showed no change over time. Initial shoot tip RS and starch concentrations were low $(1.2$ and $3.1 \mathrm{mg}$ g-1 dry wt. respectively) but starch concentrations increased more than 4-fold in air-stored bulbs by week 1 and were much greater compared with $1 \% \mathrm{O}_{2}$-stored bulbs. The carbohydrate status of scales and shoot tips of $1 \% \mathrm{O}_{2}$-stored bulbs is characterized by relative little change over time compared to air-stored bulbs. Possible effects of low $\mathrm{O}_{2}$ storage on carbohydrate transport and the effects of initial tissue carbohydrate levels on survivability under low $\mathrm{O}_{2}$ storage are discussed.

\section{(125) Osmotic Drying Behavior of Mango, Pineapple and Papaya Fruits}

Judith Zambrano*, Anne Valera

Biologia y Quimica, Universidad de Los Andes, Urb El Recreo Sector El Bosque No 60, Trujillo, Trujillo, 3102, Venezuela

Three kinds of tropical fruits-mango, pineapples and papaya- have been studied as experimental material to analyse the effect of fruit maturity, sucrose concentration and the fruit/syrup ratio. The experiment were carried out with three fruit maturity stages, three levels of sugar concentration $\left(50,60\right.$ and $\left.70{ }^{\circ} \mathrm{Brix}\right)$ and three fruit/syrup ratio (1:2; 1:3 and 1:4). Following the osmotic preconcentration, the fruit samples were dried at $50{ }^{\circ} \mathrm{C}, 2800 \mathrm{ft} / \mathrm{min}$ air flow during $12 \mathrm{~h}$. The fruit pieces were analysed for humidity, total soluble solids and water activity. Statistical analysis of data indicated significantly effect of syrup concentration ocurring at $70^{\circ} \mathrm{Brix}$ higher solute transference. Water activity in mango and pineapple fruit showed a higher decrease with osmotic solution at $70{ }^{\circ}$ Brix while it was observed in papaya fruit the same behavior with any sugar concentration.

(126) Physiological and Quality Responses of Fresh-cut 'Carabao' Mango to High $\mathrm{O}_{2}$ Controlled Atmospheres

Jutatip Poubol*, Morio Kimura, Miho Oshima, Hidemi Izumi

School of Bio-Oriented Sci. \& Tech., Kinki University, 930 Nishimitani, Uchita, Naga, Wakayama, 649-6493, Japan

Fresh-cut 'Carabao' mango cubes were held in air or high $\mathrm{O}_{2}$ atmospheres $(40,60,80$ and $100 \%)$ at 5 and 13C. Since respiration rate was the lowest with cubes held at $60 \% \mathrm{O}_{2}$, the effect of $60 \%$ $\mathrm{O}_{2}$ on physiology and quality were determined at 5 and $13{ }^{\circ} \mathrm{C}$, and 
compared with those held in air. The high $\mathrm{O}_{2}$ atmosphere slightly reduced the respiration rate of mango cubes stored at $5{ }^{\circ} \mathrm{C}$, whereas it stimulated the respiration rate at $13{ }^{\circ} \mathrm{C}$. No differences were found in ethanol contents in flesh or off-odor of cubes between air and $60 \% \mathrm{O}_{2}$ atmospheres because the cubes had only minimal ethanol concentration and emitted only slight off-odor at both atmospheres. The cubes developed brown discoloration and water soaked areas with storage with the development being greater at $13{ }^{\circ} \mathrm{C}$ than at $5^{\circ} \mathrm{C}$. The percentage of browning of cubes stored at $13{ }^{\circ} \mathrm{C}$ was accelerated by $60 \% \mathrm{O}_{2}$. The high $\mathrm{O}_{2}$ did not affect ascorbic acid content and shear force of cubes at either temperature. Mesophilic aerobic bacteria and lactic acid bacteria on all cubes were below the detection level (2.4 $\log \mathrm{CFU} / \mathrm{g}$ ), except for cubes in $60 \% \mathrm{O}_{2}$ at $13 \mathrm{C}$ where mesophilic aerobic bacteria increased to $3.4 \log \mathrm{CFU} / \mathrm{g}$ by the end of the storage period. The increased bacterial count may be related to higher $\mathrm{pH}$ of cubes stored in $60 \% \mathrm{O}_{2}$ at $13 \mathrm{C}$ than at $5{ }^{\circ} \mathrm{C}$ or in air. High $\mathrm{O}_{2}$ atmosphere of $60 \%$ in storage had no effect on physiology and quality of mango cubes at $5{ }^{\circ} \mathrm{C}$, but did have a detrimental effect at $13{ }^{\circ} \mathrm{C}$.

\section{(127) Physiological Responses of 'Braeburn' and 'Gala' Apples to High $\mathrm{CO}_{2}$}

\section{Yiping Gong*, James P. Mattheis}

Tree Fruit Research Laboratory, USDA/ARS, 1104 N. Western Ave., Wenatchee, WA, 98801

Exposing apple fruit to elevated carbon dioxide $\left(\mathrm{CO}_{2}\right)$ during ripening and storage can induce physiological disorders including internal browning. As apple fruit sensitivity to $\mathrm{CO}_{2}$ varies with cultivar, experiments using two cultivars with high ('Braeburn') and low ('Gala' ) $\mathrm{CO}_{2}$ sensitivity were conducted to evaluate physiological responses in fruit held at $20^{\circ} \mathrm{C}$ in air or $20 \mathrm{kPaCO}_{2}$. The incidence of $\mathrm{CO}_{2}$ injury (internal browning) in 'Braeburn' apples stored in air or $20 \mathrm{kPa} \mathrm{CO}$ for 10 days was $3 \%$ and $38 \%$, respectively. No injury was observed in 'Gala' apples regardless of storage environment. At harvest, lipid soluble antioxidant (LSA) and water soluble antioxidant (WSA) activity were highest in 'Braeburn' apples. After ten days at $20^{\circ} \mathrm{C}$, LSA activity was highest in 'Braeburn' apples regardless of storage conditions; however, WSA was similar between both cultivars and storage environments. No cultivar difference in in vitro superoxide dismutase (SOD) or NADH oxidase activity was detectable at harvest. Activity of SOD increased during ten days at $20^{\circ} \mathrm{C}$ and was similar for both cultivars stored in air; however, the increase in activity was less in 'Braeburn' apples stored in $20 \mathrm{kPaCO}_{2}$. NADH oxidase activity at harvest was similar between cultivars. For 'Gala', NADH oxidase activity decreased during 10 days at $20{ }^{\circ} \mathrm{C}$ and activity was lowest in fruit previously held in $20 \mathrm{kPa} \mathrm{CO}$. Activity of NADH oxidase increased relative to activity at harvest in 'Braeburn' apples held in $20 \mathrm{kPa} \mathrm{CO}_{2}$. The results suggest $\mathrm{CO}_{2}$ sensitivity in 'Braeburn' apples may be related to increased NADH oxidase and lower SOD activities that occur during exposure to high $\mathrm{CO}_{2}$.

\section{(128) Phytochrome Regulation of Lycopene Synthesis in Tomato Fruit}

Andrew Schofield*, Gopi Paliyath

Food Science, University of Guelph, Gordon St., Guelph, Ontario, N1G 2W1, Canada

Lycopene is a nutraceutical compound reported to reduce DNA damage in some cell types as well as reduce the incidence of certain cancers. In tomato fruit, the production of this red pigment via the plastid-localized carotenoid pathway is regulated by phytochrome. Discs from mature green tomatoes were ripened in total darkness, or in darkness interrupted by brief daily treatments of red light, or red light followed by far red light. After ten days of incubation, lycopene levels of red light-treated discs had reached $\approx 18 \mathrm{mg} / 100 \mathrm{~g}$ fresh weight; nearly a two-fold increase over discs ripened in total darkness. This increase was not observed in discs treated with red light followed by far red light, demonstrating the red/far red reversibility (and thus phytochrome control) of lycopene accumulation. Preliminary results are presented, using this system to examine phytochrome regulation of phytoene synthase, a key regulatory enzyme in the carotenoid pathway.

\section{(129) Seed Source Affects Post Harvest Quality of Concolor} Fir Christmas Trees

Ricky Bates*

Horticulture, Penn State University, 303 Tyson Building, University Park, PA, 16802

Concolor fir (Abies concolor) is an excellent Christmas tree and is widely grown in plantations in the eastern U.S. Genetic variation within the species is great and is related to geographical source. This study was initiated to determine the influence of seed source on post harvest needle retention and needle color. Transplants derived from seed collected in the Apache, San Juan, Rio Grande and Lincoln National Forests were planted in 1995 and harvested in December, 2001. Trees were grown under conditions of uniform fertility, appeared free of insect and disease damage, had at least 3 age classes of live foliage, and were U.S. No. 1 grade according to USDA standards. Twenty trees, 1.8 to $2.1 \mathrm{~m}$ tall, of uniform vigor and density were harvested from each seed source and 5 trees from each source were either displayed immediately in water or allowed to dry outside for 1,2 or 3 weeks prior to display in water. The trees were displayed in a post harvest display room maintained under continuous standard fluorescent lighting, at $48 \% \pm 5 \% \mathrm{RH}$, and $18 \pm 1{ }^{\circ} \mathrm{C}$. During display, water was added to each tree stand to ensure that the water level in the stand was always maintained above the base of the tree. Water use was recorded for each tree and change in moisture status was recorded with a pressure chamber. Extent of current season needle loss was evaluated on a 0 to 10 scale and overall tree quality was measured periodically and rated on a 1 to 5 scale. Needle color was measured using a Minolta colorimeter. Trees from Rio Grande and San Juan sources exhibited excellent needle retention during the 35-day display period. Needle retention for the Apache source was poor, whereas the Lincoln source was rated as fair-good. Needle color was rated as blue to blue-green for Apache, San Juan and Rio Grande sources and varied little during display. Lincoln foliage was rated green. No significant differences in stem xylem water potential were observed as a function of seed source. These results indicate that seed source influences certain post harvest quality characteristics, such as needle retention, in Concolor fir Christmas trees.

(130) Sucrose Concentration in Liquid Media Effects Carbohydrate Status and Storage Quality of Micrpropagated Hosta tokudama Tratt. 'Newberry Gold'

Nihal Rajapakse*, Jeffery Adelberg, Vani Gollagunta

Horticulture, Clemson University, D-136, P\&A Building, Clemson, SC, 29634

The effects of sucrose concentration in liquid media in the presence and absence of a cytokinin on internal carbohydrate status and growth of Hosta tokudama 'Newberry Gold' during the multiplication phase (stage II) were investigated. Cultures from all treatment combinations were transferred to media containing $3 \%$ sucrose during the rooting phase (stage III). At the end of the stage III, these micropropagules were subjected to 5 weeks of storage at $10^{\circ} \mathrm{C}$ under low light (photosynthetic photon flux of $5 \mathrm{mmol} \cdot \mathrm{m}^{-2} \cdot \mathrm{s}^{-1}$ ). Levels of endogenous shoot soluble sugar (glucose + fructose + sucrose) increased linearly as the media sucrose concentration increased from $1 \%$ to $7 \%$ during stage II. Root and shoot biomass increased with increasing media sucrose concentration. The presence of a cytokinin, benzylaminopurine (BAP), increased the biomass and multiplication rate but did not affect internal concentration of soluble sugars. Following storage, plants originally cultured in $5 \%$ and $7 \%$ media sucrose had higher dry weight and better quality than those cultured in 1\% and 3\% media sucrose (i.e. plants cultured in $1 \%$ and $3 \%$ had greater chlorosis) that was not directly related to 
endogenous soluble sugar levels. Results show that increased media sucrose levels during the multiplication cycle has a positive, long-term effect on plant morphology and quality.

(131) The Influence of Foliar Calcium Applications on 'Braeburn' and 'Jonagold' Apple Storage

\section{J. Wyatt Brown*}

Horticulture and Crop Science, California Polytechnic State University, 11-227 Perimeter Road, San Luis Obispo, California, 93407

Calcium is an influential element in cell formation and structure, and varying levels of calcium in plants have been correlated with tissue firmness. The objective of this study was to determine the effect of foliar calcium on the initial quality and storability of two commercial apple cultivars, 'Braeburn' and 'Jonagold,' susceptible to the physiological disorders bitterpit and watercore. The experimental design was a Randomized Complete Block utilizing 4 replicates and buffer rows. Treatments involved the foliar application of Miller Calcium Chelate with $9.5 \%$ chelated calcium suspended in water and sprayed on trees at a rate of $0.063 \mathrm{lbs} / 25 \mathrm{gal}$. Treatments were: Water spray (control); one application of foliar calcium at full bloom, only; one application of foliar calcium at full bloom, + application 2 weeks after full bloom; one application of foliar calcium at full bloom, + application 2 weeks after full bloom + application 4 weeks after full bloom; one application of foliar calcium at full bloom, + application 2 weeks after full bloom + application 4 weeks after full bloom + application 2 weeks prior to harvest; and one application of foliar calcium at full bloom, + application 2 weeks after full bloom + application 4 weeks after full bloom + application 2 weeks prior to harvest + application 72 hours prior to harvest. At harvest, apples of both cultivars were objectively tested for fruit firmness and color, and were rated hedonically for incidence of bitterpit and watercore. Additional apples were placed at $34{ }^{\circ} \mathrm{F}, 90 \%$ relative humidity (RH) and samples were tested for firmness, and were rated for incidence of watercore and bitterpit, 2 , 4 and 6 weeks after the initiation of storage. At 6 weeks, fruit color was also assessed. 'Jonagold' and 'Braeburn' apple firmness tended to increase as the number of preharvest calcium sprays increased and this trend was maintained during storage, though the firmness of apples of both varieties decreased by approximately $4.5 \mathrm{lbs}$. during 42 days storage. Increasing the number of preharvest calcium sprays decreased the incidence of bitterpit, both at harvest and during 42 days storage, though bitterpit increased in severity during this period. 'Braeburn' apples tended to have less bitterpit than 'Jonagold' apples. There was no observable effect of preharvest calcium sprays on color or watercore development during storage. The results of this study indicate that preharvest calcium sprays may help to reduce the incidence of bitterpit, and increase the firmness of, some apple varieties.

(132) Treatment with Methyl Jasmonate or Methyl Salicylate Increases Chilling tolerance and Alternative Oxidase Transcript Levels in Peppers

Raymond W.M. Fung*1, Chien Y. Wang ${ }^{1}$, David L. Smith ${ }^{1}$, Kenneth C. Gross ${ }^{1}$, Meisheng Tian ${ }^{2}$

${ }^{1}$ Produce Quality and Safety Laboratory, U. S. Department of Agriculture, Bldg. 002, 10300 Baltimore Ave., Beltsville, MD, 20705-2350, ${ }^{2}$ HortResearch, Mt. Albert Research Center, 120 Mt. Albert Road, Private Bag 92169, Auckland, New Zealand, 92169, New Zealand

Methyl salicylate (MeSA) and methyl jasmonate (MeJA) vapors increased resistance against chilling injury in green bell pepper (C. annuum L. cv Century). The period before chilling injury symptom (surface pitting) appeared, i.e. within 2 days of cold storage, was considered as the most critical. The expression patterns of AOX and seven other genes involved in defense against oxidative stress before and during the early chilling period suggested that pre-treatment of pepper fruit with MeSA or MeJA vapors increased preferentially the transcript levels of AOX. Transcript levels of AOX $(1.5 \mathrm{~kb})$ were increased by storage at low temperature but the steady-state mRNA accumulation rate was faster at $0{ }^{\circ} \mathrm{C}$ than at $5{ }^{\circ} \mathrm{C}$. Overnight treatment with MeSA or MeJA vapors increased transcript levels of AOX $(1.5 \mathrm{~kb})$ even at room temperature of $25^{\circ} \mathrm{C}$, whereas no change was observed with untreated control. In addition to the expected $1.5 \mathrm{~kb}$ AOX transcript, RNA gel blot analysis revealed an extra $3.5 \mathrm{~kb}$ transcript that was induced only at $0{ }^{\circ} \mathrm{C}$. At $0{ }^{\circ} \mathrm{C}$, both AOX transcripts (1.5 and $3.5 \mathrm{~kb}$ ) reached maximal levels firstly in MeSA treated fruit, secondly in MeJA treated fruit and lastly in controls. AOX transcript levels were maintained at a high level as long as the fruit were kept at $0{ }^{\circ} \mathrm{C}$. Alternative respiratory pathway was proposed to mediate chilling injury. Here, we show that the increase in AOX transcript levels by MeJA or MeSA before cold treatment was correlated with reduced incidence of chilling injury.

\section{(133) Variations in Emasculation-induced Flower Senes- cence Among Cymbidium Cultivars}

Hye-Ji Kim*, Hajime Ohno, Kiyoshi Ohkawa

Department of Biological Science, Shizuoka University, 836 Ohya, Shizuoka, Shizuoka, 422-8529, Japan

Emasculation occurring during commercial shipping and handling is a significant problem in Cymbidium flowers since it causes lip coloration accompanied by flower senescence. Commercial Cymbidium cultivars with or without an anthocyanin blaze on their lips were tested to investigate emasculation-induced flower senescence as well as physiological factors affecting lip coloration. The degree of lip coloration in response to emasculation varied among cultivars with a blaze and was associated with ethylene production rate. Although no lip coloration develops in cultivars without a blaze, discoloration of sepals and petals in response to emasculation varied among cultivars. Pollination significantly increased the first peak of ethylene production leading to flower senescence even in cultivars that were less sensitive to emasculation, but the amount of ethylene production was not changed by emasculation. The results indicate that the amount of ethylene induced by emasculation is not high enough to trigger flower senescence in emasculation-insensitive cultivars.

\section{(134) Changes in Non-Structural Carbohydrate Pools in Cut Tulip Stems Caused by Exogenous Supply of Sucrose or Trehalose}

\section{Anil Ranwala*1, William Miller ${ }^{2}$}

${ }^{1}$ Horticulture, Cornell University, 20 Plant Science Bldg., Ithaca, NY, 14853, ${ }^{2}$ Horticulture, Cornell University, Plant Science Bldg., Ithaca, NY, 14853

The postharvest life of many cut flowers can be extended by adding sucrose to the vase solution. Recent reports indicate that trehalose, a non-reducing disaccharide consisting of two glucose units, is also effective in increasing flower longevity of gladiolus and tulip stems. Trehalose seems to increase the vase life of flowers by reducing the water loss from petals. In order to investigate the physiological basis of the effects of these sugars, it is important to understand how these sugars are partitioned into different parts of the flower stem. We conducted experiments to investigate the changes in carbohydrate pools during the postharvest phase of cut tulip stems treated with sucrose or trehalose. Cut tulip stems (with intact leaves) were placed in water, $1 \%$ sucrose or $1 \%$ trehalose solutions, and kept at $22{ }^{\circ} \mathrm{C}$ for evaluation. Stems were harvested at 3-day intervals and non-structural carbohydrates in different parts were analyzed. Both sucrose and trehalose caused slight increase in flower longevity in cut tulip stems. Sucrose supplied in the vase solution increased the concentrations of glucose, fructose and sucrose in leaves as well as in tepals. Adding trehalose to the vase solution resulted in the accumulation of trehalose in leaves (as high as $8 \%$ of dry weight) and to a lesser extent in tepals (less than $1 \%$ of dry weight). Trehalose slightly increased fructose and sucrose concentrations in leaves and caused no changes in other soluble carbohydrates in tepals. Tips of trehalose-treated leaves became dry, and the trehalose concentration at the tip of the leaf was found to be much higher compared to the base of the leaf. 
2:00 pm-3:15 pm ORAL SESSION 50

$555 \mathrm{~A}$

\section{Propagation}

Moderator: John Preece

\section{2:00 Propagation of Spineless Acacia wrightii Genotypes} Donita L. Bryan*1, R. Daniel Lineberger ${ }^{1}$, W. Todd Watson ${ }^{2}$, Michael A. Arnold ${ }^{1}$, Charles R. Hall ${ }^{3}$

${ }^{1}$ Dept. of Horticultural Sciences, Texas A\&M University, Mail Stop 2133, College Station, Texas, 77843-2133, ${ }^{2}$ Dept. of Forest Sciences, Texas A\&M University, M.S. 2135, College Station, Texas, 77843$2135,{ }^{2}$ Dept. of Agricultural Economics, University of Tennessee, 314 Morgan Hall, Knoxville, Tennessee, 37996-4518

Three spineless genotypes of Acacia wrightii G. Bentham ex A. Gray (wright acacia) were identified with landscape potential. Experiments in seed, cutting, grafting, and tissue culture propagation were undertaken to perpetuate the desired phenotypes. Sulfuric acid scarification for 10, 20,30 , or 60 minutes hastened and unified germination, however, yield of spineless phenotypes was low ( 0 to $34 \%$ ). Germination rates for mechanical scarification were intermediate between non-scarified seeds and sulfuric acid scarified seeds. Vegetative propagation by cuttings was acceptable for softwood, but very low for semi-hardwood and hardwood cuttings. Rooting measures increased linearly $\left(r^{2}=0.81\right.$ to $0.98 ; P \leq$ 0.5 ) with auxin concentration from 0 to $15,000 \mathrm{mg} \cdot \mathrm{L}^{-1}$, with maximum rooting percentage, root number and root length per softwood cutting of $70 \%, 9.2$ roots, and $12.4 \mathrm{~cm}$, respectively, at $15,000 \mathrm{mg} \cdot \mathrm{L}^{-1}$ auxin. Whip-and-tongue and T-bud grafting were not successful, likely due to accumulation of phenolic compounds. Tissue culture of shoots from in vitro germinated seedlings indicated that shoot proliferation was better in Murishige and Skoog (MS) than with woody plant medium (WPM). Zeatin at 15 to $20 \mu \mathrm{M}$ in MS resulted in the highest quality shoot proliferation. Roots were regenerated in low numbers on shoots subcultured to half strength MS with 1.0 to $2.5 \mu \mathrm{m}$ benzyl adenine.

2:15 Optimization of Adventitious Root Formation in Herbaceous Stem Cuttings of Gaura coccinea

Nadilia Gomez*, Grace Pietsch, Neil Anderson

Horticultural Science, University of Minnesota, 1970 Folwell Avenue, St. Paul, MN, 55108

Wild Gaura coccinea populations from MN, CA and TX have been collected for gene transfer into commercial G. lindheimeri. Rooting protocols for commercial $G$. lindheimeri cultivars are not suitable to propagate $G$. coccinea. The objective was to determine more suitable rooting methods. Rooting environments, IBA concentrations, carriers, and duration of application were tested in two experiments. Nine genotypes from a CA population were studied (7 in Expt. 1, 4 in Expt. 2; 2 genotypes were in common). Seven categorical rooting assessments $(0-5,5=$ best $)$ were made over three weeks. The scores were used to calculate area under a rooting progress curve. In Expt. 1, 1000 ppm KIBA was significantly better than 1000 ppm IBA in ethanol, 3000 ppm IBA in ethanol, water and ethanol. No significant differences were observed between cuttings dipped for 1,3 or 30 seconds, a 300 seconds dip was significantly worse $(P<0.001)$. In Expt. 2,8000 ppm IBA in talc was significantly better than 0,1000 , and $3000 \mathrm{ppm}(P<0.001)$. Cuttings rooted better under plastic domes than mist $(P<0.001)$ in both experiments. G. coccinea rooting is improved by using $1000 \mathrm{ppm} \mathrm{KIBA}$ or 8000 ppm IBA in talc under plastic domes. Further experiments are needed to determine which treatment is best.

2:30 Study in Embryogenic Callus Potential of Rosa hybrida L. cvs. 'Tournament of Roses' $\times$ 'Baby Love' Progeny

Millie Burrell*, David Byrne

Horticultural Sciences, Texas A\&M University, HFSB MS 2133, College Station, TX, 77843-2133

In order to study the inheritance of somatic embryogenic capability, cultures from the progeny of two rose cultivars, 'Tournament of Roses' and 'Baby Love', were initiated from filament explants of rose using a B5 basal medium supplemented with 2,4-D, zeatin and caffeic acid followed by a series of subcultures onto an MS basal medium. 'Tournament of Roses' had been observed to produce significant amounts of embryogenic callus on this medium whereas 'Baby Love' had been observed to produce insignificant amounts of embryogenic callus. The resulting amounts of embryogenic callus produced by each of the eleven progeny genotypes tested were compared to the observations of parental genotypes. The spectrum of progeny responses suggests genetic control over the capacity to undergo somatic embryogenesis in rose.

2:45 Direct Planting of Alginate Encapsulated Nodes of Stage II Micropogated Hardy Hibiscus (Hibiscus moscheutos hybr. L.) for Direct Stage IV Development

Todd West*1, John E. Preece ${ }^{2}$

${ }^{1}$ Department of Plant Biology, Southern Illinois University, Life Science II Building, Mailcode:6509, Carbondale, IL, 62901, ${ }^{2}$ Department of Plant, Soil and General Agriculture, Southern Illinois University, Agriculture Building, Mailcode: 4415, Carbondale, IL, 62901

The objective of this study was to investigate direct greenhouse planting of alginate encapsulated single nodes from Stage II cultures at different depths in various greenhouse media, high humidity environments, or with or without a light pretreatment for rooting and acclimatization. The two cultivars: 'Lord Baltimore' (cutting propagated) and 'Southern Belle' (seed propagated) were tested. The alginate matrix medium contained DKW nutrient salts, $10^{-7} \mathrm{M}$ thidiazuron, 3\% sucrose, and had a pH of 5.8. Data were collected after explants were placed in the greenhouse for four weeks on shoot number, shoot length, root number, and root length. Previous experiments showed that after two weeks of exposure to light while in vitro, shoot development and elongation was sufficient to allow for emergence from the encapsulation bead. After three to four weeks, root development and elongation events occurred. In the current study, three greenhouse media (vermiculite, perlite, and peatlite) were compared and vermiculite was found to be the best greenhouse medium for explant survival. Perlite dried out resulting in dehydrated encapsulated explants. Peatlite was too wet, which resulted in the decomposition of the explant. Three different humidity controlled environments (fog, mist, and overhead watering) were compared. The use of intermittent mist resulted in higher survival rates $(20 \%)$ than fog $(0 \%$; too wet) and overhead watering $(0 \%$, too dry). Three depths of planting (above the medium surface, at medium surface line, and below medium surface) were compared using vermiculite under intermittent mist. Encapsulated explants placed at the surface line of the vermiculite performed the best. The explants that were above the surface behaved the same as those placed at the surface line but the roots had the tendency to grow along the medium surface for 10-20 $\mathrm{mm}$ prior to penetrating the medium surface. None of the explants that were planted below the medium surface survived. Light pretreatment at $40 \mu \mathrm{mol} \cdot \mathrm{m}^{-2} \cdot \mathrm{s}^{-1}$ for a 16 -hour photoperiod at $25^{\circ} \mathrm{C}$ for $2-3$ weeks prior to planting enhanced growth greatly compared to encapsulated nodes stored in darkness, or in light for 1 or 4 weeks.

\section{3:00 Growing Exotic Trees in Beijing}

Ling Guo*

Plants Introduction Department, Beijing Botanical Garden, Sleeping Buddha Temple Rd., Beijing, 100093, People's Republic of China

There are many different species and/or cultivars of hardy trees that have come from Europe, Northern America and Australia that have been successfully introduced and distributed within the Beijing, China area. The most important qualifications required for a successful introduction and domestication are not only to be able to withstand a wide annual range of temperatures from extreme cold to high heat, but to also tolerate the extreme variation in rainfall with an extended dry period. Adaptability or ability to tolerate the high $\mathrm{pH}$ of the soil adds another challenging dimension. After meeting those difficult 
conditions, introduced plants need to be further tested or observed for aggressiveness tendencies toward local or native species.

\section{2:00 pm-3:15 pm ORAL SESSION 51}

$556 \mathrm{~A}$

\section{Postharvest-Pome Fruit 2}

Moderator: Robert Prange

\section{2:00 Delayed Cooling Controls Soft Scald and Other Disorders} in 'Honeycrisp' Apple

\section{Robert Prange*, John DeLong, Peter Harrison}

Atlantic Food and Horticulture Research Centre, Agriculture and Agri-Food Canada, 32 Main St., Kentville, NS, B4N 1J5, Canada

Since its commercial release in 1991, 'Honeycrisp' apple (Malus $\times$ domestica Borkh.) has become a popular and profitable apple cultivar. Unfortunately, it has a tendency to develop Soft Scald after harvest which is threatening its commercial success. The objective of this study was to examine the effect of delayed cooling, harvest time, storage temperature and CA on the occurrence of Soft Scald and other quality-related problems in Nova Scotia-grown 'Honeycrisp' fruit. Fruit were harvested from three commercial orchards in 2002 in the Annapolis Valley, Nova Scotia on two dates, one 'early' (30 Sept.) and one 'late' (10 Oct.), as determined by growers' experience. At each harvest, half of the fruit were cooled to $5^{\circ} \mathrm{C}$ over 24 hours (control) and the other half of the fruit were held for 7 days at $20^{\circ} \mathrm{C}$ (delayed cooling treatment). Both control and delayed cooling fruit were stored in two storage temperatures $\left(3\right.$ and $\left.5{ }^{\circ} \mathrm{C}\right)$. Within each temperature room, half were stored in ambient air (RA) and half in $2.5 \mathrm{kPa} \mathrm{O}_{2}+1-1.5 \mathrm{kPa} \mathrm{CO}_{2}(\mathrm{CA})$. After 4 and 6 months storage, 15 fruit were removed from each treatment combination. Ten fruit were immediately sampled and the other five fruit were sampled after 7 days at $20{ }^{\circ} \mathrm{C}$ (shelf life). The results of both the 4 and 6 month removal show that delayed cooling was more effective than harvest date, storage temperature or storage atmosphere. A cooling delay of 7 days at $20^{\circ} \mathrm{C}$ controlled the development of Soft Scald, as well as other quality-related problems, e.g. Internal Breakdown and External $\mathrm{CO}_{2}$ damage, regardless of harvest date, storage temperature or storage atmosphere.

2:15 (259) Harvest Date and Storage Temperature Affect Softscald Occurrence and Fruit Quality of 'Honeycrisp' Apples

Renae Moran*

Plant, Soils and Env. Sciences, University of Maine, PO Box 179, Monmouth, ME, 04259

In 2002, three harvest dates and two storage temperatures were compared for prevention of soft scald and maintenance of fruit quality. Harvest dates were 13 Sept., 25 Sept. and 7 Oct, corresponding to a starch index of 4.8, 6.9 and 8.0 (scale of 18 ), respectively. Fruit were stored at $1.1{ }^{\circ} \mathrm{C}$ and $2.9^{\circ} \mathrm{C}$. A five-day prestorage exposure to $17^{\circ} \mathrm{C}$ followed by storage at $1.1{ }^{\circ} \mathrm{C}$ was also tested on fruit harvested 25 Sept. Additionally, fruit harvested 25 Sept. and 7 Oct. were exposed to MCP for a duration of 20 hours. All fruit were stored four months at $1.1{ }^{\circ} \mathrm{C}$ in regular air. In February, occurrence of soft scald was measured on 50 fruit per plot and fruit quality on ten fruit. Treatments were replicated five times. Fruit came from 'Honeycrisp'/M.26 trees planted in 1994. Harvest on 13 Sept. or 7 Oct. resulted in little or no soft scald in contrast to 25 Sept., which had $30 \%$ of fruit affected when stored at $1.1{ }^{\circ} \mathrm{C}$. MCP reduced the occurrence of soft scald to $19 \%$. When stored at $2.9^{\circ} \mathrm{C}$, none of the fruit developed soft scald. Five-day pretreatment at $17^{\circ} \mathrm{C}$ also completely prevented soft scald. Harvesting 13 Sept., resulted in the firmest fruit in February, but color was very poor. There was no difference in firmness between 25 Sept. or 7 Oct., but the later harvest resulted in unacceptably greasy fruit. Storage at $2.9^{\circ} \mathrm{C}$ reduced firmness by approximately $0.5 \mathrm{lbs}$ and also resulted in greasy fruit for both harvest dates. Five-day prestorage at $17{ }^{\circ} \mathrm{C}$ did not affect firmness, but fruit were slightly greasy. MCP did not affect firmness, but little softening occurred when fruit were stored at 1.1 ${ }^{\circ} \mathrm{C}$. Of the treatments tested, five-day prestorage at $17{ }^{\circ} \mathrm{C}$ was most promising for preventing soft scald while maintaining quality.

2:30 Effect of Heat or 1-Methylcyclopropene on Antioxidative Enzyme Activities and Antioxidants in Apples in Relation to Superficial Scald Development

Susan Lurie*1, Zohar Shaham ${ }^{2}$, Amnon Lers ${ }^{2}$

${ }^{1}$ Pomology, Univ. of Calif., 101 Shields Ave., Davis, CA, 95616, ${ }^{2}$ Postharvest Science, Volcani Center, 76 HaMaccabeim, Bet Dagan, 50250 , Israel

'Granny Smith' apples were harvested in two seasons and stored at $0{ }^{\circ} \mathrm{C}$ air storage with no pretreatment (control), after heating for $4 \mathrm{~d}$ at $38^{\circ} \mathrm{C}$, or after treating for $16 \mathrm{~h}$ at $20^{\circ} \mathrm{C}$ with $1 \mu \mathrm{L} \cdot \mathrm{L}^{-1} 1$-methylcyclopropene (1-MCP). The effects of the two treatments on superficial scald development were consistent over both seasons. Scald began to appear after 8 weeks in control fruit, after 16 weeks in heated fruit but not on 1-MCP treated fruit. $\alpha$-Farnesene accumulation and oxidation were slower in the skin of heated than in control fruit, and almost entirely absent in 1-MCP treated fruit. The activities of five antioxidant enzymes, ascorbate peroxidase, catalase, glutathione reductase, peroxidase and superoxide dismutate, were measured at two week intervals in the apple peel, quantitatively as total activity and qualitatively by isozyme analysis. Enzyme activities either increased or remained stable during 16 weeks of storage, except for superoxide dismutase activity which decreased. Ascorbate oxidase activity was higher in heated than control apples and there was an additional peroxidase isozyme present in activity gels. The activities of antioxidant enzymes were lower in 1-MCP treated fruit except for catalase for the first month of storage. Lipid soluble antioxidant activity was higher in 1-MCP treated fruit than the fruit of the other treatments, and water soluble antioxidant activity was higher in both treatments than in control fruits during the time that scald was developing in control apples. Both free and total phenol contents in the peel fluctuated during storage but no consistent trend was detected. The differences in enzyme activity and antioxidant content of the peel of 1-MCP and heated apples may play a role in preventing or delaying the appearance of superficial scald.

\section{Effects of MCPand low Oxygen, Applied Singly or Together on Apple Fruit Ripening}

Theophanes Solomos*1, Neelam Pathak ${ }^{1}$, Prabodh Trivedi ${ }^{2}$, Autar $\mathrm{Mattoo}^{3}$

${ }^{1}$ Natural Resource Science and Landscape, University of Maryland, Plant Sciences Bldg, College Park, MD, 20742, ${ }^{2}$ Plant Gene Expression, National Botanical Institute, Rana Pratap Marg, Luknow, 22601, India, ${ }^{3}$ Vegetable Laboratory, USDA, 10300 Baltimore Av, 1010A Bldg, Beltsville, MD, 20705

MCP (1-methyl-cyclopropene) in concentrations of 1-5 p.p.m. is very effective in retarding for long periods of time the onset of the ethylene climacteric when it is applied at the preclimacteric stage. Its effectiveness in retarding the initiation of the rise in ethylene evolution, and hence fruit ripening, is diminished when it is applied after the initiation of the ethylene climacteric, as is that of low oxygen. The suppression of the rise in ethylene evolution is accompanied by a strong inhibition of the expression of ACC-synthase (ACS) and the ERS1-type ethylene receptor. The combined application of MCP and $1.5 \%$ oxygen is much more effective in reducing fruit softening than when they are applied singly. Treatment of apple fruits whose rise in ethylene evolution has been initiated with either MCP or $1.5 \% \mathrm{O} 2$ does not eliminate ethylene evolution. In fact, the degree of inhibition is inversely related to the rate of ethylene production at the time of the treatment. The effect of these treatments on the expression of acs and ers genes will be discussed. 
3:00 Watercore and Sorbitol Transporters in Apple Fruit Zhifang Gao, Sastry Jayanty*, Randy Beaudry, Wayne Loescher

Horticulture, Michigan State University, A328 PSSB, East Lansing, MI, 48824-1325

Sorbitol is a major carbohydrate translocated into apple fruit, where it is normally metabolized to fructose by sorbitol dehydrogenase. In watercored apple fruit tissues, however, sorbitol content is consistently higher than in non-watercored apples, suggesting that there are alterations in transport or metabolism of sorbitol. To study sorbitol transport in apples, we isolated several putative apple sorbitol transporter genes from an apple fruit cDNA library. Two cDNAs were completely sequenced (MsSOT1, AY237400, MsSOT2, AY237401) and these showed high sequence homologies with sorbitol transporters isolated from cherry fruits (Gao et al., 2003, Plant Physiol.). Using heterologous expression in yeast for both MsSOT1 and MsSOT2, proton-dependent sorbitol uptake activities were confirmed and other characteristics were measured. We compared the expression of these transporters between affected (watercored) and healthy parts of the same fruit and between watercored and nonwatercored fruits. Expression of the sorbitol transporter MsSOT1 was significantly reduced in fruit tissues exhibiting watercore; however, affected fruit showed less expression in the whole fruit irrespective of the region with visual symptoms. Our results indicate a relationship between watercore and sorbitol transport. Apple fruit cells may, as they mature, lose the ability to transport sorbitol into different compartments, leading to accumulation of sorbitol in the intercellular air space and subsequent flooding of these spaces.

\section{2:00 pm-3:15 pm ORAL SESSION 52}

$552 \mathrm{~B}$

\section{Herbs, Spices, and Medicinal Plants \\ Moderator: To Be Announced}

\section{2:00 Black Cohosh - Genetic Diversity of a Medicinal Plant at Risk}

\section{Lorna Lueck*1, Lyle Craker ${ }^{1}$, Timothy Motley²}

${ }^{1}$ Department of Plant and Soil Sciences, University of Massachusetts, 12 A Stockbridge Hall, Amherst, MA, 01003, ${ }^{2}$ The Lewis B. and Dorothy Cullman Program for Molecular Systematics Studies, The New York Botanical Garden, 200th Street \& Kazimiroff Boulevard, Bronx, NY, 10458-5126

The rhizome of black cohosh [Actaea racemosa L., Syn.: Cimicifuga racemosa (L.) Nutt.], a plant native to the northeastern U.S. and adjacent Canada, is of considerable pharmaceutical interest for the treatment of menopausal symptoms. Recent studies on the risks of hormone replacement therapy have drawn scientific and economic interests to this species. An increasing market demand created by women seeking alternative treatment could lead to over-collection and severe endangerment of natural populations. This study develops an overview of the natural environmental factors in which the plant thrives, provides an estimate of the genetic diversity of the species, and establishes a basic gene bank, factors needed for conservation decisions as well as for cultivation and breeding processes. A total of 14 wild populations were visited and data about the geographic location, soil composition and associated canopy species were recorded. Morphometric measurements of leaves and AFLP (amplified fragment length polymorphism) fingerprinting were employed to assess the levels of intra- and inter-populational diversity. Rhizome cuttings of each population were collected to create a basic gene bank that will be available for further phytochemical screening and breeding. Morphometric characteristics of the leaves indicate a high morphological variability in the species. In some populations the variation in leaf shape reached the overall range of variation within the study, thus morphological characteristics of the leaf are not likely to be markers for different accessions. AFLP fingerprinting allowed distinction between geographically distant populations of black cohosh and showed higher genetic similarity among groups of the same geographic region. The intra- and inter-populational genetic diversity promises a broad basis for selection. Further it could be shown, that related species (Actaea pachypoda Ell.; Cimicifuga americana Michx.), that could be misidentified by their vegetative characters can easily be separated by AFLP markers.

2:15 Effects of Population, Age and Location on Ginsenoside Content of American Ginseng (Panax quinquefolium L.)

Wansang Lim*, Kenneth Mudge

Horticulture, Cornell University, 20 Plant Science Building, Ithaca, NY, 14853

International trade in the valuable medicinal herb, American ginseng, includes both collection of roots from the wild as well as agricultural production of unimproved land races. The pharmacologically active compounds known as ginsenosides are widely reported to increase with plant age. To test the hypothesis that ginsenoside content is influenced not only by age, but also by genotype and environment, we collected roots from 8 different wild populations, ranging in age from 2 to 15 years. Roots from each of the 8 populations were transplanted into 2 different forest gardens (FG1 and FG2), varying in intensity of cultivation. HPLC was used to determine the effect of population source, root age and forest garden site on levels of 6 ginsenosides. At the time of collection of roots from the wild $\left(\mathrm{T}_{0}\right)$ there were significant effects of age, population, or age $\times$ population interactions depending on the ginsenoside. One year after transplantation of the wild-collected roots to the forest farms, ginsenosides were again analyzed. Between $\mathrm{T}_{0}$ and $\mathrm{T}_{1}$, there was a significant decline in the content of ginsenosides $\mathrm{Re}, \mathrm{Rc}, \mathrm{Rb}_{2}$, and $\mathrm{Rd}$ for roots grown at the more intensively cultivated FG 1 but no decline at FG 2. At $T_{1}$, for ginsenosides $R c, R b_{1}$, $\mathrm{Rb}_{2}$, and $\mathrm{Rd}$ there was a significant three way interaction among root age, population, and forest garden site. At FG1 there were significant population $\times$ age interactions for $\mathrm{Re}, \mathrm{Rc}, \mathrm{Rb}_{1}, \mathrm{Rb}_{2}$, and $\mathrm{Rd}$, with higher ginsenoside levels in older roots for some populations but no difference or an age-related decrease for other populations. At F2 there were population-related differences for all ginsenosides, but no significant effect of age. The data suggest that not only root age and population but also intensity of cultivation and /or other farm-related differences influences ginsenoside levels.

2:30 Greenhouse Propagation Studies of Osha (Ligusticum porteri)

Karen Panter*1, Rebecca Ashley ${ }^{1}$, Karin Guernsey ${ }^{2}$, Caroline Johnson ${ }^{2}$

${ }^{1}$ Plant Sciences, University of Wyoming, P.O. Box 3354, Laramie, WY, 82071-3354, ${ }^{2}$ Owners, Elk Mountain Herbs, 214 Ord Street, Laramie, WY, 82070

Ligusticum porteri (osha) is a perennial plant native to the Rocky Mountain west. It is used as a medicinal herb, is harvested in the wild, and is believed to be in danger of over-harvest. The objectives of this study were to determine if $L$. porteri could be grown successfully from seeds, root cuttings, or vegetative crown cuttings. Seed was harvested from the wild in Fall 2000. Roots were collected in May 2001. Seed was given one of four treatments: 1) no cold treatment; 2) six weeks at $4.4{ }^{\circ} \mathrm{C} ; 3$ ) four weeks each: $4.4{ }^{\circ} \mathrm{C}, 12$ hours each $30 / 20$ ${ }^{\circ} \mathrm{C}, 4.4{ }^{\circ} \mathrm{C}$; or 4 ) 12 weeks at $4.4{ }^{\circ} \mathrm{C}$. Roots were divided into root and crown cuttings and were placed on a $21.1{ }^{\circ} \mathrm{C}$ mist propagation bench. Results indicated that 12 weeks of stratification was beneficial for seed germination. Root cuttings were not successful. Propagation of vegetative crown cuttings was most successful with $90 \%$ rooting.

2:45 Herbal Treatment for Failure of Child Development E.O. Olapade*1, C.B. Farounbi ${ }^{2}$, E.O. Olapade, Jr. ${ }^{1}$, C.O. Olapade ${ }^{1}$, O.C. Olapade ${ }^{1}$, J.B. Olapade ${ }^{1}$

${ }^{1}$ NARLSpecialist Clinic, Center for Research \& Development of Phyto- 
medicines, Univ. of Ibadan, Ibadan. P.O. Box 4010, Nigeria. ${ }^{2} \mathrm{JICON}$ Hospital and Maternity, 12, Calabar Street, off Katsina Rd., Kaduna

Many children fail to develop after birth to the extent that they can neither crawl nor walk even at 24 months. The morphological appearance of such children are often poorly developed legs, fragile looks, while some have enlarged skull. The groins of some of these children are usually lighter colored than the rest of the body, while the abdomen could be distended and the hair on the head are usually fragile. These children constitute serious problems, physically and psychologically to their parents or guardians who often seek medical assistance for them at all times. Pediatricians often work round the clock to seek medical solutions with very little success in solving the problems of these children who usually have mental retardation. The presentation of this disorder has been known in traditional medicine for a very long time. In the Yoruba tribe of Nigeria, the disorder is known as 'TINUSE'. Various recipes have been found to help these children in ethno-medicine, with records of very good responses such that the children grow up rapidly and are able to walk within 3 to 6 months of treatment. A particular formulation of Caesalpinia bonduc together with some other tropical plants has been used with a high degree of success to treat these cases in Nigeria.

3:00 Treatment of Ovarian Cyst in Women 'The Phytotherapy Option'

E.O. Olapade*, E.O. Olapade, Jr., C.O. Olapade,

O.C. Olapade, J.B.Olapade

NARL Specialist Clinic, Center for Research and Development of Phytomedicines. Univ. of Ibadan, Ibadan. P.O. Box 4010. Nigeria

There are two ovaries normally in women, which perform the function of secretion of the vital female reproductive hormone-estrogen, that regulate the monthly menstrual cycle. Each ovary also produce the eggs that carry the female gametes required to fuse with the male sperm cells in the formation of fetus. One of the abnormalities that had been recognized is the development of sacs with membranous wall enclosing fluid, semi solid matter or altered blood described as ovarian cyst that alter the size of the ovaries and make them larger. This abnormality disorganize the regular monthly cycles along with complications including pains and infertility in women. The causes for the development of ovarian cysts are not clearly understood while surgical operation had been the most popular method of treatment. There is a long history of traditional methods of treatment of ovarian cysts in Nigeria. This paper describes how 270 of clinically confirmed cases of ovarian cysts in women between the ages of 22-52 years were treated successfully without surgery at the NARL specialist clinic, Ibadan, Nigeria in the last 15 years (1988-2003) using phytomedicines compounded with the fiber of Cocos nucifera and a few other tropical natural plants.

\section{2:00 pm-4:00 pm CENTENNIAL SPOTLIGHT} $556 \mathrm{~B}$

Centennial Spotlight: Video Interviews with Noted Horticulturists

\section{2:00 pm-4:00 pm WORKSHOP 24}

\section{Historical Perspective on Weed Control and Pest Management in Horticultural Crops}

\author{
Moderator: Mathieu Ngouajio \\ Sponsor: Weed Control and Pest Management Working Group \\ (WCPM)
}

Organizer: Mathieu Ngouajio, Michigan State Univ.

Objective: The objective of this workshop is to provide the horticultural community with a critical review of the changes in weed control and pest management over the last century. As a part of the centennial celebration of ASHS, this workshop will provide an opportunity to look over our shoulder and see how far we have gone and where we are headed for weed, disease, and pest management in horticultural crops.

Summary: Over the last century, climate change, adoption of new regulations, and changes in cropping systems have significantly impacted weed and pest management in horticultural crops. This workshop will provide us with a critical review of major changes and discuss current and future trends for weed and pest management.

\section{Changes in Disease Management of Vegetable Crops During the 20th Century and Into the 21st Century}

Stephen A. Johnston*

Rutgers Agricultural Research \& Extension Center, Rutgers University, Bridgeton, NJ 08302: “.”

During the time period encompassing 1903-2003, numerous changes have occurred in the disease management of vegetable crops. In the early 1900 s only a few vegetable diseases had been identified. With tomatoes, 15 diseases were considered to be important in 1914; while, by 1993,55 tomato diseases were considered important. Cultural practices designed to manage diseases have remained similar throughout the period. In the 1920s, disease resistant varieties of vegetable crops became available commercially. Currently in the Mid-Atlantic region of the U.S., there are 168 commercial varieties that possess resistance to one or more diseases listed in the University production recommendation guides. Major changes have occurred in the area of chemical control of vegetable diseases. In 1903 only one fungicide, Bordeaux mixture, was available for use on vegetables; in 1913 the organomercurial compounds were discovered for use as seed treatments; from 1934-1944, the dithiocarbamate fungicides were being developed and resulted in providing broad spectrum protectant control of diseases in vegetables; during 1960-1970 chlorothalonil and the benzimidazole fungicides were discovered, and the later group were the first systemic fungicides available for vegetables; from 1970-1980 the DMI group of fungicides appeared; from 1998-2003 the QoI group of fungicides received registrations on vegetable crops; and in 2001 the first inducer of host plant defenses, acibenzolar-S-methyl, was registered on tomatoes. Concurrent with the development of new fungicides was the development of disease forecasting systems for various diseases of vegetable crops. Disease forecasting systems provide vegetable growers with the option of applying fungicides according to weather conditions rather than relying on a calendar spray schedule. Disease forecasting systems are now commercially accepted in carrots, cucurbits, onions, spinach, tomatoes and white potatoes. From 1935 until the 1980s the dithiocarbamates and chlorothalonil were the primary fungicides used in vegetable disease management. Since these fungicides were broad spectrum in activity with multiple sites of action against fungal pathogens, pathogen resistance was not an issue. However, with the advent of newer classes of fungicides that control a specific class of fungi with a single mode of action, pathogen resistance has occurred in several vegetable crops to several fungicides in recent years. Currently, resistance management strategies need to be developed prior to using new fungicides for vegetable disease management in order to prolong the longevity of newer fungicides. The development of biological control strategies for vegetable crops has been slow during the past century. Currently, soilless mixes containing microbial antagonists are being used to manage soilborne pathogens that cause damping-off in vegetable transplant production. The biological fungicide, Contans (Coniothyriumminitans), is being used to manage diseases caused by Sclerotinia sclerotiorum. The future of vegetable disease management into the $21^{\text {st }}$ century will involve the continued use of cultural control practices, the development of additional disease resistant varieties and the use of current fungicides, as well as, the development of additional fungicides.

\section{Climatic Trends and Potato Late Blight Risk in the Upper Great Lakes Region}

Kathleen M. Baker ${ }^{1}$, William W. Kirk*2, Jeffrey A. Andresen ${ }^{3}$ ${ }^{1}$ Dept. of Earth and Resource Science, Univ. of Michigan-Flint, Flint, MI, 48502; ${ }^{2}$ Dept. of Plant Pathology, Michigan State Univ., East Lansing, MI, 48824; ${ }^{3}$ Dept. of Geography, Michigan State Univ., East 
Lansing, MI, 48824

In the Upper Great Lakes region of the United States, potato late blight (Phytophthora infestans) is a temporally sporadic disease, occurring only when microclimate conditions within the canopy are favorable and inoculum is present. Conducive environmental conditions include air temperatures between 7 and $27^{\circ} \mathrm{C}$ and relatively long periods (10 hours or more) of leaf wetness. Increasing concern in the agricultural community over observed and projected climate change has prompted numerous studies on the possible implications for crop yields. However, relatively little work has focused on disease management. Historical trends in hourly weather variables and potato late blight risk as expressed by a modified Wallin Disease Severity Value index were analyzed at seven regional weather stations from 1948-1999. All sites showed significant trends in at least one of the risk estimates. While late blight risk was greatest at all locations in August, periods of increasing risk occurred across the region particularly during July. The increases in disease risk appeared to be associated with upward trends in dry bulb and dew point temperature at nearly all of the stations, especially during July and August. These results correspond with historical climatological trends in the Upper Great Lakes region that indicate warmer and wetter growing season conditions, as well as local increases in precipitation totals and in the frequencyof days with precipitation.

\section{History and Perspectives on the Use of Disease} Resistance Inducers in Horticultural Crops

Andrea B. da Rocha*, Ray Hammerschmidt

Dept. of Plant Pathology, Michigan State Univ., East Lansing, MI 48824

One of the major challenges facing the production of horticultural crops is the need to provide field and post-harvest disease control measures that help maintain high quality of the plant products. Producers and consumers also expect products of high quality with minimal or no pesticide residue and competitive prices. Complicating this issue is the development of resistance in many important pathogens to the major chemical control agents. Because of these concerns, the use of disease resistance inducers could be an alternative or complementary approach to disease management. Induced disease resistance has been studied in many different crops and pathogens systems for near a century. Resistance to disease can be induced systemically by early infection with pathogens or by chemical agents that have been specifically selected for this purpose. In practice, the application of inducers would trigger the plant's own defense mechanisms against a broad spectrum of pathogens. Over the last few years, a number of materials that could be used as inducers of resistance in horticultural crops have been identified. Some of these materials are being tested commercially, but many others have only been tested under controlled conditions. Although induced resistance is known to be broad spectrum, it may not be a full solution. For example, it has been observed that there is variation in the efficacy of disease resistance induction, and that the response may be dependent on the plant species and even cultivars. There is also variability in the spectrum of pathogens that resistance can be induced against. Because induction of resistance depends on the activation of biochemical processes that are triggered in the plant, a lag time between treatment and expression of resistance needs to be considered in practical application of disease resistance inducers. Since the efficacy of the inducers also depends on the part of the plant that was treated, the product delivery (i.e., how the inducers would be applied in order to optimize their action) is another factor to be considered. Some studies have shown that there may be side effects on growth or yield characteristics when certain inducers are used. Understanding the biochemical interactions occurring between plants, pathogens and the inducers will provide information that may be useful for the optimization of this new approach on disease control. Approaches to integrate induced resistance with other management practices need to be investigated as a means to aid the development of sustainable disease management programs that are effective as well as economically and environmentally sound.

\section{Managing the Soil to Manage Pests}

Milton McGiffen Jr.*1, Mathieu Ngouajio²,
Guangyao Wang ${ }^{1}$, and Shengping Yang ${ }^{1}$

${ }^{1}$ Dept of Botany and Plant Sciences, Univ. of California, Riverside, CA 92521-0124; ${ }^{2}$ Dept of Horticulture, Michigan State Univ., East Lansing, MI 48824-1325: “"”

Crop rotation and soil amendment were principal pest management methods before the widespread use of pesticides. The loss of major pesticides in many crops has led to renewed interest in non-chemical pest control strategies based upon soil management. Weeds, nematodes, and other pests are inherently soil based, and altering the soil environment can reduce pest damage. Obvious examples are crop rotations and cover crops that shade out weeds, or resistant cultivars that reduce soil diseases. But amending the soil to increase organic matter or to change other soil parameters often has a big impact on pests. Cultural and chemical control methods can also be combined for more effective control. We review soil management methods that effectively reduce or control pests using major weeds and other pests as specific examples.

History and Current Trends in the Use of Allelopathy for Weed Management

Leslie A. Weston*

Dept of Horticulture, Cornell University, Ithaca NY 14850

Allelopathy can be defined as an important mechanism of plant interference mediated by the addition of plant-produced secondary products to the soil rhizosphere. Allelochemicals are present in all types of plants and tissues and are released into the soil rhizosphere by a variety of mechanisms, including decomposition of residues, volatilization and root exudation. Allelochemical structures and modes of action are diverse, and may offer potential for development of future herbicides. In the past, allelopathy has been described by the Romans as a means of "sickening" the soil; in particular chickpea was described as problematic when successively cropped with other species. Other early plant scientists such as De Candolle in the 1800's first described the ability of plant roots to produce toxic exudates. More recently, research has focused on development of weed management strategies using allelopathic crop residues, mechanism of allelochemical action, and gene regulation of allelochemical production. This paper will review a variety of weed and crop species that establish some form of potent allelopathic interference, either with other crops or weeds, in agricultural settings, in the managed landscape or in naturalized settings. Recent research suggests that allelopathic properties can render one species more invasive to native species and thus potentially detrimental to both agricultural and naturalized settings. In contrast, allelopathic crops offer strong potential for the development of cultivars that are more highly weed suppressive in managed settings. Both environmental and genotypic effects impact allelochemical production and release over time. A new challenge that exists for future plant scientists is to generate additional information on allelochemical mechanisms of release, selectivity and persistence, mode of action and genetic regulation. In this manner, we can further protect plant biodiversity and enhance weed management strategies in a variety of ecosystems.

2:00 pm-4:00 pm WORKSHOP 25 $551 \mathrm{~A}$

\section{Breeding for Organic Farming Systems}

\section{Moderator: Chris Reberg-Horton}

Sponsor: Organic Horticulture Working Group (ORGH)

Objective: To define plant traits most needed in organic systems. To examine assumptions about crop management used in plant breeding. To discuss how cultivar release to the organic market is different.

Summary: Organic systems present a challenge for plant breeders. Because the goals and inputs in organic farming differ from conventional systems, this alters the context in which varietal selections are made. Exciting new areas of genetic improvement are addressing the requirement for cover crops and biological controls tailored to organic systems. 


\section{Introduction}

Milt McGiffen*

Dept. Botany \& Plant Sciences, University of California, Riverside, CA 92521-0124

Organic agricultural practices create a unique environment for the expression of genotype-specific traits. Fertility and pest management are among the most obvious differences. Unique market niches and grower needs can also present challenges substantially different from conventional agriculture. This workshop discusses the germplasm needs of organic agriculture, breeding and research to solve current problems, and what is needed in the future. We introduce these topics with a case study of how a traditional food and forage crop, cowpea, was developed as a cover crop in organic and conventional systems.

\section{Breeding for Organic Production of Vegetable Crops Joel Reiten*}

Seed Production Manager, Bejo Seeds Inc., Cottage Grove, OR 97424

Organic production is one of the fastest growing sectors of agriculture in the US today. This rapid growth is bringing to the forefront many questions concerning the breeding and development of vegetable varieties for the organic market. Until recently many organic growers have utilized open pollinated and heirloom varieties for their production. As the organic market has grown many larger, conventional growers are becoming involved with organic production and are demanding the higher performance and uniformity of hybrid varieties along with traits such as increased insect and disease resistance. Recent work with organic producers has highlighted other areas where work is needed such as the selection of growth patterns that more closely follow the natural nutrient cycling in the soil and the selection of breeding material that complements the use of biological pest control measures. The Research Institute for Organic Agriculture in Europe has put forth recommendations concerning breeding techniques that they consider suitable for the development of organic varieties. This list of techniques excludes techniques such as the transfer of cytoplasmic male sterility into inbred material as well as the use of any gene transfer techniques. Decisions that plant breeders and seed companies need to make revolve around their perception of the market potential and market future of organics. These potentials will be influenced by consumer demands and governmental regulation. This presentation will review how Bejo Seeds is addressing the organic market and will explore our approach for breeding and selection of organic vegetable varieties.

\section{On-farm and Centralized Approaches to Breeding Vegetables for Organic Farming Systems}

Molly Jahn*

Dept. of Plant Breeding, Cornell University, Ithaca, NY 14853

In an effort to better serve seed companies that focus on underserved regional and organic markets, we have launched the Public Seed Initiative (www.plbr.cornell.edu/psi), a cooperative effort based in the Dept. of Plant Breeding at Cornell with partners in the USDA National Plant Germplasm System and at non-profit organizations that promote organic agriculture and germplasm diversity. We have developed an extensive on-farm breeding and trialing network in the Northeast and Northwest that involves the broad distribution of both finished breeding material and earlier generations. Growers may simply evaluate material or may select among segregating germplasm for lines that perform best in a particular environment. Parallel trials are run as a usual part of our university-based vegetable breeding programs, but university-administered organic ground is in very short supply. This information has been critical in the identification of varieties that do particularly well under organic regimes and has resulted in new relationships between the university and smaller seed companies. We distribute the materials under simple material transfer agreements that allow individuals freedom to operate for their own use. In the event that a recipient is part of an organization with the capacity to commercialize a variety, we develop simple licenses to ensure broad access to good quality seed.
Breeding A More Allelopathic Rye For Use In Organic Vegetable Production

Chris Reberg-Horton*, Nancy Creamer, David Danehower, Guoying Ma, David Monks, Noah Ranells,

John Williamson, Jim Burton, Paul Murphy

North Carolina State University

Recent work with rye cover crops has revealed large differences among cultivars in their allelopathic potential. These differences raise the question of how much total variation in allelopathic potential exists within rye. Modern cultivars only represent a small and biased fraction of the variation present within the species and its close relatives. These modern cultivars have been bred as either forages or cereal grains. Selection for either goal can reduce the production of secondary metabolites, including most allelochemicals. Astudy of 268 rye accessions from the National Small Grains Collection revealed large differences in allelopathic potential as measured by bioassays. Results from this screening are being incorporated into a breeding program at North Carolina State University. In addition to allelopathic potential, cover crop characteristics such as heading date, biomass, regrowth potential, and nitrogen scavenging ability are being evaluated to improve the utility of rye as a cover crop.

\section{Research-based Information for Variety Selection and Management in Organic Vegetable Systems: Scientific and Practical Imperatives}

\section{M.D. Kleinhenz*, J. Cardina}

Dept. of Horticulture and Crop Science, The Ohio State Univ., Ohio Agricultural Research and Development Center, 1680 Madison Avenue, Wooster, OH 44691-4096

Variety selection can be a primary vehicle for profitable, sustainable, locally-driven agriculture. Varieties suited to organic (ORG) systems driven by regional markets would require few nutrient inputs, out-compete weeds, resist diseases and insects, and be nutritious and appealing. However, a lack of variety development and research-based information for variety selection may limit the productivity of ORG vegetable systems. In fact, challenges associated with variety selection and management are compounded for organic vegetable farmers, considering that: 1) Most varieties are developed under conventional (CNV), often geographically-distant systems, creating doubt about their suitability for local, ORG systems and 2) Research-based information for variety selection and management in ORG systems is rare. For example, none of the 115 recent studies completed on 20 vegetable crops at nine U.S. universities were in certifiable ORG systems. CNV and ORG systems differ in fundamental biological, chemical, physical, and market characteristics. These differences suggest that varieties developed in CNV systems may be poorly suited for ORG systems. These differences also open exciting avenues of study into the science and management of genotype-environment interactions. Recent and ongoing studies at The OSU have tested the hypothesis that proper variety selection may be useful in combating unique challenges associated with ORG systems, including nutrient and weed management. Variety-x-compost application interactions were not significant for yield, crop quality, and weed variables in a study involving short-season, certified ORG potatoes. However, variety and compost application main effects were significant for many crop variables. Comprehensive, related studies are planned for additional commodities.

2:00 pm-4:00 pm WORKSHOP 26

$555 \mathrm{~B}$

\section{Propagation of Grand Champion Trees}

\section{Moderator: Chiwon W. Lee}

Sponsor: Plant Propagation Working Group (PROP)

Objectives: To learn about the history and ongoing efforts of propagating the largest and oldest trees of the world, including the Grand Champion Trees 
Summary: Giant trees always fascinate us. Many of the majestic old trees which have survived the test of time and element for centuries or even millenia are nature's treasures for mankind. Protection, propagation, and reestablishment of clonal materials from these superior plants have been the goals of such non-profit organizations as the Champion Tree Project. This workshop will introduce the concept, history, and current efforts in propagating the Grand Champion trees scattered throughout the country and the world. We will also hear about a case story where innovative methods were successfully used to propagate and establish clonal materials from illfated historic trees. A panel discussion will follow the presentations.

\section{Old and New Methods of Clonal Propagation for Established Trees}

Chiwon W. Lee*, Wenhao Dai

Dept. of Plant Sciences, North Dakota State Univ., Fargo, ND 58105

Clonal propagation and reestablishment of historic landmark trees can be accomplished by traditional methods of cutting, grafting, budding, and air-layering as well as tissue culture. While genetic identity can be maintained by these vegetative propagation methods, the grafted and budded plants may have altered growth characteristics due to the influence of the rootstock. Generation of "own root" plants by cutting or shoot tip culture would ensure genetic purity in propagated plants. For those species that are hard-to-root or recalcitrant to the traditional vegetative propagation method, a new means of stock plant manipulation and propagule conditioning may enhance the chances for success. These include growth regulator application, forcing of dormant stems to rejuvenate shoots, apical meristem culture, and pulse feeding of indolebutyric acid (IBA) to excised shoots cultured in vitro. Effective use of the old and new techniques for cloning the largest trees of the world will be discussed.

The Evolution of the Champion Tree Project International David Milarch*

Champion Tree Project Intl., Milarch Nursery, Copemish, MI 49625

The Champion Tree Project International as a non-profit organization has been established to protect, propagate and plant a living legacy of champion trees. Working in partnership with private and public tree owners and large scale nurseries, this innovative tree introduction initiative aims to produce and market champion tree clones, called Champ Trees $^{\mathrm{TM}}$. In 2000, the Project partnered with the Washington D.C. based National Tree Trust and is now promoting private and corporate tree sponsorships to underwrite the start-up costs associated with launching the largest commercial introduction of new trees in history.

\section{Clonal Propagation and Establishment of the Wye Oak}

Francis R. Gouin*

Dept. of Natural Resource Science and Landscape Architecture, Univ. of Maryland, College Park, MD 20742

The cloning of our "National Heirlooms" the Grand Champion trees should not only be of interest to science but can be of commercial value. To the scientific community, the cloning of Grand Champion trees is preserving the genetics of these trees for future studies and comparisons. To the nursery industry these "National Heirlooms" can become a new line of plants that can be marketed as having longevity. Although much emphasis is placed on marketing newly developed cultivars that have had only a few decades of testing as compared to Grand Champion trees that have survived the test of centuries. Although numerous Grand Champion trees have been cloned by cuttings, and tissue culture, other have only been successfully cloned by grafting, which means that the roots of these plants are not of the same clone. However, it may be possible, some day, to vegetatively propagate these from cuttings or by tissue culture. Until then, cloning by grafting has enabled us to preserve the genetics of trees.

\section{Building a Sustainable Urban Forest}

Terry Mock*

Champion Tree Project International, Lake Worth, FL 33460
Sustainable urban forest, naturally occurring and planted trees in cities, are managed to provide the inhabitants with a continuing optional level of economic, social, environmental benefits today and into the future. Using Champ Tree ${ }^{\mathrm{TM}}$ as a catalyst, we can begin to build public support for comprehensive urban ecosystem master planning and urban forest best management practices in order to achieve sustainability for out cities. The "green industry" will play a major role in the coming wave of urban ecosystem restoration.

\section{Tuesday, October 7}

\section{ASHS Horticultural Landmark Ceremony}

ASHS is pleased to present the ASHS Horticultural Landmark Award to the Arnold Arboretum of Harvard University.

At the award presentation ceremony, which immediately follows a post-conference tour of the Arboretum, ASHS will present a plaque recognizing the site as "a living museum that serves local, regional and global communities while developing and promoting public understanding of the relationship between plants and people."

Remarks from Dr. Robert E. Cook, the Arboretum's Director, will follow the ceremony.

\section{Addendum}

Friday, October 3

12:30 pm-1:30 pm POSTER SESSION 2 Ballroom A

Pomology - Culture/Production/Management

(440) Late Golden Delicious Apple, A Late Blooming, Low Fruit Set Cultivar

V. Guerrero*, A. Romo, A. Orozco, G. Vargas, A. Gardea

Center for Food and Development Research, P. O. Box \# 781. Cuauhtemoc, Chih. Mexico 31570

Mexico's main apple growing area is located in the NW of Chihuahua State. Almost 30,000 planted ha include main cultivars as Red and Golden Delicious and Rome Beauty. Alocal late blooming, low fruit set mutation. Late Golden Delicious (LGD) it was originally accepted and used by growers, due to its late blooming period, which highly reduces late frost damage, risk being this fact one of the most influential factors reducing yield. However, possibly due to its late bloom, LGD has a very low initial fruit set, and consequently a low yield. Objectives for this field study were; to compare Rome Beauty (RB), also a late blooming cultivar, along with Snow Drift (SD) as pollinizers for LGD, compared to self and open pollination and evaluate initial fruit set when hand-pollinated with these pollinizers. Both, $\mathrm{RB}$ and $\mathrm{SD}$ prove to be suitable pollinizers for LGD, since they highly increased initial fruit set, overcoming the low yields for LDG. Also, pollen tube growth and ovule longevity were studied. Field trials were done during 2000 and 2001 blooming periods. 